Contractual Relationships in the Absence of Formal Enforcement: Experimental Evidence from Germany and Kenya

\author{
Dissertation \\ zur Erlangung des Doktorgrades \\ der Wirtschaftswissenschaftlichen Fakultät \\ der Georg-August-Universität Göttingen
}

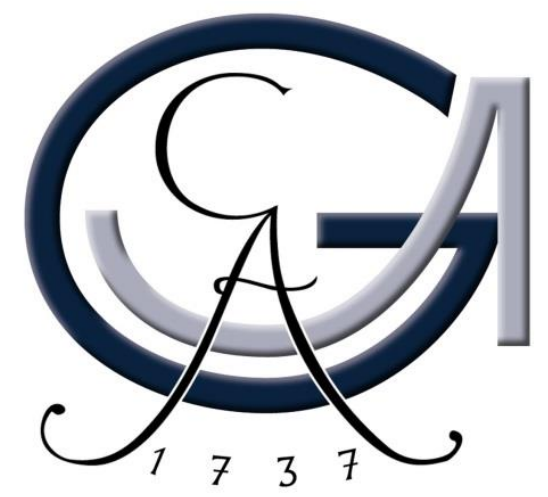

vorgelegt von

Sebastian Kunte

geboren in Erfurt

Göttingen, 2015 
Erstgutachterin: Jun.-Prof. Dr. Meike Wollni

Zweitgutachter: $\quad$ Prof. Dr. Matin Qaim

Drittprüferin: $\quad$ Prof. Dr. Claudia Keser

Tag der mündlichen Prüfung: 15. Juli 2015 
To my grandmother,

Ruth Gräser 


\section{Acknowledgements}

I wrote this dissertation during my time as doctoral researcher in the Research Training Group (RTG) "GlobalFood" at the University of Göttingen. There are many people who accompanied me on this three-year path from searching a first idea to writing these acknowledgements - and I am grateful to all of them. First and foremost I would like to thank Meike Wollni for her willingness to supervise me. I benefited tremendously from our discussions, her advice and encouragement. I also thank Matin Qaim for agreeing to be my second supervisor and always having an open door in case of problems. I am moreover indebted to Claudia Keser for her supervision and guidance. In addition, I would like to acknowledge the financial support by the German Research Foundation (DFG).

I am grateful to the whole GlobalFood family. It has been a great experience to work in such an inspiring, diverse, humorous environment. I will never forget this time. Though this is far from being an exclusive list, I want to mention in particular Nico Herforth, my office mates Edward Asiedu and Katharina Krumbiegel, Brian Chiputwa, Cristina Romero, Ayako Ebata, Iris Butzlaff, Thuy Pham and Conrad Murendo. For their reliable administrative support I thank Melanie Grosse, Diana Sieber, Katrin Pape and Jessica Torluccio. The GlobalFood HiWis helped me a lot when running the experiments here in Göttingen. Thanks for that!

Outside the RTG, I am thankful for the support, discussions and comments (or just the good company) to Lukas Semmler, Marcel Gatto and all my colleagues from the Chair of International Agricultural Economics in Göttingen, to Martin Schmidt and the Chair of Microeconomics, to Renate Strobl and to Philipp Marhold (for proof-reading). 
For fundamentally supporting my fieldwork in Kenya, I am indebted to the Busara Center team in Nairobi: Chaning Jang (for prompt e-mail replies and help during the preparation stage), Lucy Rimmington and Arun Varghese (for the patience while managing my sojourn) as well as the Busara research assistants (for applying impressive pedagogic skills when running the experiments).

My special thanks go to Christin Clajus for her love, care and friendship; for listening patiently in times of frustration and for celebrating successes together (no idea where I would be without you). To my family, Sabine, Andreas and Sarah Kunte as well as my grandma Ruth Gräser (there is nothing like unconditional support and trust). And, finally, to my Erfurt friends, who always make me want to visit home.

Thanks-Danke-Asante sana!

Göttingen, 1 June 2015 


\section{Table of contents}

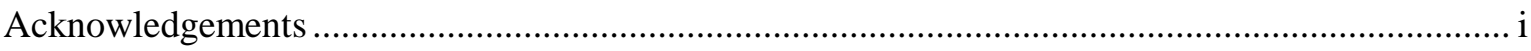

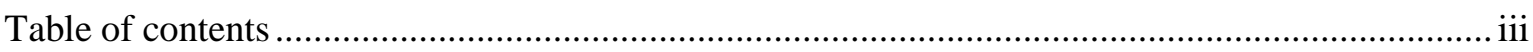

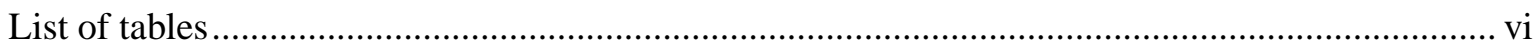

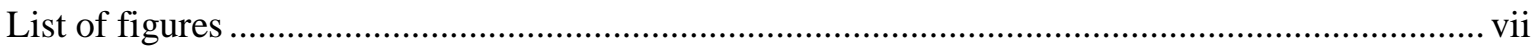

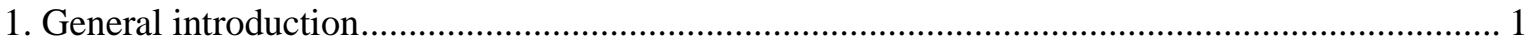

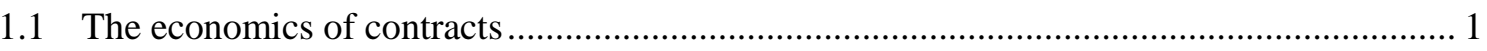

1.2 Market institutions and the means of contract enforcement ............................................. 6

1.3 Studying behavior in contractual relationships: a case for experimentation ....................... 10

1.4 Outline, research questions, and contribution of the dissertation ...................................... 15

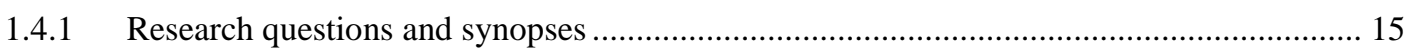

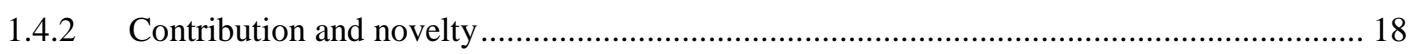

2. Making it personal: breach and private ordering in a contract farming experiment .................... 20

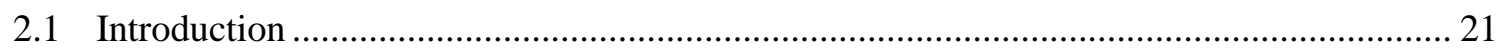

2.2 An experimental approach to study behavior in contract farming arrangements ................ 25

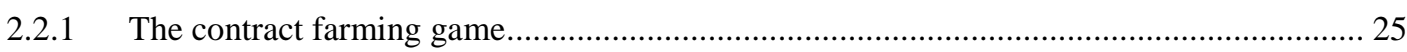

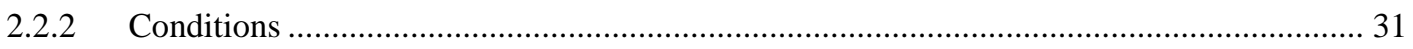

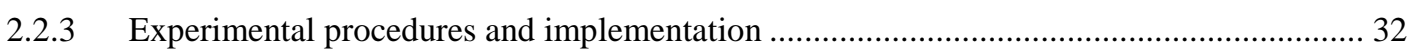

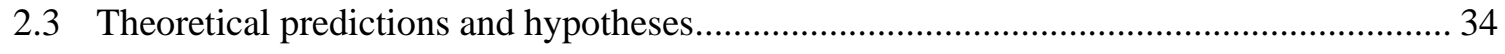

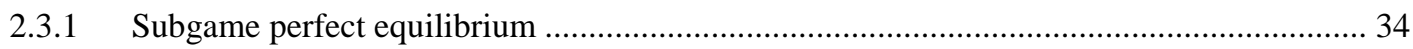

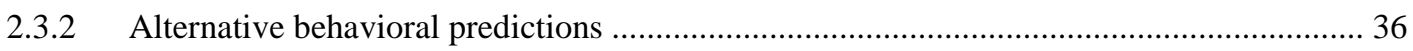

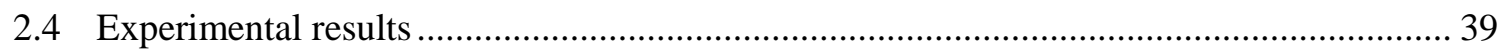

2.4.1 Contract breach and the effectiveness of private ordering ……............................................ 39

2.4.2 Price premiums as enforcement mechanism ……................................................................ 47

2.4.3 Who (potentially) benefits from private-order enforcement? .............................................. 48

2.4.4 Compliance, guilt proneness and preferences for honesty ……………………………... 52

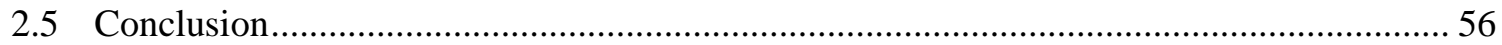

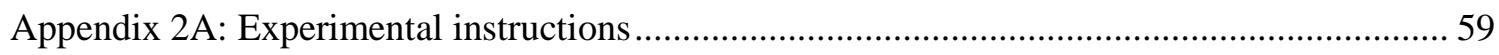


3. Risky environments, hidden knowledge, and preferences for contract flexibility: An artefactual field experiment

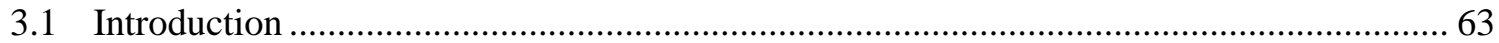

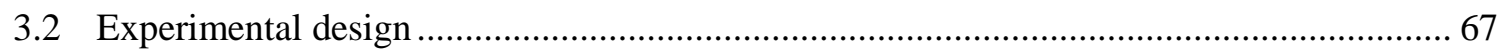

3.2.1 A modified investment game with contracts and hidden knowledge …….......................... 67

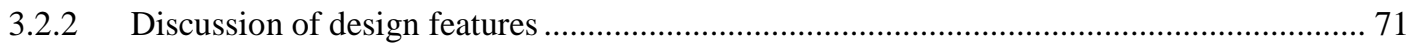

3.2.3 Subject pool, lab environment, and procedures................................................................. 72

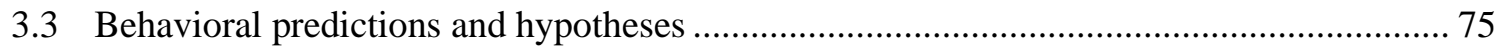

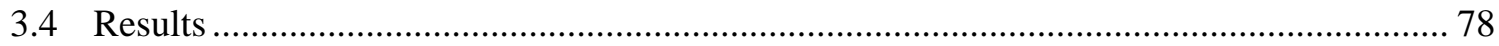

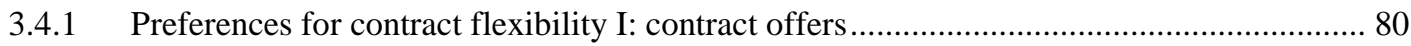

3.4.2 Preferences for contract flexibility II: contract acceptance ............................................... 83

3.4.3 Contractual flexibility, opportunistic behavior, and benefits from interaction..................... 86

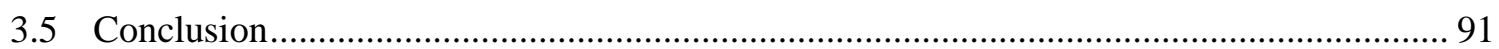

Appendix 3A: Experimental instructions, handout, and comprehension survey ......................... 94

4. Do inequalities in profit reinforce post-contractual opportunism? Experimental evidence from a

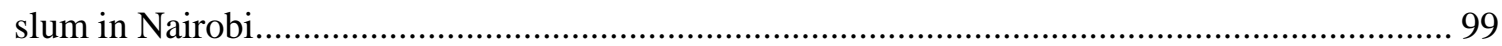

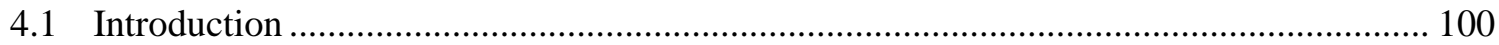

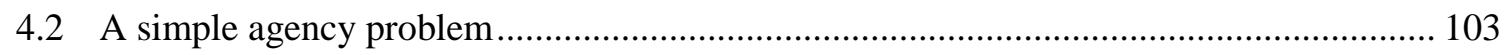

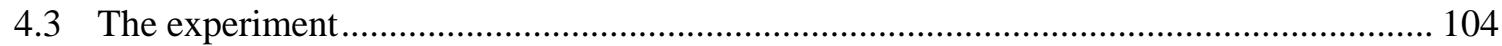

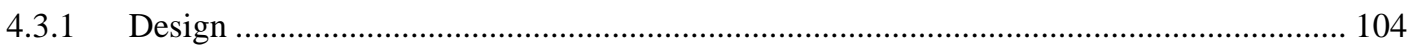

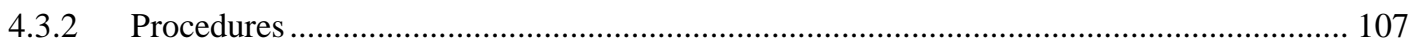

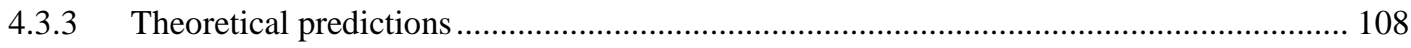

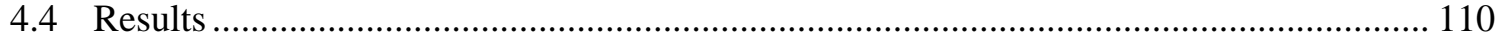

4.4.1 Descriptive statistics and findings ............................................................................... 110

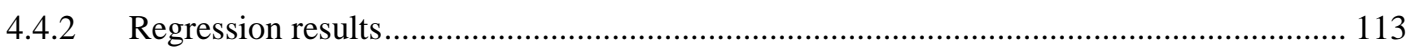

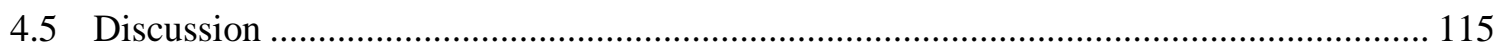

4.5.1 Inequity aversion and responses to unfairness ............................................................ 115

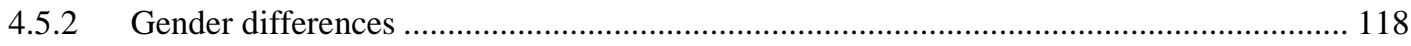

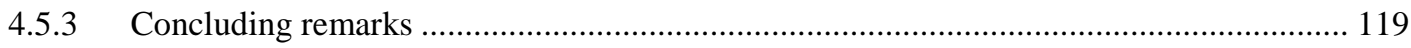

Appendix 4A: Producers' investment decision and the theory of inequity aversion ................. 120

Appendix 4B: Experimental instructions, handout, and comprehension survey........................ 123 


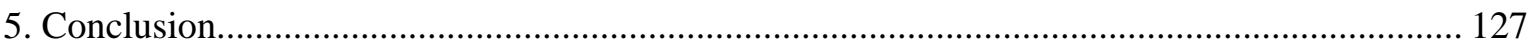

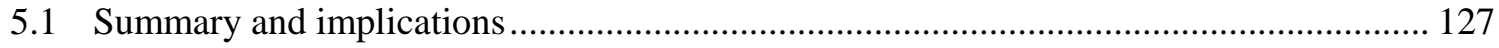

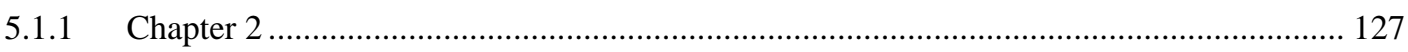

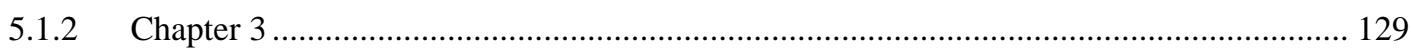

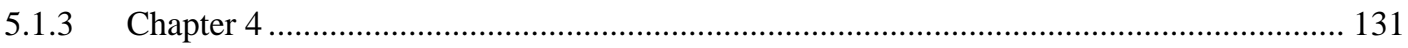

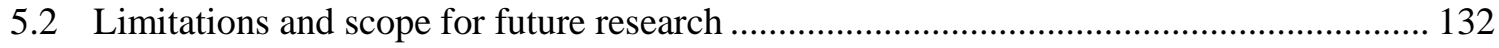

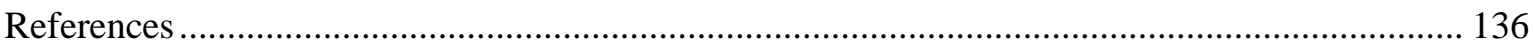




\section{List of tables}

Table 1.1: $\quad$ African firms' contractual disputes with clients and suppliers from Bigsten et al. (2000)

Table 2.1: $\quad$ Spot market prices and their probabilities of occurrence 26

$\begin{array}{lll}\text { Table 2.2: } & \text { Experimental parameters } & 28\end{array}$

Table 2.3: $\quad C$ 's expected profits depending on contract price, spot market price and $F$ 's predicted behavior $\quad 36$

Table 2.4: $\quad$ Probability of contract breach by farmer and company player 42

Table 2.5: $\quad$ Determinants of profit (in one period) 49

Table 2.6: Well- and less functioning relationships in the RC and DB condition 52

Table 2.7: $\quad$ Probability of contract compliance including data on honesty and guilt feelings $\quad 55$

$\begin{array}{lll}\text { Table 3.1: } & \text { Rigid and flexible contract terms } & 70\end{array}$

$\begin{array}{lll}\text { Table 3.2: } & \text { Summary statistics and descriptive results } & 79\end{array}$

Table 3.3: $\quad$ Probability of flexible contract offers 82

Table 3.4: $\quad$ Probability of contract acceptance by agents 85

Table 3.5: $\quad$ Regression analyses of repayment, less-than-20-returns, and opportunistic behavior $\quad 88$

Table 4.1: $\quad$ Experimental parameters and payoffs 106

$\begin{array}{lll}\text { Table 4.2: } & \text { Summary statistics and descriptive results } & 111\end{array}$

Table 4.3: $\quad$ Probability of contract acceptance and investment 112 


\section{List of figures}

$\begin{array}{lll}\text { Figure 1.1: } & \text { Average time to enforce a contract in different regions } & 7\end{array}$

Figure 1.2: $\quad$ Stylized mapping of theoretical streams and chapters 17

Figure 2.1: Timeline of events in the contract farming game 27

Figure 2.2: $\quad$ (a) Side-selling (as share of all contracts) by farmer players, (b) payment reduction (as share of all payments) by company players, and (c) mean contract prices offered

Figure 2.3: $\quad$ Side-selling (as share of all concluded contracts) conditional on the contract price-spot market price difference (CSMD)

Figure 2.4: $\quad$ Occurrence of different payment reductions (as share of all payments)

Figure 2.5: Occurrence and timing of direct bargaining communication in the $\mathrm{DB}$ condition

Figure 3.1: $\quad$ Signed flexible and rigid agreements by agents (as share of respective offers of this contract type in a condition)

Figure 3.2: $\quad$ Agents' return of (a) more than zero and (b) 20 points or more (as share of respective interactions with this contract type in a certain state)

Figure 3.3: $\quad$ Mean payoffs of (a) principal, (b) agent and (c) mean total payoffs of both players (in case of interaction)

Figure 4.1: Responses to "How much do you agree/disagree with the following statement: Other people should not own much more than I do." 


\section{General introduction}

— "To an economist, a contract is an agreement under which two parties make reciprocal commitments in terms of their behavior - a bilateral coordination arrangement." (Brousseau and Glachant, 2002: 3)

—_Trade does exist, even in stateless societies.” (North, 1990: 54)

\subsection{The economics of contracts}

Contracts are important means of vertical coordination and exchange. Economic interaction between two parties can be organized along a continuum of different vertical coordination mechanisms. On one end, there are anonymous spot markets that barely allow for relationship-specific investment, quality control or long-term adjustments. On the other end of the spectrum, there is complete vertical integration in the sense of Coase's (1937) firm, which is often rigid and inefficient. The use of contracts as an intermediate form can combine advantages of these extreme modes of economic governance, yet is associated with a number of pitfalls and new challenges.

The rise of new institutional economics has also augmented economists' interest in contractual relationships - may this interest be theoretical or empirical in nature. In the early 1970s, contract or information economics emerged; the prevailing Walrasian market theory, which analyzes the equilibration of demand and supply only through prices, seemed not appropriate for the study of outside-of-equilibrium exchange and bilateral relations (Brousseau and Glachant, 2002; Salanié, 2005). These relations are typically characterized by a fundamental transformation (Williamson, 1985) from a competitive market with many agents to a "bilateral monopoly" where relationship-specific investments are made. 
Today, a great variety of issues are analyzed under the perspective of contract theory or the economics of contracts (cf. Bolton and Dewatripont, 2005; Brousseau and Glachant, 2002; Salanié, 2005): Incentives, information (or the absence of the same), transaction costs, trust, incomplete contracts and reference points as well as their direct or indirect results, namely, moral hazard, adverse selection, hold-ups and other forms of opportunistic behavior. The range of analysis is wide because contracts are embedded in a world of institutional failures, boundedly rational agents, imperfect information and an unforeseeable future. Following Brousseau and Glachant (2002), we can identify three theoretical streams that jointly (albeit sometimes incompatibly) contribute to the economics of contracts. A brief sketch of these streams will facilitate an easier integration of the dissertation's chapters into the economic literature.

First, incentive theory typically uses the principal-agent paradigm for analytical purposes. ${ }^{1}$ Hereby, a usually less informed party (principal) makes a take-it-or-leave-it contract offer to a better informed party (agent) who carries out an activity that-deterministically or stochastically_affects the principal's profit. The principal, thus, faces the problem of designing a contract that convinces the agent to accept it (participation constraint) and, at the same time, provides the agent with sufficient incentives to choose an activity that is best for the principal (incentive compatibility constraint).

The design of an efficient and adequate incentive scheme is often hampered by information asymmetries, either with regard to exogenous or endogenous variables in the agency model. The former may lead to problems of adverse selection, that is, the principal cannot observe whether the agent is of a competent/productive/honest or rather an incompe-

\footnotetext{
${ }^{1}$ For general and easily accessible overviews of agency theory and information asymmetries refer to Arrow (1985), Sappington (1991), Milgrom and Roberts (1992) or Hart (1995) among others. A more technical and comprehensive analysis is provided by, e.g., Hart and Holmström (1987) and Bolton and Dewatripont (2005). This paragraph on incentive theory is based on these analyses.
} 
tent/lazy/unscrupulous type. The latter, again, might result in moral hazard. Here, the action consciously taken by the agent within the contractual relation (e.g., time spent on the project or effort invested) is her private knowledge. As this action is costly, it is commonly appealing to the agent to shirk or withhold inputs. The principal can only, if at all, assess the final outcome of the agent's work or production, which is a function of the chosen action-but also of some random variable beyond the agent's control. To provide incentives, a contract must link the agent's payment to the final outcome and thus shift some of the risk to her. The drawback of this incentive scheme is that risk-averse agents want to insure their payment against bad outcomes and might shy away from signing such an agreement. This "insurance-incentive dilemma" is at the heart of agency and incentive theory.

Note, however, that most real-world incentive problems do not fall precisely into one of these two theoretical categories. One example is the problem of hidden knowledge, sometimes referred to as post-contractual adverse selection (Arrow, 1985; Rasmusen, 2007). We will address hidden knowledge in Chapter 3 of this dissertation.

Second, the theory of incomplete contracts is concerned with the complexity and unpredictability of the future, which makes it impossible for contracting parties to write all contingencies down. ${ }^{2}$ The most severe problem is that the future state of nature with regard to important variables (productivity, demand etc.) or either party's actions (investments etc.) cannot be sufficiently described in the contract and thus not be verified and enforced by third parties. Hence, to some degree all agreements are left incomplete.

In anticipation of this incompleteness, it would be optimal to allow for ex post renegotiations. When knowing this ex ante, however, commitment problems arise and agents are

\footnotetext{
2 This paragraph on incomplete contract theory is based on Hart and Holmström (1987), Brousseau and Glachant (2002) as well as Aghion and Holden (2011).
} 
encouraged to underinvest. It is worth mentioning here that these agents are mostly considered to be rational (albeit not so in Aghion and Holden, 2011). Contractual incompleteness is therefore not a result of cognitive constraints, but should rather be interpreted as inevitable or the outcome of a cost-benefit analysis.

As opposed to much of incentive or agency theory, information in this approach is assumed to be complete and symmetric for both contracting parties. Yet, while the state of nature (upon occurrence) is observable to both agents, third-party institutions are explicitly imperfect in verifying it: "[I]t is the asymmetry of information between the parties on the one hand, and outsiders (such as the courts) on the other hand, which is the root of the problem" (Hart and Holmström, 1987: 134).

A recent and interesting extension of the theory of incomplete contracts is the behavioral assumption that ex ante contracts are understood as reference points and both parties feel entitled to the best outcome the contract allows for (Hart and Moore, 2008; Fehr, Hart and Zehnder, 2011a). Leaving some terms flexible and permitting ex post renegotiations would consequently result in grievance, conflicts and potential welfare-reducing activities. We will return to that issue later in this dissertation.

Third, transaction costs economics (TCE)—or "governance approach"—draws on pioneering work by Coase (1937) and Williamson (1979; 1985). Most of their arguments are well known and should not be outlined here extensively. Yet, this theory has produced some assumptions and predictions that are central to the present dissertation and hence will be introduced in brief. Similar to the theory of incomplete contracts, TCE recognizes that all contractual arrangements exhibit gaps, shortcomings and that the future is blurry. However, it is more radical in identifying the origin of these problems: Different from the above approaches, all actors are strictly boundedly rational. Therefore, contractual incomplete- 
ness is not merely a result of the impossibility to verify compliance, it is inherent to a very imperfect institutional framework (Brousseau and Glachant, 2002).

Another behavioral assumption of TCE is the explicit existence of opportunism. That is, some agents are not just self-interested, they resort to "guile" (Williamson, 1979; ibid., 1985). This includes criminal acts, but also the exploitation of information asymmetries. Different forms of opportunism were already mentioned in this introductory chapter and will loom large in the three main chapters of this dissertation: reneging on contractual commitments, shirking and moral hazard, false statements on the state of nature etc. ${ }^{3} \mathrm{~A}$ central problem is that even though not everyone behaves opportunistically, those who do are not identifiable ex ante-similar to the adverse selection issue in incentive theory.

It has been widely understood that transaction costs are associated with almost all kinds of economic exchange, with the mere exception of very simple and simultaneous spot market transactions. The extent of these costs is strongly influenced by the institutional environment agents live in (e.g., the legal system or culture), but it also, in turn, influences the institutional arrangement they opt for (the governance structure, e.g., a certain type of contract). TCE puts emphasis on the latter (Williamson, 1979; Klein, 2000).

Because external institutions are assumed to be highly imperfect, the use of private mechanisms for enforcing contracts, resolving disputes and providing information is explicitly suggested. This touches on the denotation of private ordering, a topic we will revisit many times in the upcoming chapters. We can summarize that TCE "tries to explain how trading partners choose, from the set of feasible institutional alternatives, the arrangement that protects their relationship-specific investments at the least cost" (Klein, 2000: 468). Therefore, the study of contracts in a comparative institutional fashion is at the heart of this approach.

\footnotetext{
${ }^{3}$ Although there are forms of ex ante opportunistic behavior, we only address post-contractual opportunism.
} 


\subsection{Market institutions and the means of contract enforcement}

The economics of contracts outlined in the previous section reveal that contractual relationships are prone to severe incentive problems, issues of verifying performance, bounded rationality and opportunism. In what follows, we will take a more empirical look at the problem of contract enforcement with a particular emphasis on developing countries. As shall become clear, enforcement mechanisms can be rooted in both the institutional environment and specific institutional arrangements.

Along with the micro view of institutions that Williamson and his followers take, a more macro-oriented and historical perspective developed in the last few decades, acknowledging that "institutions matter" for a country's economic performance and prosperity (e.g., North, 1990; Rodrik, Subramanian and Trebbi, 2004; Acemoglu and Johnson, 2012). Besides securing property rights, institutions are meant to support the enforcement of contracts. The "legal centralism" tradition of economics emphasizes the critical role of public institutions and contract law for contract enforcement (e.g., Posner, 1998). While in many developed countries a judicial authority-actively or through its very existencecontributes to high rates of investment, lending and anonymous trade, other states witness serious institutional failures and can hardly rely on formal means of enforcement. ${ }^{4}$

One indicator for the efficiency of formal enforcement institutions is the time required to de facto enforce a contract. Based on data by the World Bank's Doing Business Report ${ }^{5}$, Figure 1.1 depicts the average enforcement time of contracts in different regions of the world in 2003-2014. Two immediate lessons can be drawn from this diagram. First, there are large differences in efficiency between regions. In the more industrialized countries of

\footnotetext{
${ }^{4}$ For a recent systematic review on the link between contract enforcement and investment see Aboal, Noya and Rius (2014).

${ }^{5}$ Data available on www.doingbusiness.org/data
} 
Europe, Central Asia, East Asia and North America enforcement is comparatively fast. The judicial system in a second group of regions (Latin America, Middle East and North Africa, sub-Saharan Africa) needs considerably more time, whereas South Asia is a striking outlier with a duration of three years. This length is mainly driven by India and Bangladesh whose mean enforcement time exceeds 1,400 days. The second lesson from Figure 1.1 is that changes in efficiency seem sluggish and reforms need much time to have an impact.

Yet, not only the efficiency measured in time matters for contractual parties, also the effectiveness, costs and access to legal institutions are critical factors. An additional role when assessing institutional quality certainly plays corruption and bribing—elements Figure 1.1 does not take into account.

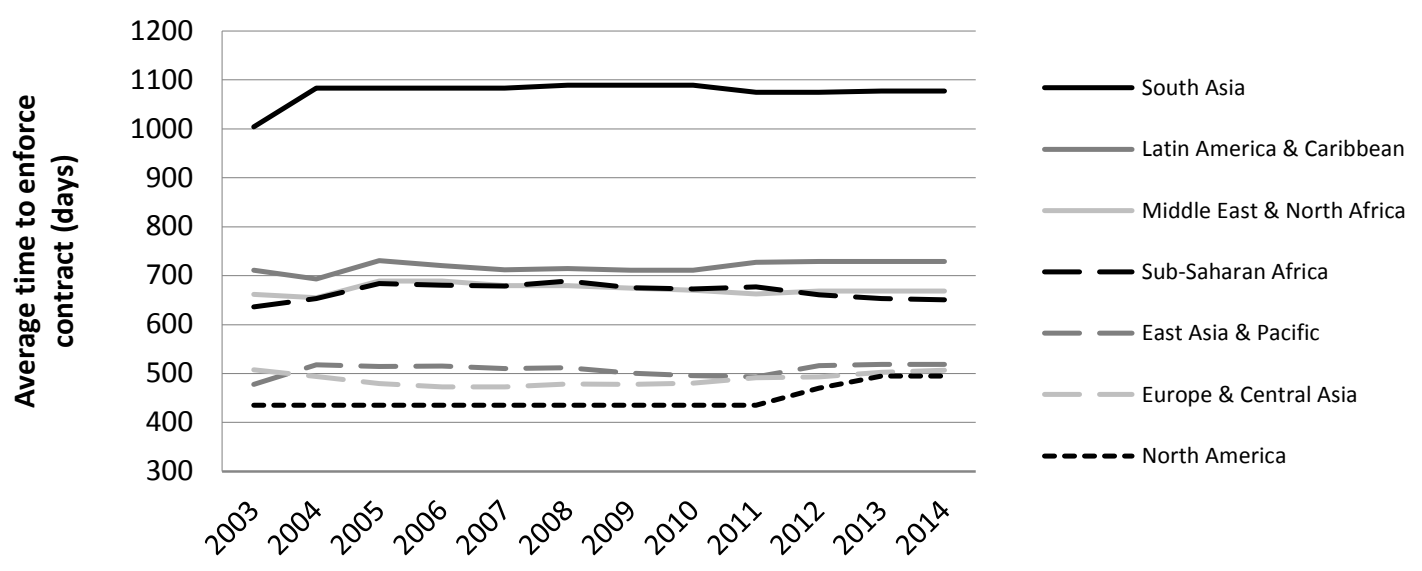

Figure 1.1: Average time to enforce a contract in different regions

Source: Own elaboration based on data available on www.doingbusiness.org/data

The question now is what individuals and businesses that find themselves in a "stateless" society, coined by weak formal institutions, can do. As the short quote by Douglass North at the outset of this introductory chapter implies, economic activity exists also in regions that are characterized by long enforcement periods in Figure 1.1 - or lack formal enforce- 
ment altogether. An immediate but general answer is: They can make use of alternative enforcement mechanisms and institutions.

Fafchamps (1996) introduces a model of contract enforcement that considers different sorts of costs for the offender (see Section 2.3.2 for a more formal illustration). We can categorize these costs in accordance with their support of first-, second- or third-party enforcement. First-party enforcement imposes an "internal" punishment to the offender in the form of guilt feelings, regret and fairness concerns. The efficacy of these mechanisms strongly depends on the individual and prevailing societal norms (Platteau, 1994). Furthermore, the aggrieved party can initiate some form of second-party enforcement or retaliation through harming the offender's reputation or terminating the trade relationship. A key implication from this argument is that a good reputation and a beneficial long-term relation are assets and relationship-specific investments; they can thus act as deposit, safeguard or, as Williamson (1985) calls it, a "hostage". All these potential costs and threats are inherent in the agreement and hence have the power to make it self-enforcing. Thirdparty enforcement, by contrast, can be public or private in nature. If agents cannot revert to public institutions (at low cost), private institutions, such as merchant guilds (Greif, Milgrom and Weingast, 1994), traders' coalitions (Greif, 1993) or mafias (Gambetta, 1993), can prevail. Besides coercion, these institutions may provide information or take on coordinating tasks (McMillan and Woodruff, 2000). We will return to the topic of enforcement mechanisms and particularly to private ordering in Chapter 2.

Within the last two decades, a strand of empirical literature on market institutions in lowincome countries and transition economies has emerged that provides insights into realworld settings, business practices and behavior in environments with high degrees of ambiguity and risk. The most extensive overview is perhaps Fafchamps' (2004) analysis of 
markets and bilateral trade relations in several African economies. One robust finding from this literature is that recourse to formal legal institutions is not the usual modus operandi in case of contractual disputes. Table 1.1 depicts some results by Bigsten et al. (2000) from the manufacturing sector in sub-Saharan Africa. In summary, surveyed firms frequently experience late or even non-payment by clients and (though somewhat less often) late deliveries or quality deficiencies by suppliers, but seek public-order dispute resolution by far less often than they use direct bargaining. Nonetheless, or possibly on these grounds, firms are satisfied with the outcome in 80 percent of cases and even continue to trade with about one in two breaching clients and the vast majority of suppliers.

Table 1.1: African firms' contractual disputes with clients and suppliers from Bigsten et al. (2000)

\begin{tabular}{|c|c|c|c|c|}
\hline & \multicolumn{2}{|c|}{ With clients } & \multicolumn{2}{|c|}{ With suppliers } \\
\hline & No. obs. & Total sample & No. obs. & Total sample \\
\hline \multicolumn{5}{|l|}{ Incidence of disputes: } \\
\hline late payment/late delivery & 1200 & $62.7 \%$ & 1199 & $32.7 \%$ \\
\hline non-payment/deficient quality & 1193 & $44.3 \%$ & 1197 & $39.0 \%$ \\
\hline \multicolumn{5}{|l|}{ Conflict resolution method: } \\
\hline direct bargaining & 780 & $78.8 \%$ & 436 & $74.3 \%$ \\
\hline private arbitration & 776 & $7.0 \%$ & 541 & $4.8 \%$ \\
\hline police & 766 & $8.7 \%$ & 547 & $1.3 \%$ \\
\hline lawyer & 777 & $25.2 \%$ & 548 & $3.8 \%$ \\
\hline courts & 777 & $25.7 \%$ & 545 & $3.3 \%$ \\
\hline \multicolumn{5}{|l|}{ Outcome of dispute: } \\
\hline dispute settled & 774 & $49.0 \%$ & 422 & $70.9 \%$ \\
\hline satisfied with outcome & 375 & $80.8 \%$ & 94 & $80.3 \%$ \\
\hline continue to trade & 603 & $43.8 \%$ & 328 & $80.8 \%$ \\
\hline
\end{tabular}

Fafchamps and Minten (2001) show how the lack of formal institutions in Madagascar leads to a "flea market economy", where agents confine themselves to simple forms of exchange and trading partners they know in order to diminish transaction costs. McMillan and Woodruff (1999a; 1999b) find that for Vietnamese firms prior screening of contractual partners and renegotiations are more important methods of preventing and resolving disputes with trading partners than engaging lawyers and courts. 
These findings from "flea markets" and the manufacturing sector can also be extended to contract agriculture. ${ }^{6}$ Gow, Streeter and Swinnen (2000) and Gow and Swinnen (2001) demonstrate how private enforcement capital and relationship-specific investments by agribusiness firms can make contracts with smallholders self-enforcing when institutions are in transition. Moreover, courts are found to be rarely involved in developing countries' agricultural supply chains and firms must find other ways to deter farmers from sideselling (Minten, Randrianarison and Swinnen, 2009). Having said this, Barrett et al. (2012) reveal that contract breach is a frequent issue affecting both sides, producer and buyer. Chapter 2 will be a case study of an experimental contract farming arrangement.

Another important — and directly related — finding from this literature is that contracts cannot be understood as rigid commitments, but exhibit a considerable degree of flexibility if circumstances so require (Bigsten et al., 2000; Fafchamps, 2004). Here, weak institutions coincide with information asymmetries, since conditions that may prevent one party from honoring its obligations are often not visible to the other. Flexible agreements can facilitate risk sharing and support exchange. To truly understand economic interaction in risky environments, a more rigorous analysis of observed voluntary contract flexibility is needed. We will contribute to this in Chapter 3.

\subsection{Studying behavior in contractual relationships: a case for experimentation}

After introducing relevant theories and some empirical evidence with regard to the central themes of this thesis, this section aims to (1) argue why experimentation is a very expedient method to study contractual relationships and (2) give a brief review of the experimental literature on contracts that is related to this dissertation.

\footnotetext{
${ }^{6}$ See $\mathrm{Wu}$ (2014) for a contract theoretical reflection and modelling of contract farming.
} 
The two main advantages associated with (laboratory) experimentation are replicability and control (Davis and Holt, 1993). The latter is central to draw causal inferences by manipulating single variables of the decision environment while holding others constant. By this means, we can create a ceteris paribus environment in which it becomes possible to trace back changes in behavior, decisions or preferences to the variation of a specific factor and foreclosing confounding effects. Another important element of indirect control in experiments is randomization (Friedman and Sunder, 1994). For instance, the problem of selection bias can be circumvented by assigning subjects in a random fashion to different roles or treatments within the experiment. Moreover, the fact that monetary payoffs are used and contingent on subjects' decisions (and thus endogenous to the experiment) engenders "real" consequences of actions and also real emotions ${ }^{7}$ (Falk and Heckman, 2009).

Experimentation is also, and in particular, advantageous for studying conduct within contractual relationships. Let us borrow the example of gift-exchange experiments from Falk and Heckman (2009). In these controlled studies, an important assumption of the efficiency-wage theory is tested, namely, whether an agent reciprocates a higher ("fairer") fixed payment with choosing a higher effort level (that only benefits the principal). The results have critical implications also for real-world contracts and the creation of appropriate incentives within contractual relations. Yet, a "clean" investigation with observational data proves challenging if not impossible, since we can barely control other factors influencing an agent's choice of effort (e.g., reputation considerations). While the identification of effort is central to this test, it appears impossible to measure/compare effort levels and effort costs in/between different naturally occurring situations. Along these lines, Just and

\footnotetext{
${ }^{7}$ An anecdote nicely illustrates this claim: After running a session of the experiment presented in Chapter 2 of this dissertation, one outraged participant approached the experimenters and urged them to restrict other subjects' "irrational" and "illogical" behavior in the game that apparently had harmed both the angry participant as well as the one blamed. Even though everyone knew they are attending an experiment and only a few euros were at stake, this participant felt seriously betrayed and reacted highly emotionally.
} 
Wu (2009) argue that carefully designed experiments can solve identification problems associated with observational studies on contract theory.

Testing theories is, however, only one purpose of economic experiments. Besides "speaking to theorists", researchers may be "searching for facts" or "whispering in the ears of princes" (Roth, 1995). The "searching for facts" intention refers to the study of observed anomalies that can hardly be explained by existing theories (Croson, 2002). These anomalies or regularities usually stem from other empirical or experimental research. "Whispering in the ears of princes" combines all experiments that aim to inform policy makers. This includes studies that test-bed new or reformed institutions or resemble a "wind tunnel" to examine policy interventions (ibid.; Croson and Gächter, 2010). Usually, research of this latter category uses more context or a specific framing, as opposed to experiments investigating theoretical predictions, or is conducted in the field (as external validity is essential). Famous examples are randomized control trials (RCTs) that evaluate the impact of specific development programs in low-income countries (Banerjee and Duflo, 2009).

Despite these advantages, we must acknowledge that experimentation in general, and laboratory experiments in particular (for a taxonomy cf. Harrison and List, 2004), are subject to criticism and have real limitations. We identified five general concerns that are recurring in the literature. ${ }^{8}$ First, most experiments are said to lack realism and external validity as their settings or games are very simplistic. Second, undergraduates or students in general are not representative and cannot replace experienced decision-makers as prevalent in many economic situations. Third, the money at stake is often trivial and, forth, the number of (independent) observations rather small. Last, the subject pools used for recruitment promote self-selection into experiments. There are many good responses to these five re-

\footnotetext{
${ }^{8}$ These points of criticism and some responses can be found in Davis and Holt (1993), Croson (2002) and Falk and Heckman (2009) among others.
} 
proofs; we will return to them in Chapter 5. For now, we want to stress the advantages mentioned above - namely, control, resolution of identification problems, exogenous manipulation of the decision environment etc. All are critical for the study of contracts.

What can we learn from existing experiments on contractual relations? In what follows, we will focus on seminal contributions that are closely linked to this dissertation and distinctly refer to contracts or use principal-agent settings. Even so, there are many revealed phenomena that are relevant for our understanding of agreements, yet not outcome of explicit "contract experiments": rejections in ultimatum games, trust and reciprocity in conventional investment games, altruistic punishment in cooperation games, to mention only a few.

Many experimental studies on agency theory or gift-exchange games examine the existence of fairness and reciprocity as opposed to the standard self-interest model. Principalagent experiments run in the lab show that contract offers by and large obey norms of fair sharing, that is, agents benefit from a contract more than standard theory would predict (Keser and Willinger, 2000; ibid., 2007; Anderhub, Gächter and Königstein, 2002; Cochard and Willinger, 2005). Fehr, Gächter and Kirchsteiger (1997) stress the importance of contracting parties' reciprocal responses and show in different treatments that reciprocity is a powerful enforcement device. Relatedly, Fehr, Klein and Schmidt (2007) compare various contract designs and find that agreements promising a bonus for the agent after performance are superior to contracts threatening with punishment if some players are fairminded. Principals in general anticipate that fairness concerns can provide enforcement and opt for corresponding contract designs.

Other studies look more specifically at relational contracting and reputation. Brown, Falk and Fehr (2004) allow for endogenous long-term relations and find that a lack of thirdparty enforcement leads to a strong "bilateralisation" in markets. Similarly, these endoge- 
nous relationships appear to have a disciplining effect regarding debt repayment in credit markets (Fehr and Zehnder, 2009). Gächter and Falk (2002) show that agents' positive reciprocity in a gift-exchange game is reinforced if players can build a bilateral reputation.

Another recent strand of literature addresses the issues of renegotiation, hold-ups and reference points. Hoppe and Schmitz (2011) present evidence from lab experiments that even if ex post renegotiation cannot be ruled out, contracts may solve the hold-up problem and encourage investment. Several studies examine Hart and Moore's (2008) hypothesis that a contract stipulates entitlements for the contracting parties' ex post outcome (cf. Sections 1.1 and 3.1). Fehr, Hart and Zehnder (2011a) confirm the existence of these entitlements that have important consequences for contract design and can make flexible agreements become inefficient. This analysis has been extended in Fehr, Zehnder and Hart (2009), Erlei and Reinhold (2010), Fehr, Hart and Zehnder (2011b) as well as Bartling and Schmidt (2015). Brandts, Charness and Ellman (2012) find that free-form communication may considerably improve the outcome of flexible contracts.

While field experiments on contracts are sparse in general ${ }^{9}$, some have been conducted by agricultural economists to better understand small-scale farmers' behavior in contractual arrangements. Sänger, Torero and Qaim (2014) provide a random group of Vietnamese dairy farmers with the opportunity to externally verify their product's quality before selling it to the purchasing company. They find that the removed information asymmetries have a significantly positive effect on smallholders' quality investment, output and welfare. In a series of framed field experiments, again with contract farmers in Vietnam, Sänger et al. (2013) and Torero and Viceisza (2011) compare the virtue of different contract designs and third-party enforcement. The first study finds that contracts including penalty clauses for

\footnotetext{
${ }^{9}$ There are some related field experiments examining the effect of incentives in employment relations-e.g., Shearer (2004), Paarsch and Shearer (2009) as well as Kube, Maréchal and Puppe (2012).
} 
low quality lead to a higher input use (and thus a higher quality outcome). Additional bonus payments for recurring high-quality production further increases farmers' purchase of inputs. Torero and Viceisza (2011) report gender-specific changes in trust following the introduction of a third-party auditor and potential collusion between auditor and trustee.

\subsection{Outline, research questions, and contribution of the dissertation}

This dissertation consists of three experimental studies on individuals' behavior in contractual relationships. While each study in Chapters 2, 3, and 4 is subject to other research questions, they share specific characteristics and are thus closely related. First, all look at voluntary bilateral relations in which both trading partners can benefit from mutual trust and bona fide exchange. Nonetheless, all underlying games include for at least one party pecuniary incentives to defect. These design features seem natural and consistent with realworld arrangements. Second, in each study we assume that no external contract enforcement is possible and that this is common knowledge. This holds true in many trade environments and causes serious efficiency issues. And third, on a methodological note, all experiments were conducted in a computer laboratory. This facilitated a reliable collection of data in a very efficient way that allows for even complex interactions. A detailed explanation of the used methodology and protocols will be part of the respective chapters.

\subsubsection{Research questions and synopses}

This dissertation will consider the following main research questions:

1. Do long-term relations and voluntary communication provide private-order enforcement and do buyers offer better contract terms to extend the self-enforcing range? 
2. Do subjects from a developing country have preferences for contract flexibility if they trade in very risky environments with asymmetric information?

3. Do large inequalities in profit from trade reinforce post-contractual opportunism?

In Chapter 2, which corresponds to the first question above, we examine contract terms and performance in a novel contract farming game. The experiment was run in the Göttingen Laboratory of Behavioral Economics (Germany) with student subjects. Previous experimental studies have analyzed "general" contracts, ignoring peculiarities of the specific environment the arrangement is embedded. In this experiment, we consider elements that are characteristic for production or resource-providing contracts used in the agricultural sector, such as credit provision and an external "spot market" as outside option for the farmer player (both hazardous factors for the buyer). In particular, we analyze if and how relational contracts and voluntary personal communication can support private enforcement, make relations work efficiently for both parties, and whether buyers offer price premiums to extend the contract's self-enforcing range-i.e., the range within external circumstances can change without making breach a profitable strategy. Since both players can breach the agreement (as is realistic), each of them is trustor and trustee at the same time.

From a theoretical perspective (cf. Section 1.1), this chapter is closest to transaction costs economics. Although we have symmetric information on the variables and actions within the game, we assume a very imperfect institutional environment and thus very high transaction costs. A link to the theory of incomplete contracts can be found in the inability of third-party institutions, even though the focus on private ordering is clearly in line with the transaction costs approach. In a very stylized way, Figure 1.2 depicts the contiguity between our chapters and the above theoretical streams. 


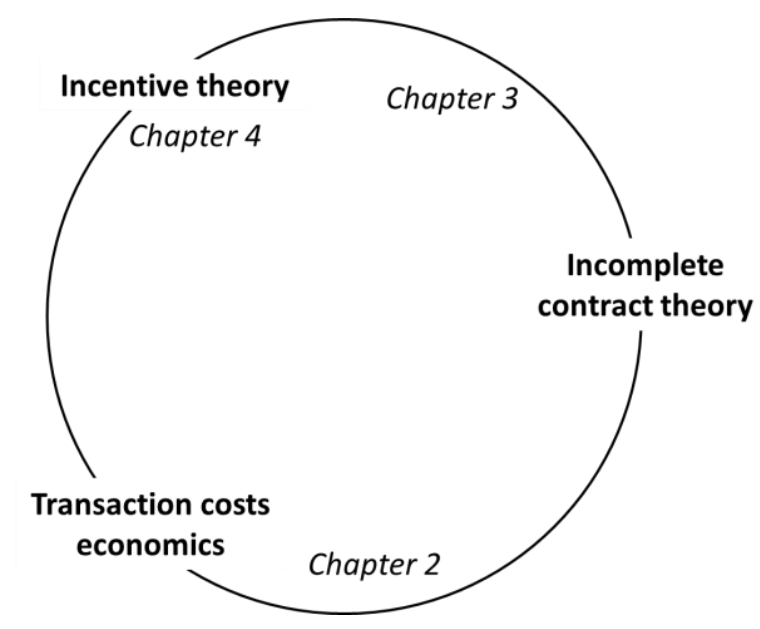

Figure 1.2: Stylized mapping of theoretical streams and chapters

Source: Own elaboration based on Brousseau and Glachant (2002)

Chapter 3 deals with the dilemma of contract flexibility in risky environments. We conducted this artefactual field experiment (Harrison and List, 2004) with slum dwellers in cooperation with the Busara Center for Behavioral Economics in Nairobi, Kenya. We examine subjects' preferences for flexible and rigid agreements, respectively, in a modified investment game with hidden knowledge regarding a potential shock. This is a common situation in developing countries, causing problems for many trade relations.

Given the strongly asymmetric information and the problem of moral hazard with hidden knowledge, this chapter is mainly concerned with incentive theory, but also bears some resemblance to the theory of incomplete contracts, since agreements may be left flexible and thus allow for "implicit renegotiation".

Chapter 4 is dedicated to the issues of hidden action and inequity aversion in a developing country context. Again, the experiment is carried out with individuals from the Kibera slum in Nairobi. In a simple principal-agent game, we investigate if reluctance to trade and post-contractual opportunism are reinforced when the agent can observe large (disadvantageous) differences in profit from trade. 
Similar to the previous chapter, this study is an experimental analysis of incentive theory owing to the general existence of hidden action. The chapter's focus, however, is not on the design of an optimal payment scheme — which is exogenously given — but on the occurrence of opportunistic behavior contingent on the (agent's knowledge of) profit inequalities between the parties. Thus, theories of fairness and other-regarding preferences are combined with an agency framework.

\subsubsection{Contribution and novelty}

Overall, this dissertation aims at contributing to a better understanding of behavior within contractual relationships - in particular, if information asymmetries, incentive issues and a lack of formal institutions make exchange more difficult and risky. Opportunistic behavior, but also the sheer potential of opportunism, may lead to inefficiencies in value chains and severe welfare losses, making this a highly relevant topic. To improve market institutions and make value chains more efficient, we need to gain better knowledge of how individuals in bilateral trade relations and different contexts actually behave and interact.

In the upcoming chapters we contribute to both the empirical literature on market institutions in developing countries as introduced in Section 1.2 and the experimental literature on behavior in contractual relationships as reviewed in Section 1.3. These experiments examine and are guided by contract theory as sketched in Section 1.1.

Our experiments complement and extend other empirical work on contracts. The research in Chapter 2 is original in applying a more complex and holistic setting that uses a specific framing and is closer to real-world contract (farming) arrangements than existing experiments: (1) Both players can honor or breach a contract, i.e., both are trustor and trustee at the same time, (2) the outside option for sellers depends on conditions in an external "spot 
market", (3) the free-form communication is voluntary, and (4) we interact this voluntary communication with repeated game/reputation effects.

The experiments in Chapters 3 and 4 investigate preferences and conduct of individuals living in an urban slum and hence go beyond the use of a student "convenience sample". Chapter 3 is novel in examining the direct link between external risk and contract flexibility. This linkage was presumed before in the empirical literature (Bigsten et al., 2000; Fafchamps, 2004). To the best of our knowledge, our analysis is the first controlled study of this relationship. For this, we introduce a modified investment game with hidden knowledge and a choice between two contract designs. Chapter 4 is among very few studies on other-regarding behavior of individuals living in extreme poverty and applies this to a principal-agent setting with moral hazard. Excluding reciprocity as a driving force, it is innovative in exploring the link between distributive inequalities and post-contractual opportunism in a developing country context.

The upcoming three chapters will present the experimental studies outlined above. The fifth and last chapter summarizes and concludes. In addition, we will suggest implications for real-world contractual arrangements and institutions. 


\title{
2. Making it personal: breach and private ordering in a contract farming experiment
}

\begin{abstract}
Contracts may be subject to strategic default, particularly if public enforcement institutions are weak. In a lab experiment, we study behavior in a contract farming game without third-party enforcement but with an external spot market as outside option. Two players, farmer and company, may conclude a contract but also breach it by sideselling or arbitrary payment reductions. We examine if and how relational contracts and personal, voluntary communication can support private-order enforcement. Moreover, we investigate whether company players offer price premiums to extend the contract's selfenforcing range. We find mixed evidence for our private ordering hypothesis. Although contract breach can be reduced by relational contracts, direct bargaining communication does not additionally improve the outcome. Price premiums are offered if other enforcement mechanisms are absent, but turn out to be only an "allurement". Most subjects are not willing to sacrifice short-term gains in favor of a well-functioning relationship that (as we show) would be beneficial for both contract parties in the long run.
\end{abstract}

Keywords: contract farming, private ordering, enforcement, contract breach, economic experiments, relational contracts, communication, price premiums

JEL classification: D02, L14, Q13

This chapter is joined work with Meike Wollni and Claudia Keser (Kunte, Wollni and Keser, 2014). For their comments, we thank Martin Schmidt, Stephan Müller and the participants of the $2^{\text {nd }}$ GlobalFood Symposium, 25-26 April 2014 in Göttingen. Financial support by the German Research Foundation (DFG) is gratefully acknowledged. 


\subsection{Introduction}

In the last decades, the use of contracts for governing agricultural supply chains has grown increasingly popular in the developing world. Contract farming, defined as agricultural production and marketing carried out according to some prior agreement between farmer and agribusiness firm (see, e.g., Eaton and Shepherd, 2001; Prowse, 2012), can be seen as one reaction to the ongoing fundamental changes in global agri-food markets. Trade liberalization and agro-industrialization, the proliferation of public and private standards, changing consumer preferences and the supermarket boom in many developing countries have triggered higher degrees of vertical coordination or even integration (Reardon and Barrett, 2000; Reardon et al., 2009). By written or verbal contracts small-scale farmers in low-income countries can potentially be linked to modern supply chains and high-value export markets. Typically, these farmers suffer from severe imperfections in markets for credit, insurance, information, inputs etc. Contract farming arrangements could cushion these failures by including credit or input provision by the buyer into the agreement (Key and Runsten, 1999). However, there are many open questions and potential hurdles that need to be investigated. Numerous studies examine farmers' preferences or motives to participate in contract farming (Masakure and Henson, 2005; Schipmann and Qaim, 2011). Others investigate whether contract agriculture increases revenue or welfare (Bolwig, Gibbon and Jones, 2009; Bellemare, 2012).

This chapter is concerned with the problem of strategic contractual default induced by incomplete agreements or institutional failures. Particularly in developing and transition countries, contract farming is subject to poorly functioning legal institutions (Cungu et al., 2008; FAO, n.d.; World Bank, 2013a; ibid., 2013b). Proper public enforcement lacking, "legal centralism" tradition of economics predicts that exchange and investment fail to take 
place due to the fear of contractual breach and hold-ups. And, as a matter of fact, even if courts are not entirely absent, law suits in the wake of breach in contract agriculture are rather unlikely since transaction costs are prohibitive (Eaton and Shepherd, 2001; Minten, Randrianarison and Swinnen, 2009).

One solution to this problem of opportunistic behavior suggested by the theoretical, empirical and historical literature on market institutions is private ordering (Williamson, 1985; ibid., 2002). That is, instead of relying on public enforcement and formal punishment mechanisms agents attempt to make contracts self-enforcing, use private third parties or apply informal mechanisms based on reputation or repeated interaction to enhance mutual trust ex ante and support dispute settlement or retaliation ex post (for an overview see McMillan and Woodruff, 2000; Ben-Ner and Putterman, 2001). Although private-order contract enforcement also matters in today's industrial countries, it is perhaps more prominent in Europe of the late medieval times and the Commercial Revolution (see Greif, 1992 for a survey) or in developing and transition economies. For instance in sub-Saharan Africa (Bigsten et al., 2000; Fafchamps, 2004), Vietnam (McMillan and Woodruff, 1999a; ibid., 1999b) or Russia (Hay and Shleifer, 1998) economic activities are crucially supported by long-term relations, reputation mechanisms and social networks.

Fafchamps (1996) categorizes the offender's cost of contract breach in guilt, threat of retaliation and coercive action. Considering their origin, we can interpret these costs as supporting first-, second- and third-party enforcement, respectively. First-party enforcement implies that private ordering can have its roots in a (potential) cheater's other-regarding preferences, moral norms or feelings of guilt. Preferences for honesty, general morality or the intrinsic value of living up to a promise may well convince agents to stick to an agreement (Platteau, 1994). Moreover, the second party (the one cheated on) can threaten with retalia- 
tion-usually in terms of terminating the business relationship and harming the offender's reputation, both potentially resulting in suspension of future trade (see, e.g., Klein, 1996; MacLeod, 2007) or social ostracism (e.g., Posner, 1997). Finally, third-party enforcement is accomplished through coercive action by other institutions of public or private order. Obviously, not all third parties necessarily use coercion, as state institutions and some private enforcers outside the law do. Instead, a third party may also provide information or coordinate community responses (McMillan and Woodruff, 2000). Whatever mechanism or institution is being applied, enforcement of contracts and a trustful relationship is said to be achieved when long-term costs of reneging for a party outweigh its short-term benefits.

A growing body of literature addresses contract farming arrangements empirically. In practice, contractual default appears to be an issue for both producer and buyer. Guo, Jolly and Fischer (2007) and Guo and Jolly (2008) stress that informal enforcement mechanisms are central to the Chinese agricultural sector and producers' contract performance critically depends on contract design. Beckmann and Boger (2004) find that even if Polish farmers have the opportunity to involve courts, they also consider the indirect costs of doing so. In other words, the value of the affected relationship determines whether punishment is used. Gow and Swinnen (2001) and Gow, Streeter and Swinnen (2000) present case study evidence for Klein's (1996) self-enforcing range for transition economies. They show how formerly unreliable companies can enhance their trustworthiness through relationshipspecific investments, thus making breach more expensive for themselves.

The present study uses an experimental approach to investigate subjects' behavior in a contract farming setting and the effectiveness of private ordering through long-term and personal relationships. We design a novel experimental game that is akin to real-world contract farming arrangements with an exogenous spot market as outside option. Both players, 
farmer and company, may conclude a contract and breach it by side-selling (farmer) or arbitrarily reducing the promised price ex post (company). This way, both players are trustors and trustees at the same time. By using the laboratory, we are able to create a controlled ceteris paribus environment and disentangle the effects of different enforcement mechanisms, which is hardly possible with the analysis of survey data (see also Just and $\mathrm{Wu}, 2009)$. Even though there are some related experiments on contract farming conducted in the field (Torero and Viceisza, 2011; Sänger et al., 2013; Sänger, Torero and Qaim, 2014), most experiments on contractual relationships have been run within lab environments. They usually assume the form of trust, principal-agent or gift-exchange games. Many interesting findings shed light on the existence and role of fairness preferences, reciprocity and trust in contractual relations (Keser and Willinger, 2000; ibid., 2007; Fehr, Gächter and Kirchsteiger, 1997; Bohnet, Frey and Huck, 2001; Fehr, Klein and Schmidt, 2007), but also on the formation of long-term contracts (Brown, Falk and Fehr, 2004; Wu and Roe, 2007) and the impact of communication (Ellingsen and Johannesson, 2004; Charness and Dufwenberg, 2006; Ben-Ner and Putterman, 2009).

We add to this literature by investigating the informal factors influencing contract breach in an experimental setting. Unlike others, we do not focus on moral hazard or adverse selection problems (representing special cases of contractual issues) but on the more fundamental and often neglected "incentive problems associated with getting parties to honor their promises" (Wu, 2014). In particular, we address the following research questions:

- To what extent do long-term relations provide private-order enforcement and are relationships improving when agents can personally bargain about contractual terms and communicate discontent? 
- Do company players offer price premiums to increase the self-enforcing range ${ }^{10}$ of the contract in highly uncertain environments?

- Who benefits from private-order enforcement and does trade in general become more efficient?

- In how far is contract performance associated with subjects' honesty preferences and their general guilt proneness?

The remainder of this chapter is structured as follows. Section 2.2 explains the experimental game and procedures. Section 2.3 derives our behavioral hypotheses. Section 2.4 presents and discusses the experimental results. The last section concludes.

\subsection{An experimental approach to study behavior in contract farming arrangements}

\subsubsection{The contract farming game}

Our experimental game comprises two marketing channels and, depending on the channel, five potential (decision) stages. These stages are guided by the conceptual framework in Barrett et al. (2012) to ensure that the game closely resembles a real contract farming arrangement. In each of the $T=15$ trading periods, a player in the role of an agri-business company $(C)$ purchases units of an agricultural product, and a player in the role of a farmer (F) sells her produce. The product is assumed to be of consistent quality. The two players may agree on a contract or alternatively use the local spot market for exchange.

\section{(1) Pre-harvest phase: contract negotiation}

In a first stage, $C$ decides whether to offer $F$ a contract for the purchase of $q_{h}$ units of $F$ 's product. If so, she sets a contract price $p_{c}>0$ per unit and the game proceeds to the next

\footnotetext{
${ }^{10}$ That is, the extent to which external circumstances may change without making contract breach beneficial.
} 
stage. In the second stage, $F$ decides whether to accept or reject the contract. If $F$ accepts, the contract is being concluded. If no offer is made by $C$ in the first stage or if $F$ rejects the contract offer in the second stage, both players go directly to the spot market, where they buy/sell at an exogenously determined spot market price.

After the above decisions have been made, in the third stage both players observe the perunit spot market price $p_{s m}$ determined by a computerized random device. As known to all subjects from the beginning, prices can take (integer) values between 1 and 7 (unless otherwise stated all prices are expressed in experimental currency units). As shown in Table 2.1 , a price of 4 is most likely with a probability of 30 percent.

Table 2.1: Spot market prices and their probabilities of occurrence

\begin{tabular}{cccccccc}
\hline $\boldsymbol{p}_{\boldsymbol{s m}}$ & $\mathbf{1}$ & $\mathbf{2}$ & $\mathbf{3}$ & $\mathbf{4}$ & $\mathbf{5}$ & $\mathbf{6}$ & $\mathbf{7}$ \\
Prob. & .05 & .1 & .2 & .3 & .2 & .1 & .05 \\
\hline
\end{tabular}

\section{(2) Post-harvest phase: contract performance}

After observing $p_{s m}$, in the fourth stage $F$ decides whether to comply with the agreement and deliver to $C$ or to sell to the spot market instead (side-selling). If $F$ delivers, we proceed to the fifth stage, where $C$ decides if she pays $F$ the agreed-on contract price, $p_{c}$, or arbitrarily reduces this price by $p_{\text {default }}$. If in the fourth stage $F$ decides not to deliver, both $F$ and $C$ go to the spot market.

There are some additional features associated with the two marketing channels that influence the players' incentives and are crucial elements in real-world contract farming arrangements:

- Contract. To distinguish our game from other contract experiments, we introduce a special form of agreement frequently used in agricultural supply chains, namely a resource- 
providing contract. Each time a contract is concluded, $C$ bears contracting costs of $s$ and provides $F$ with a loan $c$ that increases her production capacity from $q_{l}$ to $q_{h}$ (with $\left.q_{l}<q_{h}\right)$. The existence of this relationship-specific investment in the game is important, since it provides a strong motivation for $F$ to accept a contract and enhances her production (as in many real-world arrangements). At the same time, it increases the risk that $C$ has to bear. According to the agreement, $c$ has to be paid back at the end of a trading period. If $F$ breaches the contract, though, she also refuses to repay $c$.

- Spot market. Each time players use the spot market, they face transaction costs of $k_{C}$ and $k_{F}$ (with $k_{C}, k_{F}>0$ ), respectively. For these costs it is irrelevant if the market is used directly or after non-delivery.

Figure 2.1 summarizes the timeline of events in our contract farming game.

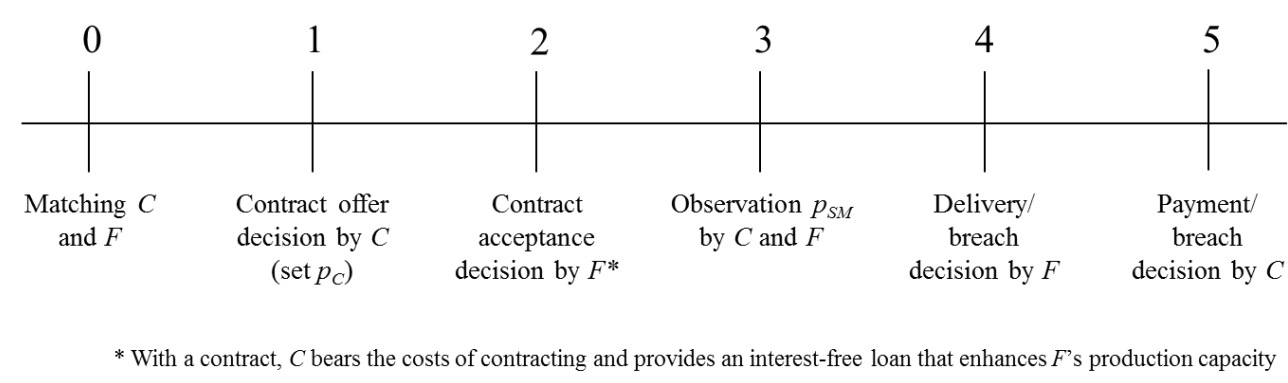

Figure 2.1: Timeline of events in the contract farming game

A player's profit is determined by her revenue minus costs and depends on several factors: the quantity sold/bought (smaller for $F$ if no contract is concluded), the price received/paid (through the contract or on the spot market), whether the credit is paid back and which marketing channel is eventually being used (resulting in the associated transaction or contracting costs). For $C$, each unit of the purchased produce has a positive value of $v$ (e.g., the marginal revenue when processing the good). The players' general (and abstract) profit functions are as follows. 
Company player's profit: $\quad \pi_{C}= \begin{cases}q_{h} v-q_{h} p_{s m}-k_{C} & \text { if no contract } \\ q_{h} v-q_{h} p_{c}-s & \text { if both perform } \\ q_{h} v-q_{h} p_{s m}-c-s-k_{C} & \text { if breach farmer } \\ q_{h} v-q_{h}\left(p_{c}-p_{\text {default }}\right)-s & \text { if breach company }\end{cases}$

Farmer player's profit: $\quad \pi_{F}= \begin{cases}q_{l} p_{s m}-k_{F} & \text { if no contract } \\ q_{h} p_{c}-c & \text { if both perform } \\ q_{h} p_{s m}-k_{F} & \text { if breach farmer } \\ q_{h}\left(p_{c}-p_{\text {default }}\right)-c & \text { if breach company }\end{cases}$

In order to play the game in the laboratory, we have to assign parameters to the variables.

Table 2.2 presents the list of all parameters and a brief explanation for a better overview.

Table 2.2: Experimental parameters

\begin{tabular}{ll}
\hline Parameter & Explanation \\
\hline$q_{l}=10$ & Produced (low) quantity by $F$ without contract \\
$q_{h}=15$ & Produced (high) quantity by $F$ under contract; demanded quantity by $C$ \\
$p_{c} \in\{1,2, \ldots, 7\}$ & Price per unit set in the contract \\
$p_{\text {sm }} \in\{1,2, \ldots, 7\}$ & Spot market price per unit, stochastically determined \\
$p_{\text {default }} \in\{1,2\}$ & Arbitrary payment reduction per unit by $C$ after $F$ 's delivery \\
$k_{C}=40$ & $C$ 's transaction cost for purchasing on spot market \\
$k_{F}=10$ & $F$ 's transaction cost for selling on spot market \\
$c=10$ & Credit provided by $C$ to $F$ \\
$s=10$ & Contracting cost paid by $C$ \\
$v=12$ & One unit's value for $C$ (revenue per unit)
\end{tabular}

Given these parameters, $C$ always buys $q_{h}=15$ units, while $F$ can only supply this quantity with a contract and accordingly with a credit of $c=10$. Without contract, $F$ can only produce $q_{l}=10$ units. In case a contract is offered and accepted, $C$ bears the contracting 
cost of $s=10$. All prices per unit are integers and may range from 1 to 7 . $C$ can ex post reduce the contract price arbitrarily by 1 or 2 per unit. On the spot market, $C$ faces transaction costs of $k_{C}=40$, whereas $F$ 's transaction costs equal $k_{C}=10 . C$ values each unit of the purchased produce with $v=12$.

Considering the above parameters, we can simplify the profit functions to make the different outcomes of the game easily comparable for both players.

Company player's profit: $\quad \pi_{C}= \begin{cases}140-15 p_{s m} & \text { if no contract } \\ 170-15 p_{c} & \text { if both perform } \\ 120-15 p_{s m} & \text { if breach farmer } \\ 170-15\left(p_{c}-p_{\text {default }}\right) & \text { if breach company }\end{cases}$

Farmer player's profit: $\quad \pi_{F}= \begin{cases}10 p_{s m}-10 & \text { if no contract } \\ 15 p_{c}-10 & \text { if both perform } \\ 15 p_{s m}-10 & \text { if breach farmer } \\ 15\left(p_{c}-p_{\text {default }}\right)-10 & \text { if breach company }\end{cases}$

We tried to design the stages of our model so as to resemble a real-world contract farming arrangement that yet is not too difficult to be played in the lab by non-experts. Unlike in many other studies, we deliberately use framing and introduce context to make the diverse associations about farmers and agri-business companies part of the experiment. Deploying realistic context, compared to the difficult attempt to eliminate it altogether, may boost the external validity of experimental findings (Loewenstein, 1999) and, not least, supports the subjects' intuitive understanding of the rather complex payoff functions. However, in the instructions and messages displayed on the computer screen we refrain from using strong 
normative terms, such as "breach", "default" or "perform", and frame decisions and actions neutrally to avoid demand effects. ${ }^{11}$

As mentioned earlier, the decisions are broadly guided by the conceptual framework in Barrett et al. (2012), but also by other academic and non-academic literature on contract farming that inspired and underpins the individual elements of our game. Among others, Rehber (2007) states that farmers oftentimes only have the option to accept or reject a contract; they have no say in determining conditions. Glover (1984), Key and Runsten (1999) and Masakure and Henson (2005) mention that credit provision, also in-kind, for investing in the farm and enhancing productivity is common and one major motivation for smallholders to participate in contract schemes. This is partly due to the high transaction costs that characterize input and output markets in many developing countries. If agents did not face such high transaction costs (as is the case for more standardized agricultural commodities), contracts would become redundant (Minot, 2007). Although the spot market prices and their probabilities are somewhat arbitrary in our experimental game, producers and processors do experience strong fluctuations also in real-world settings, exposing smallholders and agri-business firms to considerable price risk (MacDonald et al., 2004). Most importantly for the relevance of our experiment, previous empirical work has found strategic contract default from either party to be a frequent problem in contract farming arrangements (Glover, 1984; Minten, Randrianarison and Swinnen, 2009; Swinnen and Vandeplas, 2010).

\footnotetext{
${ }^{11}$ More specifically, we avoided their German equivalents and other terminology that comes with strong negative or positive associations. See Appendix 2A for the experimental instructions.
} 


\subsubsection{Conditions}

Our experiment consists of three conditions that differ with respect to their nature of company-farmer relationships and potential private-order enforcement. First, with the shortterm or classical contract (CC) we define a baseline as reference point for comparison with the private-order enforcement conditions. Farmer and company players are matched randomly in each period. The counterpart's identity is unknown and there is no possibility to observe past behavior. A subject may interact with the same partner again, but no one knows if and when this will happen. After each repetition (except for the last), a message on the computer screen reminds participants of the following random assignment. With this stranger matching protocol, reputational and relational effects are very unlikely and thus private enforcement mechanisms are largely absent. ${ }^{12}$

Second, we introduce a relational contract (RC). In this condition company-farmer pairs remain steady over the $T=15$ trading periods, i.e., the game is played as a (finitely) repeated game and every player can observe the other's behavior in this ongoing relationship. ${ }^{13}$ Unlike in Brown, Falk and Fehr (2004) and Wu and Roe (2007), relationships in our experiment are exogenous and players cannot change partners. The spot market represents an outside option, though, if they do not wish to interact with their particular counterpart.

\footnotetext{
${ }^{12}$ Some informal enforcement mechanisms may work nonetheless. It is still possible for $C$ to offer attractive contract conditions (we will return to this in Section 2.4.2). If subjects in the CC condition comply in cases where contract breach would be beneficial for them, this may be due to, e.g., guilt aversion or cognitive constraints (see also Section 2.3.2). We will address guilt feelings and honesty in Section 2.4.4.

${ }^{13}$ Relational contracts are typically modelled as a repeated game with infinite horizon. In the lab, we would thus need to implement an unknown or probabilistic rather than a known deterministic termination rule. However, we believe that we would considerably lose control when playing the game with unknown or random termination. Subjects might have very different expectations about when the game will end. Normann and Wallace (2012) show that the termination rule does not significantly affect average cooperation. To control for endgame effects (Selten and Stoecker, 1986), we shall provide, where appropriate in the data analysis, additional analysis excluding the final period.
} 
Our third condition is a direct bargaining (DB) treatment. In terms of matching protocol, the DB equals the RC. However, we introduce the opportunity for a more personal relationship and dispute resolution. While rarely mentioned in the theoretical literature, the important role of direct bargaining and personal visits for contract enforcement is extensively discussed in the empirical literature (e.g., Fafchamps, 2004)—either as an ex ante mechanism of inspection and information gathering or an ex post method of conflict resolution. In our game, before a new period begins, $C$ can opt for a "farm visit", which implies that $C$ and $F$ can communicate for 120 seconds in an electronic chat room. Framing this action neutrally as a "visit" comes with the advantage that subjects are free in what they communicate about and we largely avoid demand effects. $C$ decides if and when this freeform communication takes place, however it is restricted to one during the entire 15periods game.

While a comparison between the $\mathrm{CC}$ and $\mathrm{RC}$ enables us to isolate the impact of relational contracting on contract formation, performance and profits, a comparison between the RC and the DB outcomes helps to understand the additional effect of communication on the self-enforcement of contracts. An analysis of the behavior within the DB condition can reveal if this personal communication device can contribute to strengthening relationships and enforcing promises.

\subsubsection{Experimental procedures and implementation}

The experiment was carried out in the Göttingen Laboratory of Behavioral Economics in Germany between May and August 2013 and was computerized with the software package z-Tree (Fischbacher, 2007). For the recruitment of participants we used a university subject 
pool and the ORSEE system (Greiner, 2004). Consequently, the vast majority of participants are students.

Upon arrival, participants received the experiment's written instructions and they were read aloud to them. Subsequently, everyone went to a computer booth and individually answered questions to prove full comprehension of the different decisions and their consequences. Facilitators were on hand to assist with individual queries. Since the number of parameters is large and the payoff functions are rather complex, participants were required to perform several test calculations. Only after everyone had successfully completed the questionnaire, the actual experiment started. ${ }^{14}$ The game was played for $T=15$ trading periods either in the $\mathrm{CC}, \mathrm{RC}$ or DB condition (between-subject comparison). Afterwards, a post-experimental questionnaire was administered, followed by the participants' individual cash payment. Company players earned EUR 0.01 for each currency unit they earned in the game, farmer players earned EUR 0.02 per currency unit. ${ }^{15}$ Both additionally received a show-up fee of EUR 3. On average, a participant in the role of a company made EUR 16 in a session, a farmer player almost EUR 18 (the mean of EUR 17 equals about USD 23 at the time of implementation). A typical session lasted approximately 1.5 hours.

We implemented a total of eleven experimental sessions - five for the $\mathrm{CC}$, three for the RC and three for the DB condition. In each CC session we had 20 participants, while each RC and DB session was attended by 24 subjects. Hence, we have a total of 244 participants with nobody attending more than one session. Each subject is randomly assigned the role

\footnotetext{
${ }^{14}$ We have good reason to believe that the level of understanding the game among participants was sufficiently high. In our post-experimental questionnaire, subjects were asked to rate the comprehension of instructions from 0 (very incomprehensible) to 10 (very comprehensible). The mean value in our experiment is 8.14 .

${ }^{15}$ We did not want participants to leave the lab with large income differentials contingent on their role. Therefore, the different exchange rates are necessary when we intend to maintain the profit differences in the game. This, however, does not change the players' incentives.
} 
of a company or a farmer player at the beginning of the experiment. There is the same number of company and farmer players in a session. With 72 subjects in the RC and DB, respectively, we obtain 36 steady pairs due to a partner matching protocol and thus 36 independent observations per condition. In the $\mathrm{CC}$, however, we use a stranger matching protocol. Unbeknownst to the subjects, we divide a session into two matching groups, containing five company and five farmer players. Matching is only done within a matching group and there is no interaction between groups. By this means, we obtain ten independent observations for the CC.

\subsection{Theoretical predictions and hypotheses}

\subsubsection{Subgame perfect equilibrium}

To derive our first hypothesis, we determine the subgame perfect equilibrium (SPE) for risk-neutral, rational and selfish agents by backward induction. As participants know that this game has a finite horizon, we can apply the following predictions to every single repetition.

In the final stage, $C$ chooses

$$
\max \left\{q_{h} v-q_{h} p_{c}-s, q_{h} v-q_{h}\left(p_{c}-p_{\text {default }}\right)-s\right\}
$$

Given that $p_{\text {default }}>0, C$ will always opt for breach and reduce the contract price by the $\operatorname{maximum} p_{\text {default }}$.

Anticipating this, in the fourth stage, $F$ only delivers if her profit from delivery and the following breach by $C$ is at least equal to the profit from side-selling. That is,

$$
q_{h}\left(p_{c}-\max \left(p_{\text {default }}\right)\right)-c \geq q_{h} p_{s m}-k_{F}
$$


Hence, delivery is guaranteed if the price difference satisfies

$$
p_{c}-p_{s m} \geq \max \left(p_{\text {default }}\right)+\frac{c-k_{F}}{q_{h}}
$$

For our specific parameters, $F$ 's delivery constraint is thus

$$
p_{c}-p_{s m} \geq 2
$$

which implies that $F$ will comply with the agreement if and only if the contract price is at least 2 above the observed spot market price. Otherwise, she will sell to the spot market instead. Note, $F$ 's transaction costs in case of side-selling and the credit non-repayment cancel each other out in this calculation.

In the second stage, $F$ always accepts a contract since

$$
\max \left\{q_{h} p_{\text {sm }}-k_{F}, q_{h}\left(p_{c}-p_{\text {default }}\right)\right\}>q_{l} p_{\text {sm }}-k_{F}
$$

with $q_{h}>q_{l}$. That is, $F$ is always better off receiving the credit, increasing her production capacity from $q_{l}$ to $q_{h}$ and then reverting to the spot market (if more beneficial), than directly selling $q_{l}=10$ in the spot market.

Considering all of the above, in the first stage, $C$ chooses the maximum between her expected payoff without offering a contract $\left(q_{h} v-q_{h} p_{s m}-k_{C}\right)$ and her expected payoff with contract (taking $F$ 's responses into account). Solving this maximization problem for the optimal decision and the optimal choice of $p_{C}$ is far from being trivial. This is why we provide a numerical solution for our specific parameters in Table 2.3. Accordingly, $C$ maximizes her expected profit if she offers a contract with a price of $p_{c}=7$. 
Table 2.3: $C$ 's expected profits depending on contract price, spot market price and $F$ 's predicted behavior

\begin{tabular}{lc|ccccccc|c}
\hline & $\boldsymbol{p}_{\text {sm }}$ & $\mathbf{1}$ & $\mathbf{2}$ & $\mathbf{3}$ & $\mathbf{4}$ & $\mathbf{5}$ & $\mathbf{6}$ & $\mathbf{7}$ & $\boldsymbol{E}\left(\boldsymbol{\pi}_{\boldsymbol{C}}\right)$ \\
$\boldsymbol{p}_{\boldsymbol{c}}$ & $($ Prob. $)$ & $(.05)$ & $(.1)$ & $(.2)$ & $(.3)$ & $(.2)$ & $(.1)$ & $(.05)$ & \\
\hline $\mathbf{1}$ & 105 & 90 & 75 & 60 & 45 & 30 & 15 & 60 \\
$\mathbf{2}$ & 105 & 90 & 75 & 60 & 45 & 30 & 15 & 60 \\
$\mathbf{3}$ & 155 & 90 & 75 & 60 & 45 & 30 & 15 & 62.5 \\
$\mathbf{4}$ & 140 & 140 & 75 & 60 & 45 & 30 & 15 & 66.75 \\
$\mathbf{5}$ & 125 & 125 & 125 & 60 & 45 & 30 & 15 & 74.5 \\
$\mathbf{6}$ & 110 & 110 & 110 & 110 & 45 & 30 & 15 & 84.25 \\
$\mathbf{7}$ & 95 & 95 & 95 & 95 & 95 & 30 & 15 & $84.5^{*}$ \\
No offer & 125 & 110 & 95 & 80 & 65 & 50 & 35 & 80 \\
\hline * highest expected profit for $C$ \\
Notes: For the grey-shaded contract price-spot market price combinations, \\
$F$ 's delivery constraint is not satisfied, which indicates that she breaches the \\
contract. Thus, $C$ 's profit is contingent on the spot market price. In the non- \\
shaded areas (excluding "No offer"), $F$ is predicted to comply with the con- \\
tract, and $C$ 's profit thus depends on the contract price.
\end{tabular}

\section{Standard economics hypothesis:}

(i) Side-selling occurs if the farmer player's delivery constraint $\left(p_{c}-p_{s m} \geq 2\right)$ is not satisfied. The company player, however, will always breach the contract reducing the paid price by the maximum $p_{\text {default }}=2$ when the farmer player delivers.

(ii) Anticipating this, the company player offers the highest contract price of $p_{C}=7$ at the beginning of the game.

\subsubsection{Alternative behavioral predictions}

The predicted SPE of our stage game theoretically holds true for all repetitions and conditions. Economic theory also starts from the premise that personal communication is merely "cheap talk" and does not change the equilibrium, as promises are not enforceable and both players know that. This, however, does not mean that we in fact expect real subjects to behave that way if selfishness and complete rationality are not common knowledge and if we allow for relational and reputational effects. It remains an empirical question, how 
long-term relations and personal communication for direct bargaining and coordination influence contract performance, prices and (as a consequence) players' profits.

That is, while our first hypothesis predicts a player's utility to solely depend on her immediate pecuniary payoff, we now consider additional indirect costs of breach and a more complex utility function based on the conceptual framework and notation by Fafchamps (1996; 2004):

$$
U_{i}=\pi_{i}-G_{i}\left(\tau_{i}, \varepsilon\right)-P_{i}\left(\tau_{i}, \varepsilon, \theta\right)-E V_{i}\left(\tau_{i}, \varepsilon\right)-E W_{i}\left(\tau_{i}, \varepsilon\right)
$$

where $i \in\{C, F\}, \pi_{i}$ is the player's immediate monetary payoff, $G_{i}$ the cost of feeling guilty, $P_{i}$ coercive action, e.g., by state institutions, $E V_{i}$ denotes the suspension of future trade with this trading partner, and $E W_{i}$ the damage to the offender's multilateral reputation. These indirect costs depend on the player's type $\tau_{i}$ and the state of nature $\varepsilon$. Coercive action by the state is additionally contingent on the form of contract $\theta$. This general formula, holding for virtually all contractual relationships, can be simplified for our experimental conditions. While third-party coercion $P_{i}$ is considered impossible (and thus zero), we can also ignore $E W_{i}$ as former behavior is not observable to players other than the one trading with. In the CC, even $E V_{i}$ becomes zero. As $\varepsilon$ can be considered constant ${ }^{16}$, a player $i$ in our contract farming game will maximize her expected utility with respect to $\pi_{i}, G_{i}\left(\tau_{i}\right)$ as well as - in the RC and $\mathrm{DB}$ condition- $E V_{i}\left(\tau_{i}\right)$, contingent on her type $\tau_{i}$ (unscrupulous/honest).

Thus, departing from the standard theoretic predictions, we believe that private enforcement through relational contracts generally works here by influencing the subjects' utility

\footnotetext{
${ }^{16}$ We interpret $\varepsilon$ here as a measure of, e.g., the occurrence of a negative production shock. However, $\varepsilon$ does not refer to the stochastic spot market price. While also being an element of the trade environment, spot market prices can be understood as opportunity cost of an agreement and do not influence the ability to comply with the contract terms (only, perhaps, the willingness).
} 
from trade. Previous studies have found that subjects consider the "shadow of the future" and care about their bilateral reputation in contractual relations (e.g., Gächter and Falk, 2002). We build on this literature, investigating whether repetition is a sufficient condition for relationships to work well and analyzing the magnitude of such effects in our contract farming experiment. We expect the direct bargaining communication—by personalizing exchange and facilitating coordination - to further strengthen relationships (e.g., Ben-Ner and Putterman, 2009). If a company player can credibly show that she will pay the offered price, the rate of side-selling could be lowered and both players may move to a more cooperative equilibrium. Hence, we expect to observe fewer dysfunctional relationships and less contract breach in the DB condition.

Furthermore, some of the literature emphasizes that contract parties can use price premiums to make agreements self-enforcing if other mechanisms are absent (e.g., Swinnen and Vandeplas, 2011). We hypothesize that this endogenous enforcement device will be used by company players, in particular in the absence of other private-order enforcement mechanisms.

\section{Private ordering hypothesis:}

(i) In the RC and DB condition contract breach from either party can be significantly reduced relative to the $\mathrm{CC}$. Moreover, the $\mathrm{DB}$ outperforms the $\mathrm{RC}$ as it provides additional opportunities for private-order enforcement.

(ii) The offered contract price in the $\mathrm{CC}$ is higher than in the other conditions, as in the absence of other private-order enforcement mechanisms company players offer price premiums to extend the contract's self-enforcing range. 


\subsection{Experimental results}

\subsubsection{Contract breach and the effectiveness of private ordering}

Opportunistic contract breach by farmer players (side-selling) is expected to depend on the contract price-spot market price difference (henceforth CSMD). According to our standard economics hypothesis farmer players breach if the CSMD is smaller than 2. Contract default by the company, in turn, does not depend on other factors and reducing the price by the maximum $\left(p_{\text {default }}=2\right)$ is a dominant strategy.

Side-selling. On average, side-selling occurs in 44.6 percent of concluded contracts ${ }^{17}$ in the $\mathrm{CC}$, in 27.6 percent in the RC and 26.3 percent in the DB. Also Figure 2.2, panel (a) suggests that side-selling is significantly more frequent in the $\mathrm{CC}$ compared to the RC $(p=0.0739)$ and the DB $(p=0.0427) .{ }^{18}$ That is, long-term relationships seem to mitigate contract default from farmers' side in our experiment. However, the possibility for direct bargaining has no additional effect (RC-DB difference: $p=0.8611)$. This does not change if we exclude the final period from the analysis.

Over the 15 periods, there is no clear trend of increasing or decreasing levels of sideselling. Rather, we observe many ups and downs, which are associated with the volatile spot market price and the resulting changes in the CSMD. In the RC and DB condition, side-selling increases towards the end of the game when the relationship becomes less valuable given the weaker "shadow of the future".

\footnotetext{
${ }^{17}$ A contract was offered on average in 82.5 percent (CC), 83.9 percent (RC) and 81.9 percent (DB) of all trades. These differences are not significant using non-parametric Mann-Whitney $U$ tests. Contract acceptance rates are 94.2 percent (CC), 91.2 percent (RC) and 97.1 percent (DB). Differences between DB and the other conditions are significant on the 5-percent level. The CC-RC difference is not significant.

${ }^{18}$ Unless otherwise stated, significance levels refer to two-sided, non-parametric Mann-Whitney U tests based on the session means of all independent observations (i.e., steady pairs or matching groups).
} 
(a)

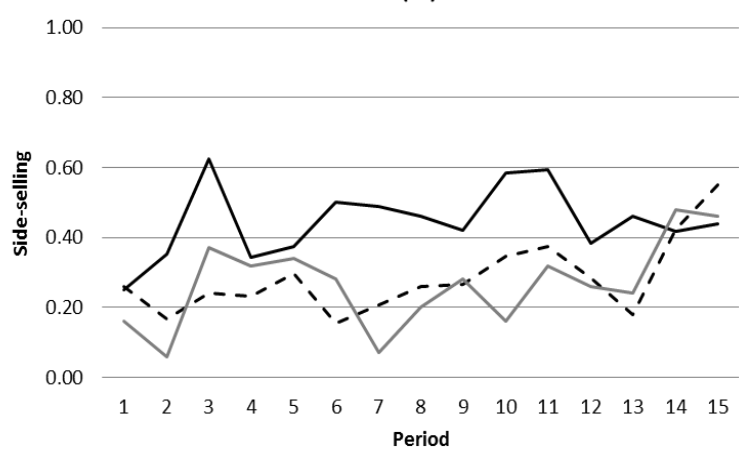

(c)

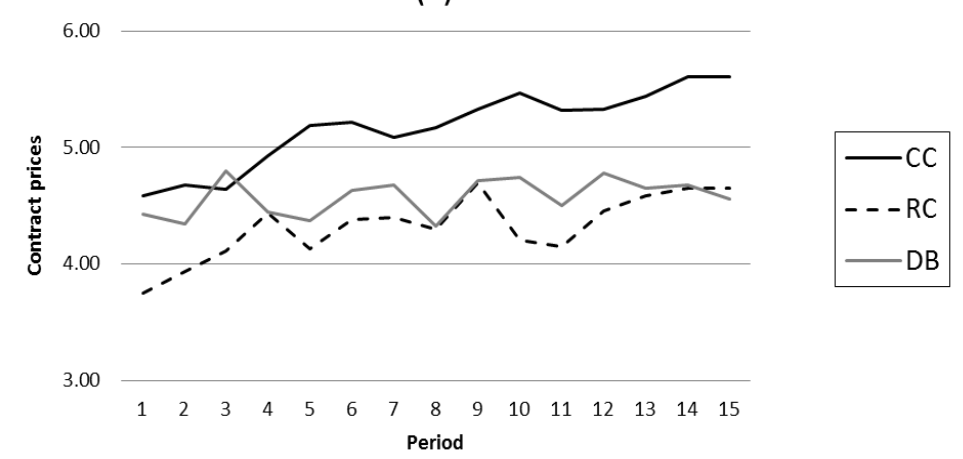

(b)

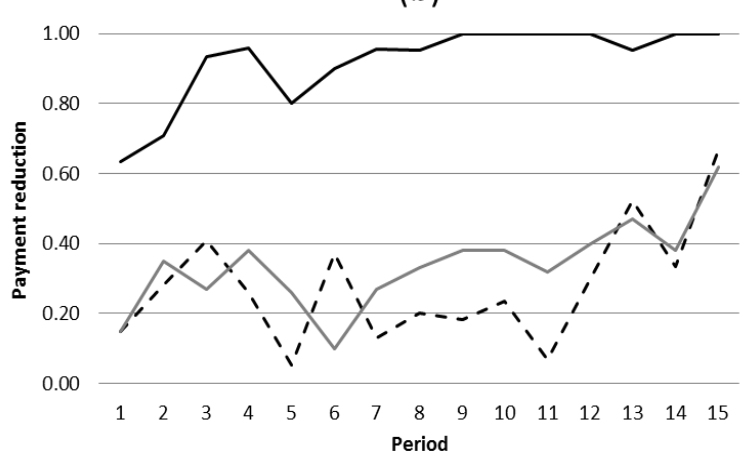

.

Figure 2.2: (a) Side-selling (as share of all contracts) by farmer players, (b) payment reduction (as share of all payments) by company players, and (c) mean contract prices offered

However, the positive effect of the long-term relationship on side-selling is likely to be underestimated here. As we will discuss in the next section, the offered mean contract price in the $\mathrm{CC}$ is significantly higher than in the $\mathrm{RC}$ and $\mathrm{DB}$ and side-selling is indeed strongly contingent on the CSMD. This price difference is on average 1.23 in the CC and only 0.18 in the $\mathrm{RC}(p<0.0001)$ and 0.48 in the $\mathrm{DB}(p=0.0004)$. Consequently, we need to apply regression analysis to control for price differences and obtain the real treatment effects.

The first part of Table 2.4 summarizes the results of different probit regression models with Side-selling as the dependent variable, which takes the value of 1 if the farmer player breaches the contract and 0 otherwise. The results show that side-selling is significantly more likely in the $\mathrm{CC}$ relative to the other conditions. There is no additional treatment ef- 
fect of the DB, though, suggesting that the long-term relationship is the mechanism at work here. The coefficient of Period is positive and significant in all estimated models (except for the first), indicating that farmer players become less reluctant to breach over time. Model (1) reveals that a farmer player is much more likely to breach if she suffered from breach by the company player in the previous round (Lagged breach experienced). The impact of the difference between contract and spot market price (CSMD) is negative and highly significant, as expected. This negative relationship is particularly strong in the CC compared to the other conditions, as contract breach here does not depend on relational and reputational factors, but rather on a pure profit calculus. The results in model (3) do not change considerably if we exclude the final period.

As hypothesized in Section 2.3.1, rational and selfish farmer players, expecting the company player to reduce the price by the maximum, will sell to the spot market when the CSMD is below 2. To assess whether farmer players in the experiment consider their delivery constraint, Figure 2.3 displays side-selling as the share of all concluded contracts subject to a certain price difference. Results show that only 55 percent of the farmer players in the CC breach the contract when the CSMD is positive and below 2; in the RC and DB this share is even lower at 17 and 15 percent, respectively. The design of our experiment does not allow to disentangle whether this is due to the farmer players' own dislike of breach, reputation concerns or expectation of how the company will behave in the final stage. But based on our data we can conclude that even in the $\mathrm{CC}$, side-selling is not as frequent as predicted by standard theory. 


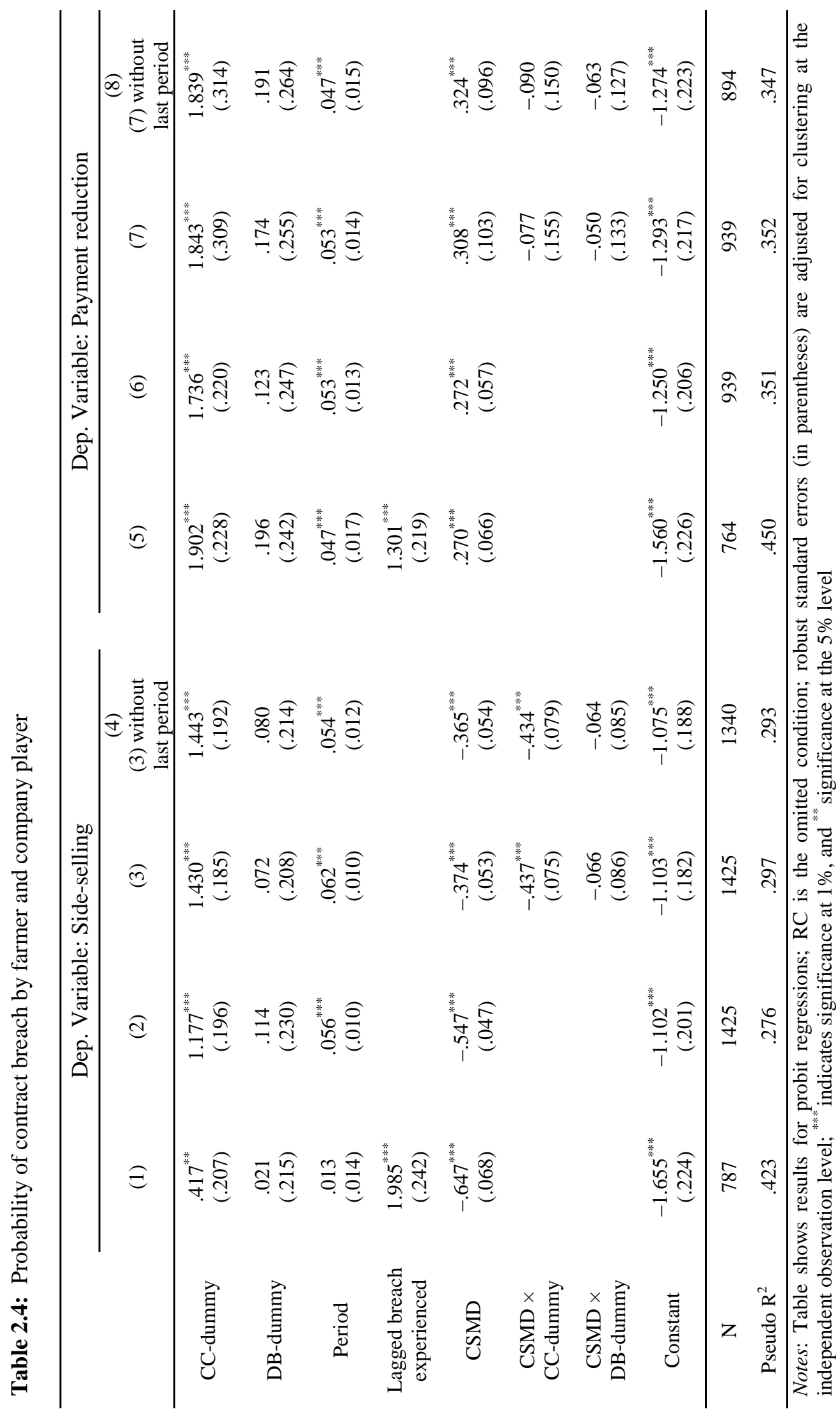




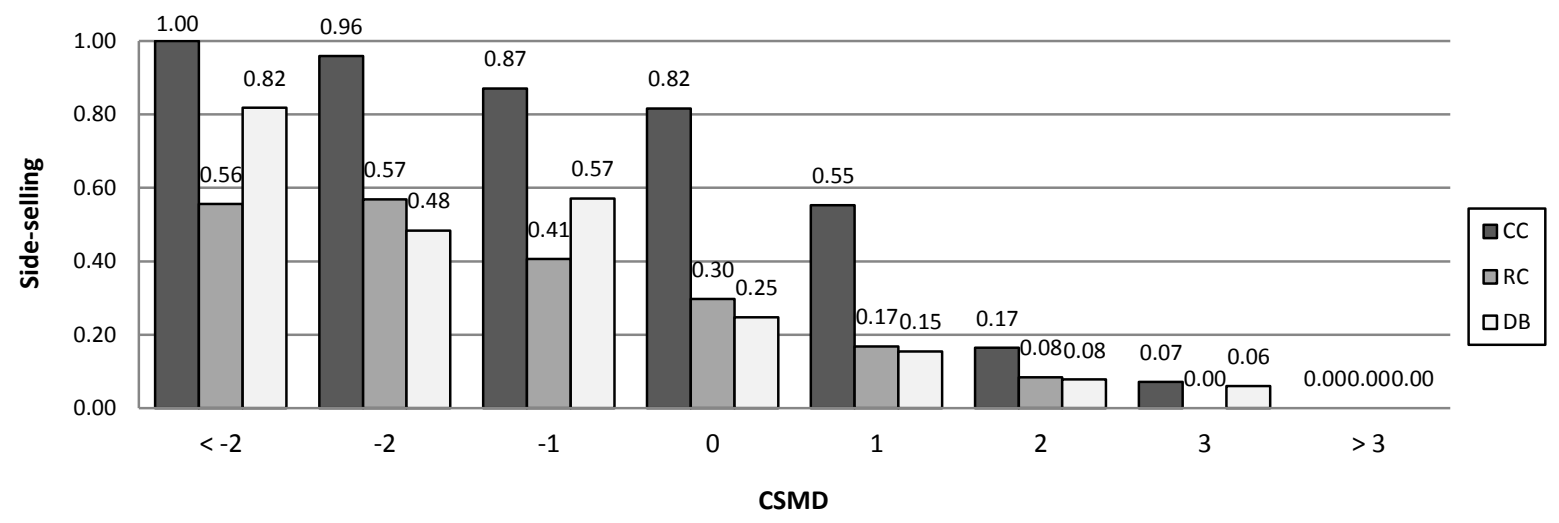

Figure 2.3: Side-selling (as share of all concluded contracts) conditional on the contract pricespot market price difference (CSMD)

Payment reductions. In the CC, company players are somewhat reluctant to breach during early periods, but almost always reduce the paid price in the second half of the experiment (Figure 2.2, panel (b)). On the average, they pay 1.65 currency units less than promised. In the RC and DB, subjects behave much more in favor of the relationship, although default still occurs - particularly in the end, when the value of the relationship tends to fall. Company players reduce the price, on average, by 0.46 in the $\mathrm{RC}$ and by 0.53 in the $\mathrm{DB}$ in the case of delivery.

As for side-selling, the CC-RC $(p=0.0033)$ and CC-DB differences $(p=0.0047)$ are significant, but no additional effect from the direct bargaining communication can be found (RC-DB difference: $p=0.8375)$. The same picture holds if we exclude the final period from the analysis. Accordingly, company players' breach can also be significantly reduced in long-term relationships.

Probit regression analyses with payment reductions as the binary dependent variable shed more light on what determines the company players' behavior. The second part of Table 2.4 reveals that in all estimated models the occurrence of payment reductions can be decreased in the $\mathrm{RC}$ and $\mathrm{DB}$ condition relative to the $\mathrm{CC}$, yet without an additional treat- 
ment effect of the DB. Moreover, company players' breach slightly increases over time. As for farmer players, a bad experience in the previous period increases the probability of own contract breach significantly (even though the farmer player delivered in the current period). Interestingly, the coefficient of CSMD is always positive and significant, indicating that company players are more likely to breach with an increasing difference between contract and spot market price-even though theoretically the CSMD should not influence their decision. Apparently, we do not only observe strategic default, but also what we interpret as "emotional contract breach": In case of a large positive price difference, company players realize that they could have earned more without an agreement and that the farmer is the main beneficiary of the contract arrangement. As a consequence, they can justify reducing the price arbitrarily (presumably feeling less guilty).

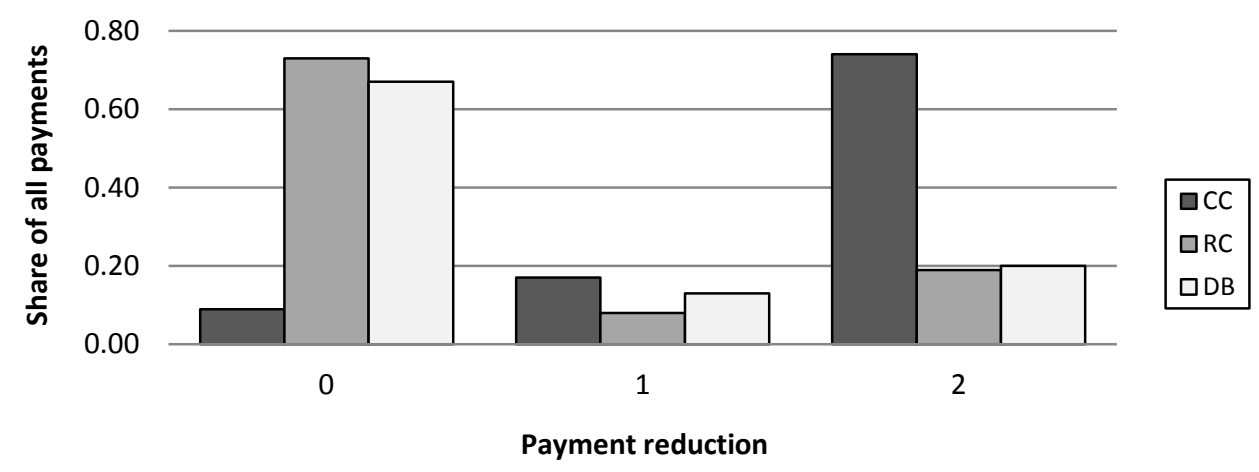

Figure 2.4: Occurrence of different payment reductions (as share of all payments)

The aggregated results in Figure 2.2, panel (b) as well as the probit estimations in Table 2.4 treat payment reductions as a binary variable, taking the value of 1 if the company player reduces the paid price (regardless of by how much) and 0 otherwise. According to the subgame perfect equilibrium, the company player will always reduce the payment by the maximum amount of 2 , and if a company player considers reputational effects or feels guilty when reneging, she should not breach at all. Indeed, as can be seen in Figure 2.4, 
across all conditions only a small share of payments is reduced by 1 currency unit, whereas in most of the cases either a zero or a maximum reduction is chosen.

Direct bargaining and conflict resolution. Before we turn to the analysis of contract terms, we address the question of why the direct bargaining communication did not additionally improve contract compliance at the aggregate level as expected by our private ordering hypothesis. In the empirical literature, direct bargaining and personal visits are considered one method for contract enforcement, preventing and resolving contractual disputes when public enforcement institutions are weak as is often the case in developing countries (McMillan and Woodruff, 1999a; Bigsten et al., 2000; Fafchamps, 2004).

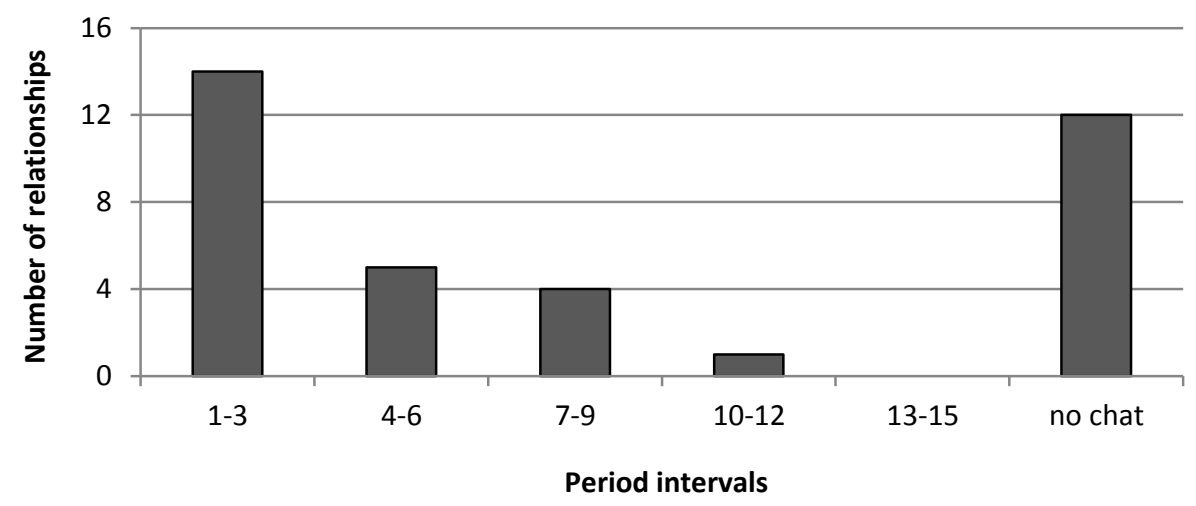

Figure 2.5: Occurrence and timing of direct bargaining communication in the DB condition

One potential answer to this question can be found in Figure 2.5, which not only depicts the timing of communication, but also the number of company players who did not contact their counterpart at all. We can see that most chats take place within the first periods of the experiment and the number declines in later rounds. This choice indeed makes sense when company players hope to positively influence as many upcoming game periods as possible. Surprisingly, in one-third of the DB relationships no communication took place at all. This is particularly astonishing as communication did not entail any direct costs in the game. 
Apparently, some company players did not regard one-time communication as a promising means for consolidating the relationship and coordinating exchange.

In fact, a closer look at those relationships in which a personal contact was established shows that the effectiveness of communication for reducing contract breach is limited. Comparing the level of contract breach before and after the chat reveals that no significant decrease of side-selling could be achieved ( $p=0.2059$, Wilcoxon signed-rank test). For company players, default even increases after the communication due to the endgame effect in the DB ( $p=0.0606$, Wilcoxon signed-rank test). The latter finding vanishes when we exclude the final period, but a significant impact in the expected direction is not observable for either type of player. However, when we distinguish well-functioning and rather dysfunctional relationships (see Section 2.4.3 and Table 2.6), it is striking that in all well-functioning relations in the DB the company player opted for a chat at a certain point throughout the experiment. We thus can reject the conjecture that individuals refrained from communicating because their trading relationship was already functioning well.

Result 1: In the CC condition, side-selling is not as frequent as predicted by our standard economics hypothesis. In contrast, payment reductions tend to occur in almost every transaction.

Result 2: Contract breach from either side can be significantly reduced by relational contracts, reflecting a repeated game effect. Surprising is, however, that the additional direct bargaining communication does not improve contract compliance. In addition, for one-third of the company players communication did not represent an attractive option.

Result 3: We find evidence that company players' default is not only strategic, but also "emotional", i.e., the probability of an opportunistic payment reduction increases with a larger difference between contract price and spot market price. 


\subsubsection{Price premiums as enforcement mechanism}

In all three conditions, average contract prices offered by company players are well below the price of 7 suggested by the subgame perfect equilibrium (Figure 2.2, panel (c)). In the $\mathrm{CC}$, company players offer 5.15 on the average, which is significantly higher than the contract prices of 4.30 offered in the $\mathrm{RC}(p=0.0001)$ and 4.57 offered in the DB condition $(p=0.0016)$. Furthermore, the RC-DB difference is also significant at $p=0.0153$.

One potential explanation for the higher contract prices offered in the $\mathrm{CC}$ is that company players know they can "allure" farmer players with an attractive contract price (i.e., an efficiency premium) and thereby increase the probability of delivery. This is in line with the literature on price premiums in agricultural value chains, arguing that "[m]aking the contract self-enforcing by paying [or offering] an efficiency premium is a rational strategy for the buyer, as it can earn him a better payoff than her outcome when being held up, or upon contract breakdown" (Swinnen and Vandeplas, 2011). As we have shown in the previous section, company players in the $\mathrm{CC}$ are also more likely to reduce the price in the end. In the $\mathrm{RC}$ and $\mathrm{DB}$ condition, in contrast, subjects rather try to stick to what they promiseand thus promise less - in order not to sour the relationship. In fact, once we compare the actual contract prices paid at the end of the period (after potential payment reduction by the company player), we do not find a significant difference between the average price paid in the $\mathrm{CC}$ (3.87) and those paid in the RC (4.03) and DB (4.13). ${ }^{19}$ Only the RC-DB difference is significant at $p=0.0903$. This supports the interpretation that high-price offers in the $\mathrm{CC}$ are used as an "allurement tactic" to increase the probability of delivery, given that company players can later breach the contract without fearing consequences.

\footnotetext{
${ }^{19}$ This only takes into account those trades in which a contract was formed and the farmer delivered to the company player.
} 
While all average contract prices are substantially below the maximum, we do find that in the $\mathrm{CC}$ and $\mathrm{RC}$ prices are rising over time, indicating that company players tend to learn that it is rational to offer higher prices. Wilcoxon signed-rank tests comparing mean prices in periods $1-7$ with mean prices in periods $8-15$ reveal significant price increases in the case of the $\mathrm{CC}$ and RC conditions (CC: $p=0.0069$; RC: $p=0.0056$; $\mathrm{DB}: p=0.9037)$.

In the DB somewhat different dynamics are at work and the average contract prices offered do not display a similar increase over time. We believe that this - as well as the higher average contract price offered in the $\mathrm{DB}$ relative to the $\mathrm{RC}$ - can be ascribed to the direct bargaining communication. As discussed above, most chats were conducted in an early period of a session, providing the opportunity for early coordination and bargaining. During these chats, subjects often tried to negotiate a certain contract price and promised to mutually comply. ${ }^{20}$ As a result, the offered prices are already relatively high in the beginning, but do not grow over the course of the game.

Result 4: In a highly uncertain environment where no relational and reputational capital can be accumulated, company players offer price premiums to increase the contract's self-enforcing range. However, this is only an "allurement tactic" as they do not pay the premium in the end.

\subsubsection{Who (potentially) benefits from private-order enforcement?}

On the average, the profit per period earned by company players amounts to $\pi_{C}=82.95$ in the $\mathrm{CC}, \pi_{C}=89.26$ in the $\mathrm{RC}$, and $\pi_{C}=88.40$ in the DB condition. These differences are, however, not statistically significant according to non-parametric tests. This result does not change when we exclude the final period from the analysis.

\footnotetext{
${ }^{20}$ An overview of all chat messages will be provided upon request.
} 
Table 2.5, column (1) presents results from a regression analysis taking into account all possible trades. The results reveal that company players generally earn more in a contractual relationship and when long-term relations are possible. Moreover, profits slightly decrease over time. Taking only those trades into account in which contracts were concluded (column (2)), we see that company players' profits are by far lower in the $\mathrm{CC}$, as sideselling occurs significantly more often under this condition than in long-term contractual relations. There is no additional treatment effect associated with the DB. Companies' profits increase with a rising CSMD (again because of the self-enforcing effect). This influence is smaller in the RC and DB, albeit still positive, since here also other mechanisms besides short-term price incentives apply.

Table 2.5: Determinants of profit (in one period)

\begin{tabular}{|c|c|c|c|c|c|c|}
\hline & \multicolumn{2}{|c|}{ Profit company } & \multicolumn{2}{|c|}{ Profit farmer } & \multicolumn{2}{|c|}{ Joint profit } \\
\hline & $\begin{array}{c}(1) \\
\text { All trades }\end{array}$ & $\begin{array}{c}(2) \\
\text { If contract }\end{array}$ & $\begin{array}{c}(3) \\
\text { All trades }\end{array}$ & $\begin{array}{c}\text { (4) } \\
\text { If contract }\end{array}$ & $\begin{array}{c}(5) \\
\text { All trades }\end{array}$ & $\begin{array}{c}(6) \\
\text { If contract }\end{array}$ \\
\hline CC-dummy & $\begin{array}{c}-6.419^{* * *} \\
(2.164)\end{array}$ & $\begin{array}{c}-23.082^{* * *} \\
(3.220)\end{array}$ & $\begin{array}{c}-.199 \\
(1.495)\end{array}$ & $\begin{array}{l}3.610^{* *} \\
(1.780)\end{array}$ & $\begin{array}{c}-6.618^{* * *} \\
(1.785)\end{array}$ & $\begin{array}{c}-19.472^{* * * *} \\
(2.435)\end{array}$ \\
\hline DB-dummy & $\begin{array}{l}-1.113 \\
(2.637)\end{array}$ & $\begin{array}{l}-3.316 \\
(3.942)\end{array}$ & $\begin{array}{c}1.458 \\
(1.551)\end{array}$ & $\begin{array}{c}2.126 \\
(1.881)\end{array}$ & $\begin{array}{c}.346 \\
(2.345)\end{array}$ & $\begin{array}{l}-1.190 \\
(3.149)\end{array}$ \\
\hline Period & $\begin{array}{c}-.552^{* * *} \\
(.170)\end{array}$ & $\begin{array}{c}-1.088^{* * * *} \\
(.173)\end{array}$ & $\begin{array}{l}.133 \\
(.092)\end{array}$ & $\begin{array}{l}.281^{* * * *} \\
(.100)\end{array}$ & $\begin{array}{c}-.419^{* * *} \\
(.112)\end{array}$ & $\begin{array}{c}-.807^{* * *} \\
(.122)\end{array}$ \\
\hline $\begin{array}{l}\text { Contract- } \\
\text { dummy }\end{array}$ & $\begin{array}{l}8.486^{* * * *} \\
(1.543)\end{array}$ & & $\begin{array}{c}24.228^{* * *} \\
(.982)\end{array}$ & & $\begin{array}{c}32.714^{* * * *} \\
(1.140)\end{array}$ & \\
\hline CSMD & & $\begin{array}{l}7.179^{* * *} \\
(1.517)\end{array}$ & & $\begin{array}{l}-2.085^{*} \\
(1.196)\end{array}$ & & $\begin{array}{c}5.094^{* * * *} \\
(.677)\end{array}$ \\
\hline $\begin{array}{c}\text { CSMD } \times \\
\text { CC-dummy }\end{array}$ & & $\begin{array}{l}5.732^{* * * *} \\
(1.703)\end{array}$ & & $\begin{array}{l}-1.293 \\
(1.323)\end{array}$ & & $\begin{array}{c}4.439^{* * * *} \\
(.729)\end{array}$ \\
\hline $\begin{array}{c}\text { CSMD } \times \\
\text { DB-dummy }\end{array}$ & & $\begin{array}{c}.867 \\
(2.333)\end{array}$ & & $\begin{array}{c}-.279 \\
(1.687)\end{array}$ & & $\begin{array}{c}.588 \\
(1.069)\end{array}$ \\
\hline Constant & $\begin{array}{c}87.184^{* * * *} \\
(2.269)\end{array}$ & $\begin{array}{c}98.688^{* * * *} \\
(3.018)\end{array}$ & $\begin{array}{c}28.919^{* * *} \\
(1.363)\end{array}$ & $\begin{array}{c}52.547^{* * * *} \\
(1.543)\end{array}$ & $\begin{array}{c}116.103^{* * * *} \\
(1.669)\end{array}$ & $\begin{array}{c}151.235^{* * *} \\
(2.457)\end{array}$ \\
\hline $\mathrm{N}$ & 1830 & 1425 & 1830 & 1425 & 1830 & 1425 \\
\hline $\mathrm{R}^{2}$ & .028 & .281 & .283 & .083 & .319 & .318 \\
\hline
\end{tabular}

Notes: Table shows results for OLS regressions; RC is the omitted condition; robust standard errors (in parentheses) are adjusted for clustering at the independent observation level; ${ }^{* * *}$ indicates significance at $1 \%$, significance at $5 \%$, and ${ }^{*}$ significance at the $10 \%$ level 
For farmer players, relational contracts seem to have no general positive effect. On the average, they earn $\pi_{F}=48.61$ per period in the $\mathrm{CC}, \pi_{F}=48.51$ in the $\mathrm{RC}$ and only slightly more in the DB condition $\left(\pi_{F}=50.69\right)$. As for company players, these differences are not significant using non-parametric tests. This may seem surprising as contract breach by the company player can be significantly reduced in long-term relationships. However, as shown above, prices actually paid to the farmer players in the end do not significantly differ between the $\mathrm{CC}$ and the other conditions. Yet, farmer players in the $\mathrm{RC}$ and $\mathrm{DB}$ are more reluctant to breach and go to the spot market, in cases where this would be more profitable.

The regression results in Table 2.5 confirm our non-parametric test results. We find no statistically significant differences between conditions considering all trades (column (3)). The coefficient of the Contract-dummy is large and significant as farmer players (by design) earn much more when a contract is formed. Looking only at the trades in which a contract was concluded (column (4)), we even find that farmers earn slightly more in the $\mathrm{CC}$ compared to the long-term contracts. Profit is marginally rising over time, and a higher CSMD is associated with lower farmer profits, although the latter finding is only significant at the 10-percent level.

Regarding joint profits, we find that efficiency slightly increases with the opportunity for more private ordering. While both players together earn $\pi_{C}+\pi_{F}=131.56$ per period in the CC, they obtain $\pi_{C}+\pi_{F}=137.77$ in the RC and $\pi_{C}+\pi_{F}=139.08$ in the DB, on the average. These differences are not statistically significant and only the CC-DB difference becomes significant $(p=0.0984)$ when we exclude the last period from the analysis to control for endgame effects. 
The regression results in Table 2.5 (column (5) and (6)) depict that long-term relationships do lead to significantly higher efficiency — unlike non-parametric tests suggest — once we control for other factors. This holds true for all trades, and even more so when only considering trades in which a contract is concluded. Again, we cannot identify an additional treatment effect for the DB. In general, contracts are associated with higher efficiency in our experiment, which is mostly due to the experiment's design (column (5)). Over time, joint profits slightly decrease (as contract breach increases). Also, CSMD is positively correlated with joint profits, as a higher price difference reduces side-selling and joint profits are largely determined by company players' payoffs. Analogous to company players' profits, the positive influence of CSMD is greater in the CC (column (6)).

Concluding this section on profits and efficiency, Table 2.6 offers a comparison of wellfunctioning and dysfunctional relationships in our partner matching conditions. The categorization of relationships is based on the definitions stated in Table 2.6. We find that both players, company and farmer, in well-functioning relations earn significantly more than their peers in rather dysfunctional ones, although there is no significant difference in the offered contract prices between well- and less functioning partnerships (RC: $p=0.8732$; DB: $p=0.3792$ ). We further see that not even one-third of the relationships in each condition can be considered well-functioning and, in particular, the DB did not substantially increase this share. It is somewhat unexpected that the opportunity for more coordination and more personal relationships, the direct bargaining communication, was not useful (or was not used) to build better functioning relations.

The large number of dysfunctional relations may also be due to the quasi-locked-in situation. Unsatisfied subjects cannot switch to other contract partners since our game does not provide a competitive market for contracts with different potential buyers or sellers as, for 
instance, in Brown, Falk and Fehr (2004). In the real world, companies have a larger pool of farmers with whom to contract and thus may replace reneging producers in the long run for more reliable suppliers.

Table 2.6: Well- and less functioning relationships in the RC and DB condition

\begin{tabular}{|c|c|c|c|c|}
\hline & & well-functioning & less functioning & $p$ value \\
\hline & Definition & $\begin{array}{c}\text { Contract formation } \geq 80 \% \\
\text { Side-selling } \leq 20 \% \\
\text { Default company } \leq 20 \%\end{array}$ & $\begin{array}{c}\text { Contract formation }<80 \% \\
\text { Side-selling }>20 \% \\
\text { Default company }>20 \%\end{array}$ & \\
\hline \multirow{4}{*}{$\mathrm{RC}$} & Number of relationships & 10 & 26 & \\
\hline & Mean profit company & 100.67 & 84.87 & 0.0005 \\
\hline & Mean profit farmer & 55.07 & 45.99 & 0.0225 \\
\hline & Mean joint profit & 155.73 & 130.86 & $<0.0001$ \\
\hline \multirow{4}{*}{$\mathrm{DB}$} & Number of relationships & 11 & 25 & \\
\hline & Mean profit company & 97.64 & 84.33 & 0.0020 \\
\hline & Mean profit farmer & 57.18 & 47.83 & 0.0046 \\
\hline & Mean joint profit & 154.82 & 132.16 & $<0.0001$ \\
\hline
\end{tabular}

Result 5: Both players earn more within a contractual relationship (which is also due to the experimental design). In our setting, where both players may breach a contract, the company player alone can skim off the benefits from private-order enforcement.

Result 6: Both players benefit from well-functioning relationships that are characterized by high contract formation and compliance rates, compared to dysfunctional or short-term relations. However, most subjects do not sacrifice short-term profits on behalf of long-term benefits, challenging the theory of self-enforcing contracts.

\subsubsection{Compliance, guilt proneness and preferences for honesty}

As discussed in the beginning of this chapter, besides (the fear of) retaliation and the use of third-party contract enforcement, honest behavior and order can also originate in the moral 
norms within a society and the offender's "cost" of feeling guilty (i.e., first-party enforcement). Platteau (1994) argues that a generalized morality may reduce enforcement costs, and moral norms largely determine the conditions under which honesty is likely to be established and sustained. Hence, besides the potential mechanisms for private ordering incorporated in the different conditions in our experiment, moral norms internalized by the subjects (and learned outside the lab) may explain part of the compliance rate. According to Platteau, there are five such conditions that positively correlate with honesty:

(1) If many individuals generally prefer honesty.

(2) If they trust in others to prefer honesty as well.

(3) If this preference is not readily weakened by bad but strengthened by good experiences.

(4) If offenders are prone to guilt feelings.

(5) If honest individuals sanction offenders, even if they are not directly affected.

In the following, we empirically investigate Platteau's proposition and assess whether honesty in our experiment (i.e., compliance with a contract) is directly correlated with the conditions (1) to (5). ${ }^{21}$ While the dependent variable is based on our experimental data, information on the explanatory conditions is collected through a questionnaire. The questionnaire was administered to all subjects directly after the actual experiment and, among others, contained questions related to honesty preferences and guilt feelings. To increase the reliability of the answers, subjects were again reminded that the evaluation of the data would be completely anonymous. In addition, at the end of the questionnaire they were asked to indicate how honest and complete they would rate their answers. It was conferred

\footnotetext{
${ }^{21}$ Unlike Platteau's argumentation, our investigation is based on the individual level. That is, we are not looking at breach or compliance rates within a session but at the behavior of a subject in a contractual situation, which deviates from Platteau's focus on "society" and breaks his conditions down to the micro level. Therefore, although the five conditions guide our investigation, it is not an evaluation of Platteau's theory in a strict sense.
} 
that this statement would not affect their payment, but only help us to exclude unreliable observations. $^{22}$

Table 2.7 displays the results of probit regressions for company and farmer players, respectively. In all regression models we control for cluster-correlated standard errors at the individual subject level. In addition to treatment dummies and other factors from the experiment that may influence contract breach or compliance (cf. Section 2.4.1), we now include questionnaire responses linked to Platteau's five conditions. We can see that the signs and significance levels of the explanatory variables generated in the experiment remain robust (cf. Table 2.4). Here, we thus focus on the discussion of the seven variables related to honesty and guilt.

The first variable, Wallet, refers to Platteau's condition (1), the individual preference for honesty. We asked subjects to imagine they find a wallet with money and an ID with the owners address in the streets and no one is around; what is the probability (0-100 percent) that they return the wallet including all money. For both types of players, coefficients are small and insignificant.

The second variable, Contract breach, refers to trust in the honesty of others. We asked participants whether they believe that the other participants breached a contract in the game whenever it was beneficial to them and they did not have to fear any consequences. The variable equals 1 if the answer is yes and 0 if it is no. For both players, we find a negative effect on contract compliance, as predicted by theory, but only for farmer players the coefficient is significant at the 10-percent level.

\footnotetext{
${ }^{22}$ Subjects were asked to rate the honesty and completeness of their own answers from 0 (very dishonest/incomplete) to 7 (very honest/complete). From our analysis we excluded every subject with a score below 6 , that is 13 subjects in total.
} 
Table 2.7: Probability of contract compliance including data on honesty and guilt feelings

\begin{tabular}{|c|c|c|}
\hline & \multicolumn{2}{|c|}{ Dep. Variable: Contract compliance } \\
\hline & $\begin{array}{c}(1) \\
\text { Company player }\end{array}$ & $\begin{array}{c}(2) \\
\text { Farmer player }\end{array}$ \\
\hline CC-dummy & $\begin{array}{c}-1.970^{* * *} \\
(.276)\end{array}$ & $\begin{array}{c}-1.139^{* * * *} \\
(.206)\end{array}$ \\
\hline DB-dummy & $\begin{array}{l}.058 \\
(.239)\end{array}$ & $\begin{array}{l}-.148 \\
(.222)\end{array}$ \\
\hline Period & $\begin{array}{c}-.055^{* * *} \\
(.013)\end{array}$ & $\begin{array}{c}-.059^{* * *} \\
(.010)\end{array}$ \\
\hline CSMD & $\begin{array}{c}-.252^{* * * *} \\
(.057)\end{array}$ & $\begin{array}{l}.587^{* * * *} \\
(.045)\end{array}$ \\
\hline (1) Wallet & $\begin{array}{l}.010 \\
(.007)\end{array}$ & $\begin{array}{l}-.0003 \\
(.004)\end{array}$ \\
\hline (2) Contract breach & $\begin{array}{l}-.379 \\
(.306)\end{array}$ & $\begin{array}{l}-.690^{*} \\
(.401)\end{array}$ \\
\hline (3.1) Negative influence & $\begin{array}{l}.398^{*} \\
(.234)\end{array}$ & $\begin{array}{l}.372^{* * *} \\
(.168)\end{array}$ \\
\hline (3.2) Positive influence & $\begin{array}{c}.320 \\
(.250)\end{array}$ & $\begin{array}{l}-.108 \\
(.195)\end{array}$ \\
\hline (4) Guilt score & $\begin{array}{l}-.015 \\
(.017)\end{array}$ & $\begin{array}{c}.014 \\
(.013)\end{array}$ \\
\hline (5.1) Sanctioning & $\begin{array}{c}.325 \\
(.227)\end{array}$ & $\begin{array}{l}.282^{*} \\
(.170)\end{array}$ \\
\hline (5.2) Receive sanctioning & $\begin{array}{l}.006 \\
(.004)\end{array}$ & $\begin{array}{l}-.002 \\
(.003)\end{array}$ \\
\hline Constant & $\begin{array}{l}0.176 \\
(.909) \\
\end{array}$ & $\begin{array}{c}1.209^{* *} \\
(.617) \\
\end{array}$ \\
\hline $\mathrm{N}$ & 886 & 1366 \\
\hline Pseudo $\mathrm{R}^{2}$ & .415 & .314 \\
\hline $\begin{array}{l}\text { Notes: Table shows results f } \\
\text { standard errors (in parenthe } \\
\text { level; } 13 \text { subjects are exclu } \\
\text { complete answers; } \\
{ }^{*} \text { significance at the } 10 \% \text { leve }\end{array}$ & $\begin{array}{l}\text { tegressions; RC } \\
\text { adjusted for clus } \\
\text { re as they indica } \\
\text { gnificance at } 1 \%\end{array}$ & $\begin{array}{l}\text { ted condition; } r \\
\text { he individual st } \\
\text { level of hones } \\
\text { icance at } 5 \%\end{array}$ \\
\hline
\end{tabular}

The variables Negative influence and Positive influence refer to condition (3). We asked subjects if they would break a rule more often (less often) if others in their environment would do the same. Again, both variables are dummies and take a value of 1 if the answer is yes and 0 if it is no. Interestingly, those who consider themselves to be vulnerable to negative influence were less likely to breach a contract in the game, which seems contradictory to theory. We do not find a significant effect of the variable Positive influence for either type of player. 
Furthermore, we asked subjects to rate their level of guilt feelings in six fictitious but specific situations from 1 (not guilty at all) to 7 (very guilty). These situations range from canceling a meeting with friends using a false excuse to the theft of money. The variable Guilt score is simply the aggregate of these six ratings, without weighting the different situations. Our results do not show a significant relation between a subject's general susceptibility to guilt feelings and contract compliance in the experiment.

Finally, the variables Sanctioning and Receive sanctioning relate to condition (5). The first is a dummy taking the value of 1 if the subject was willing to anonymously and appropriately punish someone who finds the above-mentioned wallet and does not return the money, and 0 if she would refrain from sanctioning. The latter variable is the subject's expectation of receiving anonymous and appropriate punishment by others if being observed not returning the wallet (probability $0-100$ percent). We find that farmer players who claim that they would punish dishonest individuals are more likely to comply with a contract in the game, which is significant at the 10-percent level. The regression does not show a significant relation between the breaching behavior in the experiment and the stated expectation of punishment by others.

Result 7: There is only limited evidence that individuals' honesty preferences correlate with their contract performance in the experiment. We find no impact of the stated guilt proneness on contract compliance.

\subsection{Conclusion}

In this chapter we have shown how real subjects behave in a contract farming experiment - in which a player is both trustor and trustee - and how behavior changes with the introduction of potential private-order enforcement via relational contracts and the oppor- 
tunity for direct bargaining communication. Additionally, we investigate if buyers offer price premiums when lacking other formal and informal enforcement mechanisms, and whether contract compliance correlates with subjects' honesty preferences and their general guilt proneness.

We find only mixed evidence for our private ordering hypothesis. Not all of the above results ought to be repeated here, yet three findings are particularly remarkable from our point of view. First, long-term relations do indeed help to mitigate contract breach, but one-time communication or "visits" do not suffice to make them more personal and further improve cooperation. Hence, in respect of contractual self-enforcement, at least this kind of communication appears to be mere "cheap talk" and some subjects seem to anticipate that. Second, contract terms offered to farmer players are more favorable in an environment without reputational effects, but these premiums are not paid in the end. Third, the fact that well-functioning relations pay in the long run but were formed relatively rarely in our experiment does not support the proposition that an agreement readily becomes selfenforcing when short-term profits from reneging are smaller than the loss of future gains.

Therefore, these contractual relations would be likely to benefit by some coordination from outside, leading to mutual gains. If a judicial system is not entirely absent, small-claims courts can be useful to credibly threat offenders with legal consequences. Additionally, producer organizations may function as intermediaries between buyer and farmer (Minot, 2007). The possibility for neutral, third-party quality checks (Sänger, Torero and Qaim, 2014) could in practice reduce the probability of arbitrary payment reductions and thus side-selling.

There is certainly much scope for future research to design new mechanisms and institutions for private (or public) ordering and test their effect on contract enforcement experi- 
mentally. In this context, the existence of producer organizations, intermediaries or different contract designs may represent interesting treatments. One variation of our study could be running sessions excluding the final stage (i.e., without possible breach by the company player). If the number of dysfunctional relationships is significantly diminished, compared to what we observe, a possible conclusion would aim at buyers' influential role in determining the outcome of contract farming arrangements and the necessity to police the payment process.

One issue with most laboratory experiments is their use of student subjects mainly from Western, educated, industrial, rich, and democratic backgrounds (usually referred to as the "WEIRD" problem). Future research may also take similar experimental designs to the field and run them in a developing country context with actual farmers. This should then allow deriving more applied policy recommendations to improve contract farming arrangements and the operation of agricultural value chains in practice. 


\section{Appendix 2A: Experimental instructions*}

We will play a game in which you make decisions and earn real money. How much you earn depends both on your own decisions and the decision of other players. Please do not talk to other participants until the experiment is finished.

In this game you are randomly assigned the role of a farmer or a food company that purchases agricultural products for processing. Each participant remains in his or her role until the end of the game. In each round, you will be randomly paired with one participant of the opposite role. Consequently, you do not interact with the same player in every round. All participants remain anonymous at all times.

The game consists of 15 repetitions (periods).

Each period, the farmer produces a certain quantity of a good. The company purchases a certain quantity of the same good. Both have the opportunity to conclude a contract on production and trade, in which the company sets a contract price. If a contract is concluded, the company provides an interest-free loan to the farmer, which is invested and increases the farmer's production capacity. Alternatively, the farmer can sell on the local market and the company can purchase on this market. In that case, both depend on the stochastically determined market price and both pay socalled transaction costs for using the market.

\section{The Decisions}

In each period, the following decisions are made:

1. The company decides whether or not to offer the farmer a contract. If so, she sets a contract price she is willing to pay the farmer per unit. If no offer is made, both players directly go to the local market.

2. The farmer observes whether or not a contract was offered and, if so, the offered contract price. If an offer was made, the farmer decides about accepting the contract. In that case, the contract is concluded and the farmer increases her production capacity from 10 to 15 units. If she rejects, both go to the local market. There, the farmer sells 10 units, the company purchases 15 units.

3. The local market price per unit is determined stochastically. It can take a value between 1 and 7 ECU (experimental currency units), while the probabilities of the prices' occurence differ:

\footnotetext{
* This document is an English translation of the experiment's German instructions used when running sessions of the CC condition. The original version and the instructions of other treatments will be provided upon request.
} 
A price of $\mathbf{1 E C U}$ occurs with a probability of $\mathbf{5} \%$.

A price of $\mathbf{2}$ ECU occurs with a probability of $\mathbf{1 0} \%$.

A price of $3 \mathbf{E C U}$ occurs with a probability of $\mathbf{2 0} \%$.

A price of $4 \mathbf{E C U}$ occurs with a probability of $30 \%$.

A price of $5 \mathbf{E C U}$ occurs with a probability of $20 \%$.

A price of $6 \mathbf{E C U}$ occurs with a probability of $10 \%$.

A price of $7 \mathbf{E C U}$ occurs with a probability of $5 \%$.

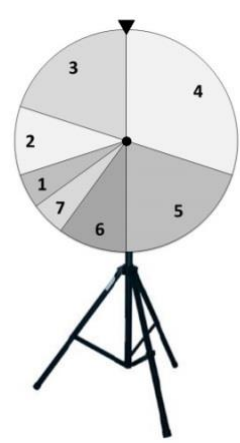

4. Both players observe the determined market price. If a contract was concluded, the farmer now decides whether she delivers the quantity promised in the contract and repays the loan. Alternatively, she can sell everything (15 units) on the local market for the current market price. In that case, the company's loan is not being repaid.

5. If the farmer delivered the promised quantity, the company now decides whether she pays the contract price as agreed upon. Alternatively, she can reduce this price by 1 or 2 ECU.

For the company, each unit of the purchased good has a value of 12 ECU (for processing).

Is a contract concluded, the company bears the contracting cost (10 ECU) and grants the farmer a loan (10 ECU). The loan's repayment upon delivery is stipulated in the contract.

Does the company use the local market, she pays transaction costs of $40 \mathrm{ECU}$. Does the farmer use the local market, she pays transaction costs of $10 \mathrm{ECU}$. Here, it does not matter when a player uses the market.

\section{The Payoffs}

The farmer's payoff in one period consists of the following:

- For units she delivers to the company in accordance with the contract, she receives the contract price, possibly less the company's payment reduction.

- For units sold on the market, she receives the local market price reduced by the transaction cost (10 ECU).

- If she delivers in accordance with the contract, she repays the loan (10 ECU).

The company's payoff in one period consists of the following:

- She receives the value of 12 ECU for each unit she purchases (no matter where). Thus, in total she receives $180 \mathrm{ECU}$.

- For units delivered by the farmer in accordance with the contract, she pays the contract price, possibly less the payment reduction.

- For units purchased on the market, she pays the local market price and her transaction cost (40 ECU).

- If a contract is concluded, she bears the contracting cost (10 ECU) and grants an interestfree loan (10 ECU) to the farmer that is repaid if the farmer delivers. 
After each period, farmer and company players are informed about their individual payoffs of the period just completed. Afterwards, a new period with a randomly assigned trading partner begins. On the computer screen, you will obtain an overview of the decisions made in previous rounds.

The game ends after 15 periods and you will get paid. Your total payment results from the ECUs earned in the game (exchange ratio: $1 \mathrm{ECU}=0.02 €$ for farmer players and $1 \mathrm{ECU}=0.01 €$ for company players) plus your show-up fee.

Thank you for your participation!

(I) Pre-harvest phase: Contract negotiations

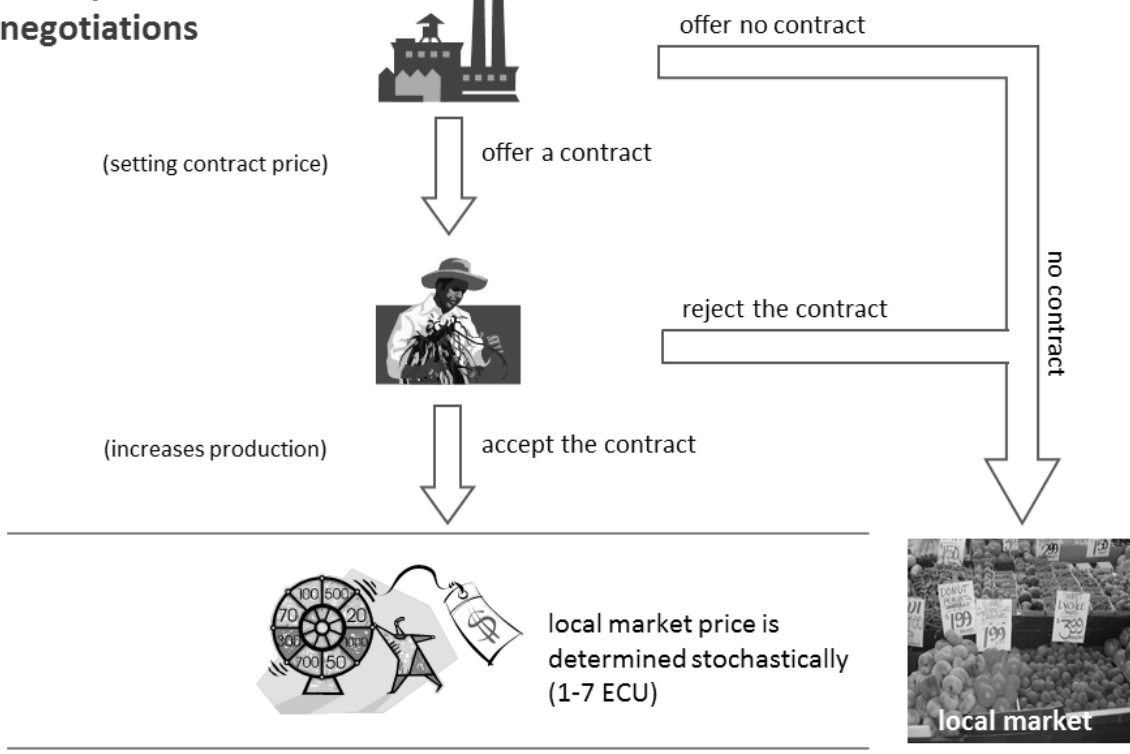

(II) Post-harvest phase: Transaction
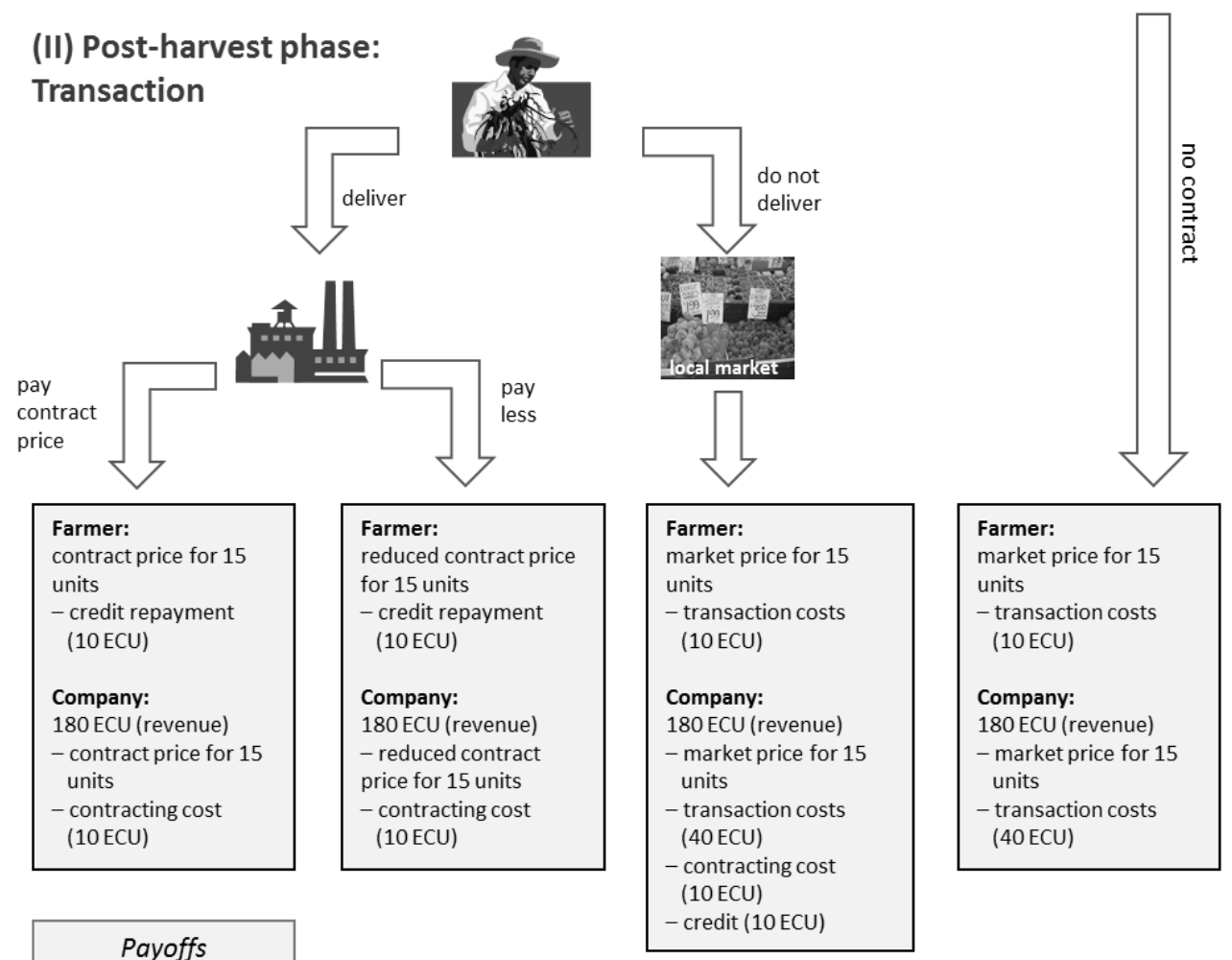

Payoffs 


\title{
3. Risky environments, hidden knowledge, and preferences for contract flexibility: An artefactual field experiment
}

\begin{abstract}
Contract flexibility can be expedient for economic exchange in environments with high ambiguity and risk, but may also encourage opportunistic behavior. We run a modified investment game, including the choice between two different contract designs and asymmetric information about the realized surplus (i.e., hidden knowledge). We examine if Nairobi slum dwellers choose flexible over rigid contracts when interacting in risky environments and whether preferences for contract flexibility are sensitive to the exogenous probability of experiencing a negative shock. We find that most interaction is realized through flexible agreements. Principals offer a higher level of flexibility if the likelihood of a shock is high, relative to the low-risk environment. Agents are somewhat more reluctant to sign rigid agreements when facing the threat of a bad state. While agents and the overall efficiency benefit from higher flexibility, principals always do better by opting for a rigid contract.
\end{abstract}

Keywords: contract flexibility, risk sharing, hidden knowledge, artefactual field experiment, investment game, Nairobi slums, Kenya

JEL classification: C72, D82, L14, O12

This chapter is joined work with Meike Wollni (Kunte and Wollni, 2015). For their comments, we thank Holger Rau, Martin Schmidt, Renate Strobl, Iris Butzlaff, Angelino Viceisza, and the participants of the International Conference on Globalization and Development, 11-12 May 2015 in Göttingen. Moreover, we are grateful to the Busara Center team in Nairobi, in particular Chaning Jang, James Vancel, Lucy Rimmington, Arun Varghese and the research assistants. Financial support by the German Research Foundation (DFG) is gratefully acknowledged. 


\subsection{Introduction}

Renegotiations and contract flexibility do not always have a good record in contract theory- for at least two reasons. First, when contracts are incomplete or public enforcement is inefficient, the possibility for renegotiating contract terms may lead to commitment problems, to hold-ups and underinvestment (see, e.g., Klein, Crawford and Alchian, 1978; Williamson, 1985; Hart and Holmström, 1987; Milgrom and Roberts, 1992; Hart, 1995). Similarly, if the agreement leaves space for discretion and unilateral changes due to information asymmetries, strong incentives for strategic behavior and false statements arise.

A second argument against contract flexibility is offered by a more recent strand of literature, suggesting that contracts serve as reference points (Hart and Moore, 2008). Involved parties feel entitled to the best outcome an ex ante agreement allows for, even if they know that the eventual outcome may be less favorable. Accordingly, flexibility and renegotiations might result in aggrieved agents, conflicts and even welfare losses.

In spite of all these arguments, the empirical literature on market institutions in developing countries has a different view on renegotiations and stresses that without ex post flexibility exchange in highly uncertain environments could often not occur at all. The reason is that after signing an agreement some agents may find it hard or even impossible to comply with rigid contract terms - albeit willing to do so- due to external shocks and they fear harsh retaliation. Moreover, a first-moving principal is usually better off receiving part of the promised surplus or a reimbursement of her investment than receiving nothing at all upon contract breakdown.

The prominent problem is one of asymmetric information and post-contractual opportunism. Regularly, a principal cannot observe if breach of contract is due to an external shock 
or strategic behavior by the agent. It is therefore impossible to make sanctioning (say, terminating the relationship or harming the offender's reputation) contingent on the reason of breach. ${ }^{23}$ Hence, principals are faced with a trade-off: Harsh sanctioning can help to daunt fraudulent agents and opportunistic behavior, but may also prevent bona fide trade from taking place as agents are generally assumed to be risk-averse. No sanctioning, in turn, can support exchange, but also opportunistic behavior and adverse selection.

Contract flexibility may help in situations of uncertainty and induces an implicit sharing of risk between the contracting parties. Some literature suggests that it is regularly used in business relations in Kenya (Fafchamps et al., 1994), Ghana (Fafchamps, 1996), Zimbabwe (Fafchamps, 1997), and other economies in sub-Saharan Africa (Bigsten et al., 2000; Fafchamps, 2004). Vietnamese firms appear to be reluctant to retaliate against breaching trading partners, because it is not possible to perfectly distinguish between strategic default and "acts of nature" that are beyond an individual's or firm's control (McMillan and Woodruff, 1999b).

Bigsten et al. (2000: 5) understand contract flexibility as a voluntary adjustment to particular environments or circumstances:

\begin{abstract}
"Flexibility arises when contractual performance is made explicitly or implicitly contingent upon external events affecting one of the parties. The idea is that a supplier who cannot deliver or client who cannot pay is allowed to renegotiate the contract and default from his or her original obligations. Flexibility is thus a form of insurance, of risk sharing."
\end{abstract}

To the best of our knowledge, there is so far no experimental research with subjects from low-income countries that investigates preferences for contract flexibility in a controlled

\footnotetext{
${ }^{23}$ Here we assume that courts cannot be used for various reasons, yet the problem is also likely to occur with the existence of a functioning legal system as many circumstances are unobservable to a third party.
} 
environment, and additionally examines if the risk of a (production) shock directly and positively correlates with the use of flexible agreements. Identification issues, critical differences in political and market institutions or the impossibility to objectively evaluate risk make the use of observational data for studying contractual relations highly problematic (see, e.g., Just and Wu, 2009). Experimentation, by contrast, enables us to exogenously alter the trade environment while holding other influencing factors constant.

With this chapter we contribute to both the experimental literature on behavior in contractual (principal-agent) relationships and the empirical literature on informal market institutions in the developing world. We address the question of whether poor individuals from sub-Saharan Africa, who are regularly affected by and vulnerable to external shocks, choose flexible over rigid contracts when trading in environments of high risk and asymmetric information. Moreover, we raise the question if flexible contracts are more often accepted relative to rigid ones and if agents exploit this discretion and act increasingly opportunistically. Finally, we explore whether both parties benefit from contract flexibility, especially in high-risk environments.

Following the taxonomy by Harrison and List (2004), we run an "artefactual field experiment" ${ }^{24}$ with urban slum dwellers from Nairobi, Kenya. All subjects live in Kibera, the city's largest informal settlement and a playground for vivid informal economic activity. Residents' regular exposure to shocks and the many economic and social interactions beyond the reach of formal institutions make them a very relevant population for our study.

Using a modified investment game (based on Berg, Dickhaut and McCabe, 1995), we intend to create a very simplistic and easily understandable setting of sequential exchange.

\footnotetext{
${ }^{24}$ The distinction between artefactual and framed field experiment is somewhat blurred. We believe that our study rather belongs to the former category as the use of field context and framing is still limited (see Harrison and List, 2004).
} 
Unlike the standard game, our version involves agreements and asymmetric information on the state of nature and, thus, realized surplus. We are only aware of very few other papers studying investment games with information asymmetries of this or similar kind (Coricelli, Morales and Mahlstedt, 2006; Castillo and Leo, 2010; Clots-Figueras, Hernán Gonazáles and Kujal, 2012), which are very different from our contribution in terms of design, research question and study population, however. Technically speaking, we examine a problem of moral hazard with hidden knowledge or "post-contractual adverse selection" (Rasmusen, 2007: ch. 10). Arrow (1985) understands hidden knowledge-in distinction from hidden action problems - as the agent's private information on a state (e.g., productivity). Others emphasize the timing of a particular information asymmetry and define hidden knowledge as one that occurs after a contract is signed (Holmström and Milgrom, 1987; Tirole, 1999). As argued above, this information and incentive issue is undisputedly common in many principal-agent relations in risky environments, but rather neglected in the behavioral and experimental economics literature. ${ }^{25}$ We aim to fill this gap by applying the problem to a developing country context and investigate whether contractual flexibility provides a solution.

In our game, a first-moving principal can decide to transfer points to a second-moving agent, using a flexible or a rigid contract. With a certain probability the transferred amount is productive or subject to an external production shock. Yet this state is private information of the agent who can then return points to the principal. In case a rigid contract is used, repayment is considered a fixed amount, and if the agent cannot—or is not willing to- transfer the agreed points, she returns zero and the principal can harshly retaliate. If a

\footnotetext{
${ }^{25}$ One reason for this is perhaps the experimental literature's emphasis on problems of hidden action, where the state of nature (e.g., the quality outcome) is a random variable with a distribution contingent on the agent's action choice. Another might be the oftentimes missing distinction against problems of adverse selection that appear before the contract is concluded. The situation examined in this chapter is indeed similar, but not identical.
} 
flexible contract is used, the agent is free to also return any different amount, contingent on the observed state (which is unknown to the principal). This design enables us to compare preferences for contract flexibility and their allocative consequences in environments with different degrees of risk. ${ }^{26}$

We find that the majority of observed interaction is realized through flexible agreements. In high-risk environments the probability of a flexible contract offer is significantly higher relative to the low-risk environment. Agents accept more flexible than rigid agreements when facing the threat of a negative shock. The high degree of flexibility is particularly surprising given that principals do not benefit from it and are in general better off when opting for rigid agreements. At the same time, rigid contracts lead to considerable welfare losses owing to extensive retaliation and the higher rejection rate in the conditions that exhibit risk.

The rest of this chapter is organized as follows. In Section 3.2 we explain the experimental game, procedures and protocols. Section 3.3 reveals our theoretical predictions and hypotheses. Section 3.4 summarizes our main results. The last section concludes.

\subsection{Experimental design}

\subsubsection{A modified investment game with contracts and hidden knowledge}

In our sequential game, a principal and an agent player can conclude a contract on the transfer and repayment of points. The game is played for a finite number of $T=8$ repeti-

\footnotetext{
${ }^{26}$ It is, however, not suitable to investigate the aforementioned reference-points hypothesis (for experimental evidence see Fehr, Zehnder and Hart, 2009; Erlei and Reinhold, 2010; Fehr, Hart and Zehnder, 2011a; ibid., 2011b; Bartling and Schmidt, 2015). This is because in our design no response to outcomes of flexible agreements is possible and, moreover, the incomplete contracts literature throughout assumes symmetric information on the state of the world. Yet, the assumption that this state is public information is not realistic for many economic interactions. This is why we consider the distinction between an incomplete contract and a contract under asymmetric information as essential (as argued in Hart and Moore, 1988).
} 
tions, following two practice periods in which no points can be earned. To largely avoid reputation effects, we use a stranger matching protocol and a principal player is not matched with the same agent in each period. ${ }^{27}$ We conduct three different conditions with varying probabilities of an external shock in order to study subjects' behavior contingent on the degree of risk in the environment of trade. Both players receive the same initial endowment of $M=10$ (points) at the beginning of a period.

Our modified investment game consists of the following five stages:

Stage 1 (Contract offer and choice) - The principal decides whether to offer the agent an agreement that can be flexible or rigid in nature, $c \in\{0, f, r\}$. As the terms "flexible" and "rigid" might be loaded and rather complicated, subjects chose between a blue (mkataba wa bluu) and a yellow agreement (mkataba wa njano). An agreement $c \neq 0$ states that the principal transfers her entire endowment $M=10$ to the agent who returns $R$ eventually. If $c=0$, both players keep their initial endowments $M$. Note that unlike in the standard investment game the principal can only send all points or none (for a summary of the different contract terms see Table 3.1).

Stage 2 (Contract acceptance) - The agent observes the potential contract offer and type. If $c \neq 0$, she decides whether to sign this contract and thereby accept its terms, $s \in\{0,1\}$. If $s=0$, both keep their initial endowments; if $s=1$ the principal's points are sent and we proceed to the next stage.

\footnotetext{
${ }^{27}$ In sessions with 16 or more subjects we used a perfect stranger matching protocol. Yet, this was not possible in smaller sessions since not enough matching partners for eight periods were available (owed to noshows). We believe, however, that subjects were practically unable to assess if there is a sufficient number of matching partners in the room and they are matched with one or two participants twice. We are thus optimistic that there is no systematic difference between smaller and larger sessions and the one-shot nature of the experiment is retained. When running regressions, we control for small sessions by including a dummy variable.
} 
Stage 3 (State of nature) - The agent (and only the agent) observes the state of nature $\varepsilon$ which may be good (hali nzuri) or bad (hali mbaya), $\varepsilon \in\{g, b\}$ with $\operatorname{prob}(\varepsilon=b)=p$ and $\operatorname{prob}(\varepsilon=g)=1-p$. If $\varepsilon=g$, the amount sent by the principal will be tripled $(k=3)$ and the agent now owns 40 . If $\varepsilon=b$, the transferred points remain unchanged $(k=1)$ and the agent now owns 20 . The outcome of $\varepsilon$ is and remains the agent's private information.

Stage 4 (Contract performance) - The agent decides on the amount $R$ she returns to the principal. If the agreement is flexible, then $R \in\{0,1, \ldots, 10+10 k\}$. That is, the agent can send back any amount between zero and the maximum she owns (with $k$ depending on $\varepsilon$ ). If a rigid agreement was chosen, then $R \in\{0,20\}$ and repayment can thus only be the amount of 20 fixed in the contract or nothing, respectively. That means, a rigid agreement stipulates an even division of surplus in case the state turns out to be good. In a bad state (where no surplus is produced), compliance would still be possible but leaves the agent with zero and therefore the loss of her endowment. The principal will not observe if a repayment of less than 20 points is due to an unfortunate situation beyond the agent's control or to opportunistic behavior (that, in reality, could be masked as an external shock).

Stage 5 (Retaliation) - If a rigid agreement was chosen and $R=0$, the principal can retaliate with reducing the agent's profit by $\delta \in\{0,15\}$ ( $\delta$ can be interpreted, e.g., as damage to the agent's reputation). However, there is no contract enforcement possible. That is, $\delta$ does not influence the principal's payoff $(\pi)$, only reduces the agent's $(u)$ by 15 points. Table 3.1 summarizes the contract terms. 
Table 3.1: Rigid and flexible contract terms

\begin{tabular}{|c|c|c|c|}
\hline & & $\begin{array}{l}\text { Rigid contract } \\
\qquad(c=r)\end{array}$ & $\begin{array}{l}\text { Flexible contract } \\
\qquad(c=f)\end{array}$ \\
\hline \multirow{3}{*}{ 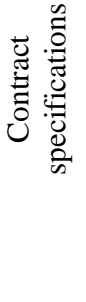 } & "quid" & Principal's endowment $M$ & Principal's endowment $M$ \\
\hline & "quo" & Fixed amount of $2 M$ & $\begin{array}{l}\text { Also more or less than } 2 M \text { contingent } \\
\text { on } \varepsilon \text { (unobservable to the principal) }\end{array}$ \\
\hline & $\begin{array}{c}\text { Consequences of } \\
\qquad R<2 M\end{array}$ & $\begin{array}{l}\text { Agent returns } 0 \text {, principal } \\
\text { can retaliate by } \delta\end{array}$ & $\begin{array}{l}\text { Agent returns "what she can", } \\
\text { no retaliation possible }\end{array}$ \\
\hline
\end{tabular}

If no contract is offered or signed, both players keep their initial 10 points. If they interact, the principal will earn whatever the agent returns. The agent's payoff consists of her own endowment and the principal's points sent (either tripled or unchanged), reduced by the amount she returns and the potential sanction in case of breaching a rigid agreement.

Both players' payoffs are summarized below.

$$
\begin{array}{ll}
\text { Payoff principal: } & \pi= \begin{cases}10 & \text { if } c=0 \text { or } s=0 \\
R & \text { if } c \neq 0 \text { and } s=1\end{cases} \\
\text { Payoff agent: } & u= \begin{cases}10 & \text { if } c=0 \text { or } s=0 \\
10+10 k-R-\delta & \text { if } c \neq 0 \text { and } s=1\end{cases}
\end{array}
$$

We first implement a so-called "LOW" condition, in which a bad state occurs with a probability of $p=0.1$. Second, in the "HIGH" condition, probability of a bad state is $p=0.5$. To have a comparison of how individuals behave without the general possibility of a shock, we run a few sessions of a third "NO SHOCK" condition $(p=0)$ in which a principal player, like in the standard investment game, has complete information on the realized surplus. 


\subsubsection{Discussion of design features}

Before we turn to the experimental procedures and protocols, we discuss some of the choices we made with regard to our game. Note that in all conditions we use an extreme form of flexibility and mere "implicit" renegotiation, where the agent has full discretion on the repayment. This extreme form as well as the fact that an agent is aware of her discretion before accepting an agreement may seem little realistic. Similarly, one might argue that in reality a later (ex post) relaxation of rigid contract terms and an actual renegotiation are likely if the agent can credibly communicate the occurrence of a shock. With our design, however, we follow previous experimental studies examining flexible and rigid contracts, e.g., Fehr, Hart and Zehnder (2011a) and Brandts, Charness and Ellman (2012), and introduce a clear distinction between the two contract designs. The exclusion of "hybrid forms" allows us to make the difference between the two contract designs more salient and thus better capture individuals' preferences for flexibility or rigidity in exchange.

Moreover, one may claim that the rigid agreement differs from the flexible with respect to two elements: The reduced action space (agent has fewer return options) and the potential retaliation. However, we reckon that fixed repayment and punishment directly belong together and characterize a rigid contract design ("Either you send me what we agreed on, or I will retaliate"). With a flexible agreement the same reference value for repayment (20 points) is given by the contract. As a deviation from this reference value is allowed to facilitate risk sharing, though, no sanctioning can be possible by definition.

Further note that the potential retaliation amount of 15 points lies between $M$ and $2 M$. It is thus more than the unproductive transfer received by the agent in a bad state, but less than the "compliance amount" fixed in the rigid contract. As we do not intend to measure negative reciprocity (or the extent of altruistic punishment) and only the general threat of sanc- 
tioning is important to our design, we try to avoid overload and confusion by omitting punishment costs for the principal (as, e.g., de Quervain et al., 2004 do in one treatment).

In addition, one needs to bear in mind that in the LOW and HIGH condition the principal faces two different kinds of risk: the shock risk and what can be labeled the "strategic risk" of opportunistic behavior by the agent. Our design does not allow disentangling these different sources of risk. Even so, as subjects are randomly assigned to a condition we can assume that "strategic risk" and the perception thereof is distributed equally between conditions - and all differences in behavior and preferences trace back to a variation in shock risk.

Finally, we should briefly discuss why we decided against a compulsory contract offer by the principal (and a mere choice of contract type). We intend to examine a situation of voluntary contracting, in which both principal and agent have the chance to also refuse interaction. This is not only more realistic and generates more information; we additionally believe that a "forced" contract offer would be likely to influence the principal's decision on the contract type, which, in turn, results in a biased statement of preferences. ${ }^{28}$

\subsubsection{Subject pool, lab environment, and procedures}

We ran our experiment with subjects from the Kibera slum in Nairobi, Kenya, the city's largest informal settlement with an estimated 170,000-270,000 residents. ${ }^{29}$ A closer look at the life in the slum reveals that, in particular, two instances make Kibera residents a very relevant population for our study.

\footnotetext{
${ }^{28}$ For example, a player who is reluctant to send her points in our game might be biased towards a rigid contract design if forced to offer an agreement. As a consequence, the flexible-rigid contract ratio would alter compared to a situation with voluntary exchange.

${ }^{29}$ For long time, Kibera was considered the biggest African slum with an estimated population of up to 1.5 million. An official census in 2009 and investigations by the Map Kibera Project drastically refuted and scaled down these figures, however (see, e.g., Karanja, 2010).
} 
First, there is a widespread engagement in economic activity outside the reach of formal institutions and regulations (for a portrayal of the slum's business practices see The Economist, 2012). In Kenya, about 11.2 million people (more than 80 percent of workforce) are estimated to have a job in the informal sector, and the rate is increasing (KNBS, 2014). According to the country's statistical service, "[t]he informal sector is characterized by small scale-activities that are semi-organized [and] unregulated [...]. The sector plays a vital role in the economic development by increasing competition, fostering innovation, besides generating employment" (ibid.: 78). Compared to the country's average, the scope of informal economic activity is likely to be even higher in Kibera, a place without any formal legal basis (Amis, 1984). In fact, legal institutions are hardly ever used for settling conflicts about property rights or contractual issues. Instead, besides bilateral negotiations, enforcement in Kibera relies on ethnic gangs or community based NGOs (Joireman and Vanderpoel, 2010). Both lack proper legal status and come with considerable social cost (gangs) or are only semi-effective (NGOs).

Second, interviews with business owners during field trips suggest that dwellers are regularly affected by unpredictable events and shocks (health, production, weather, etc.). Usually, informal insurance mechanisms, such as borrowing from friends and neighbors, are used to cope with these risks.

All of the above indicates a need for private ordering and flexibility when engaging in exchange with others. At the same time, potential preferences for flexibility are unlikely to be overestimated, since trust levels in the slum have been reported to be particularly low. While Kenya in general is regarded as a country with abundant corruption and a very low level of mutual trust among people (Camerer, 2003: ch. 2.7), Kibera gained reputation as 
"a place considered among those in the world where cooperation and trust/trustworthiness are scarcest" (Becchetti, Conzo and Romeo, 2014: 284).

Our experimental sessions were run between July and August 2014 in the Busara Center for Behavioral Economics close to the slum. The Busara Center is affiliated to the NGO Innovations for Poverty Action Kenya (IPA-K) and offers a state-of-the-art infrastructure for behavioral research, including a laboratory with twenty touchscreen computers (for details see Haushofer et al., 2014).

Participants were randomly invited from the Busara subject pool of roughly 2,500 Kibera residents via SMS. As a sufficient understanding of probabilities is crucial to our study, subjects were required to have a minimum level of education, namely completed primary school. Upon arrival, facilitators confirmed participants' identity via fingerprint and randomly assigned them to a computer booth. After signing a consent form, everyone completed a short test to prove sufficient ability to handle the touchscreen. Experimental instructions were read aloud and explained in Swahili while subjects received an English handout with figures and important concepts of the game, such as an overview of the different agreements, the decisions and the probabilities. ${ }^{30}$ After individual queries were answered, participants went through a number of comprehension questions. Like all onscreen elements, these questions were programmed by the software package z-Tree (Fischbacher, 2007) and did not allow subjects to merely guess answers in a trial-and-error manner. If a participant got an answer wrong, a facilitator was required to "unlock" the screen and explain the respective part of the experiment again. Only after everyone successfully completed all questions, the game started with two practice rounds and proceeded with

\footnotetext{
${ }^{30}$ See Appendix 3A for an English version of the instructions, handout and comprehension questions.
} 
eight "real" periods, in which points could be earned. ${ }^{31}$ Following this game, another short experimental test was conducted (part of Chapter 4 in this dissertation) and subjects filled a post-experimental survey.

At the end of a session, participants were informed about their earnings from the game they will obtain in addition to a show-up fee of KES $200 .^{32}$ While they received this show-up fee in cash (for transport), additional earnings were transferred to the participants' MPesa accounts (again, see Haushofer et al., 2014 for details). One point earned in the game was exchanged to KES 2 resulting in an average payment of KES 420 (in total; excluding earnings from the second experiment). A typical session lasted approximately two hours.

We ran a total of 15 sessions; six of the LOW, six of the HIGH, and three of the NO SHOCK condition. A session was attended by at least 12 and at the most 20 subjects, which yields a total number of 240 participants. The differences in turnout between the sessions are owed to no-shows.

\subsection{Behavioral predictions and hypotheses}

Under the assumption of full rationality and exclusively selfish preferences, the theoretical solution of the standard investment game also holds here. Anticipating that the agent will not return anything, the principal decides not to send her points and both leave the game with their initial endowments. As our game explicitly contains two different types of contract and the chance for a negative shock, we still need to determine the agent's best response if an agreement is being offered. It is straightforward to see that there is no reason

\footnotetext{
${ }^{31}$ In the post-experimental survey, subjects assessed their own understanding of the game with 4.08 on a scale reaching from 1 ("very poorly") to 5 ("very well"). We thus believe that the general comprehension level was sufficiently high.

${ }^{32}$ At the time of the study USD 1 was worth about KES 88. Earnings were well above participants' average opportunity costs of time. Average monthly income in our sample is KES 4.800 as stated by the participants.
} 
not to sign a flexible agreement, as the agent (like in the standard investment game) can freely decide how much she returns and sanctioning is ruled out. With a rigid contract, though, a rational response is not so obvious. If a bad state occurs and the agent returns the fixed amount of 20 , she is left with 0 . If she returns 0 and is being punished, she earns 5 which, again, is lower than her payoff without interaction. In general, the agent accepts a rigid contract if

$$
E[u(c=r)] \geq M,
$$

that is, her expected payoff from interaction is at least as high as her reservation payoff. Analogous to (3.2), the agent's expected payoff in case of a rigid contract is

$$
E[u(c=r)]=10+10 p+30(1-p)-R-\delta
$$

with $0 \leq p \leq 1, R \in\{0,20\}$ and $\delta \in\{0,15\}$.

As a return of $R=20$ is higher than the potential sanction $\delta=15$, we can assume that the agent knows she will always breach the contract. Hence, her expected payoff becomes

$$
E[u(c=r)]=40-20 p-\delta .
$$

Thus, even if the agent conservatively expects the principal to always retaliate, (3.3) is satisfied with a shock probability of $p \leq \frac{3}{4}$. Consequently, a risk-neutral agent accepts every contract, even in the HIGH condition.

Contrary to the backward induction solution, the experimental literature on investment games suggests that there is a non-negligible number of individuals who do trust and reciprocate (for a meta-analysis see Johnson and Mislin, 2011; for a developing country survey see Cardenas and Carpenter, 2008). Some papers even report investment/trust game results from the Nairobi slums in particular (Greig and Bohnet, 2008; Becchetti, Conzo and Ro- 
meo, 2014). Following these studies, we expect a proportion of subjects to show willingness to interact and examine the following four hypotheses.

Hypothesis 1: The higher the risk of a bad state in the environment of exchange, the more likely principals are to offer a flexible contract.

Hypothesis 1 predicts that subjects have preferences for flexibility and risk sharing in environments with high risk, based on their experience with informal money lending or insurances and their own business activities. As argued above, one reason is that agents are expected to dislike rigidity when risk is high and shocks are private knowledge (cf. hypothesis 2); thus principals may choose flexible contracts to increase the likelihood that their offer will be accepted. Second, in a bad state the principal might expect the agent to reciprocate and to return at least the investment $M$, which is possible under flexibility.

Hypothesis 2: Agents are more likely to sign flexible than rigid contracts. They are particularly reluctant to sign rigid contracts in the high-risk environment.

Hypothesis 2 is closely related to hypothesis 1, but considers the agent's perspective. Agents fear retaliation if they experience a bad state and do not return the agreed amount (they are left with zero if they do). Hence, they always prefer flexible agreements - and more so if the probability of experiencing a shock is high.

While our focus is on the preferences for different contract designs and thus on hypotheses 1 and 2, we also formulate expectations about the agent's ex post behavior and both players' benefits under the different contractual arrangements.

Hypothesis 3: With flexible agreements agents more often fail to return 20 points and show more opportunistic behavior relative to rigid contracts. 
There are two reasons why we expect this. First, a flexible contract allows agents to adapt to bad states without having to return nothing at all to the principal. This is the potential advantage and risk-sharing function flexibility provides. Second, even in a good state agents do not fear consequences when returning less than 20. This is what can be interpreted as opportunistic behavior.

Hypothesis 4: In the high-risk condition, both players benefit from using flexible agreements. Yet, this does not hold in the other conditions.

This hypothesis is based on the premise that ex post flexibility can potentially lead to better outcomes than rigidity in environments where external shocks are likely (Fafchamps, 2004; Bigsten et al., 2000). Therefore, even if agents in general return fewer points with flexible agreements as posed by hypothesis 3 , these contracts still lead to more interaction and higher returns in the HIGH condition where zero returns otherwise would occur frequently.

\subsection{Results}

In this section we report and discuss our experimental findings. Our focus is on the players' ex ante behavior, namely, their preferences for a certain contract design (Sections 3.4.1 and 3.4.2). Findings on repayment and allocative outcomes will be reported in Section 3.4.3. Besides showing descriptive results, we mainly rely on regression analysis. ${ }^{33}$ Table 3.2 summarizes descriptive statistics for our major findings and selected sociodemographic variables.

\footnotetext{
${ }^{33}$ In experimental research, commonly non-parametric tests (e.g., Mann-Whitney U test) are used for comparing the outcomes between treatments. These tests, however, are run based on entirely independent observations. Due to our stranger-matching protocol, conservatively speaking, we only obtain six (HIGH and LOW), respectively three (NO SHOCK), independent observations per condition. Even though other studies with a comparable number of sessions do not refrain from using non-parametric tests, we believe that the number of observations is insufficient to reliably test hypotheses using this method. Therefore, we run regressions at the participant level controlling for cluster-correlated standard errors at the session (i.e., independent observation) level.
} 
Table 3.2: Summary statistics and descriptive results

\begin{tabular}{|c|c|c|c|c|c|c|}
\hline & \multirow{2}{*}{$\begin{array}{l}(1) \\
\text { LOW }\end{array}$} & \multirow{2}{*}{$\begin{array}{l}(2) \\
\text { HIGH }\end{array}$} & \multirow{2}{*}{$\begin{array}{l}\text { (3) NO } \\
\text { SHOCK }\end{array}$} & \multicolumn{3}{|c|}{ Difference } \\
\hline & & & & $(1)-(2)$ & (1)-(3) & $(2)-(3)$ \\
\hline \multicolumn{7}{|l|}{ Demographic and economic variables } \\
\hline $\begin{array}{l}\text { Age } \\
\text { (in years) }\end{array}$ & $\begin{array}{l}32.81 \\
(10.97)\end{array}$ & $\begin{array}{l}30.78 \\
(9.40)\end{array}$ & $\begin{array}{l}29.90 \\
(9.32)\end{array}$ & 2.03 & 2.91 & .88 \\
\hline $\begin{array}{l}\text { Gender } \\
(1=\text { female })\end{array}$ & $\begin{array}{l}.500 \\
(.503)\end{array}$ & $\begin{array}{l}.612 \\
(.490)\end{array}$ & $\begin{array}{l}.510 \\
(.505)\end{array}$ & -.112 & -.010 & .102 \\
\hline Number of children & $\begin{array}{c}1.91 \\
(1.99)\end{array}$ & $\begin{array}{c}1.61 \\
(1.66)\end{array}$ & $\begin{array}{c}1.30 \\
(1.40)\end{array}$ & .30 & $.61^{*}$ & .31 \\
\hline \multicolumn{7}{|l|}{ Marital status } \\
\hline Single & $\begin{array}{l}.467 \\
(.502)\end{array}$ & $\begin{array}{l}.531 \\
(.502)\end{array}$ & $\begin{array}{l}.480 \\
(.505)\end{array}$ & -.064 & -.013 & .051 \\
\hline Married, cohabitating & $\begin{array}{l}.435 \\
(.498)\end{array}$ & $\begin{array}{l}.418 \\
(.496)\end{array}$ & $\begin{array}{l}.440 \\
(.501)\end{array}$ & .017 & -.005 & -.022 \\
\hline Divorced, separated, widowed & $\begin{array}{l}.098 \\
(.299)\end{array}$ & $\begin{array}{l}.051 \\
(.221)\end{array}$ & $\begin{array}{l}.080 \\
(.274)\end{array}$ & .047 & .018 & -.029 \\
\hline 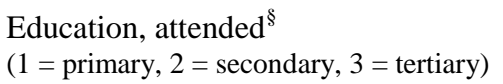 & $\begin{array}{l}2.10 \\
(.367)\end{array}$ & $\begin{array}{l}2.19 \\
(.397)\end{array}$ & $\begin{array}{c}2.16 \\
(.370)\end{array}$ & $-.09^{*}$ & -.06 & .03 \\
\hline $\begin{array}{l}\text { Job } \\
(1=\text { has currently a job })\end{array}$ & $\begin{array}{l}.293 \\
(.458)\end{array}$ & $\begin{array}{l}.265 \\
(.444)\end{array}$ & $\begin{array}{l}.220 \\
(.418)\end{array}$ & .028 & .073 & .045 \\
\hline \multicolumn{7}{|l|}{ Descriptive results } \\
\hline \multirow[t]{2}{*}{$\begin{array}{l}\text { Contract offer } \\
(1=\text { contract offered })\end{array}$} & $\begin{array}{l}.774 \\
(.419)\end{array}$ & $\begin{array}{l}.579 \\
(.494)\end{array}$ & $\begin{array}{l}.580 \\
(.495)\end{array}$ & $.195^{* * *}$ & $.194^{* * *}$ & -.001 \\
\hline & $N=368$ & $N=392$ & $N=200$ & & & \\
\hline \multirow[t]{2}{*}{$\begin{array}{l}\text { Flexible contract offered } \\
(1=\text { flexible; } 0=\text { rigid })\end{array}$} & $\begin{array}{l}.642 \\
(.480)\end{array}$ & $\begin{array}{l}.727 \\
(.447)\end{array}$ & $\begin{array}{l}.647 \\
(.480)\end{array}$ & $-.085^{* * *}$ & -.005 & .080 \\
\hline & $N=285$ & $N=227$ & $N=116$ & & & \\
\hline \multirow[t]{2}{*}{$\begin{array}{l}\text { Contract acceptance } \\
(1=\text { contract signed })\end{array}$} & $\begin{array}{l}.821 \\
(.384)\end{array}$ & $\begin{array}{l}.863 \\
(.344)\end{array}$ & $\begin{array}{l}.828 \\
(.379)\end{array}$ & -.042 & -.007 & .035 \\
\hline & $N=285$ & $N=227$ & $N=116$ & & & \\
\hline \multirow[t]{2}{*}{$\begin{array}{l}\text { Points returned } \\
\text { (by agent if interaction) }\end{array}$} & $\begin{array}{l}9.71 \\
(8.72)\end{array}$ & $\begin{array}{c}7.79 \\
(8.64)\end{array}$ & $\begin{array}{l}9.63 \\
(9.41)\end{array}$ & $1.92^{* *}$ & .08 & $-1.84^{*}$ \\
\hline & $N=234$ & $N=196$ & $N=96$ & & & \\
\hline \multirow[t]{2}{*}{$\begin{array}{l}\text { Payoff principal } \\
\text { (including non-interaction) }\end{array}$} & $\begin{array}{l}9.82 \\
(6.95)\end{array}$ & $\begin{array}{l}8.90 \\
(6.20)\end{array}$ & $\begin{array}{c}9.82 \\
(6.50)\end{array}$ & $.92^{*}$ & .00 & $-.92^{*}$ \\
\hline & $N=368$ & $N=392$ & $N=200$ & & & \\
\hline \multirow[t]{2}{*}{$\begin{array}{l}\text { Payoff agent } \\
\text { (including non-interaction) }\end{array}$} & $\begin{array}{c}20.25 \\
(10.98)\end{array}$ & $\begin{array}{c}15.24 \\
(10.10)\end{array}$ & $\begin{array}{c}18.81 \\
(10.98)\end{array}$ & $5.01^{* * * *}$ & 1.44 & $-3.57^{* * *}$ \\
\hline & $N=368$ & $N=392$ & $N=200$ & & & \\
\hline \multirow[t]{2}{*}{$\begin{array}{l}\text { Retaliation } \\
(1=\text { retaliated })\end{array}$} & $\begin{array}{l}.971 \\
(.171)\end{array}$ & $\begin{array}{l}.833 \\
(.381)\end{array}$ & $\begin{array}{l}.867 \\
(.352)\end{array}$ & $.138^{*}$ & .104 & -.034 \\
\hline & $N=34$ & $N=24$ & $N=15$ & & & \\
\hline
\end{tabular}

Notes: Data are reported as means with standard deviations in parentheses; significance levels of $1 \%\left({ }^{* * *}\right), 5 \%\left({ }^{* *}\right)$, and $10 \%\left(^{*}\right)$ refer to two-sample $t$ tests; ${ }^{\S}$ variable is ordinary, means are thus for information only 


\subsubsection{Preferences for contract flexibility I: contract offers}

We start by analyzing the principal's behavior. As the descriptive results in Table 3.2 reveal, contract offers by the principal - and thus the willingness to send all points to the agent-are with $58-77$ percent well above the theoretical prediction of zero offers. This is especially remarkable as players have to send their entire endowment and survey results indicate a very low level of general trust in others. ${ }^{34}$ In the LOW condition the rate of contract offers is significantly higher than in the other two conditions.

However, unlike examinations of the standard investment game we are not primarily interested in the general level of trust and interaction, but rather in the endogenous choice of contract design. Generally speaking, two out of three agreements offered by a principal are flexible. The share of flexible agreements in the HIGH condition is 73 percent and thus, as predicted by our first hypothesis, higher than the share in the other conditions (around 64 percent).

The results of different probit regressions reported in Table 3.3 largely confirm these descriptive findings. In all specifications, Flexible contract is the dependent variable, taking the value of 1 if an offered agreement is flexible and 0 if it is rigid. The estimates suggest that the offer of a flexible contract is significantly more likely in the HIGH relative to the LOW condition (LOW is the omitted category in all regressions). Yet, the magnitude of the average marginal effect of HIGH ranges between 8 and 11 percentage points, when considering all eight periods (models (1) to (4)), and is thus not very large.

\footnotetext{
${ }^{34}$ As a matter of fact, 98 percent of respondents answered the question "Generally speaking, would you say that most people can be trusted or that you need to be very careful in dealing with people?" with "Need to be very careful".
} 
One potential explanation for the relatively small effect size is that we use a betweensubject design, implying that individuals are not able to compare risk levels. Vice versa, if the same subject witnessed a gradual increase in risk, the treatment effect would likely be larger due to the existence of reference values. ${ }^{35}$ Another potential reason is alignment. It takes time for a subject to learn the optimal (or presumably optimal) behavior within the course of a session. Since for a principal the risk of a bad state and the strategic risk of an agent acting opportunistically co-exist (cf. Section 3.2.2), she certainly requires some periods to shape expectations, in particular, about the latter form of risk. In the second half of periods, when principals are more experienced with the game and have formed specific expectations about agents' behavior, the HIGH-LOW difference becomes larger and more significant. Models (5) and (6) in Table 3.3 consider only periods 5-8, where a principal, who is willing to send points, is (on the average) up to 24 percentage points more likely to offer a flexible contract in the HIGH compared to a principal in the LOW condition. Yet, we find no difference between the LOW and NO SHOCK conditions.

Models (1) to (5) additionally reveal a slight general decrease of offered contract flexibility over time. In model (3) we add interaction terms of the condition dummies and Period. ${ }^{36}$ The coefficient of HIGH $\times$ Period suggests that the decrease over time is smaller for the HIGH condition, but this result is not significant.

\footnotetext{
${ }^{35}$ We decided to vary the level of risk only between conditions, because the inclusion of different probabilities within conditions would have increased the complexity of the experiment.

${ }^{36}$ We refrain from reporting marginal effects for probit regressions with interaction terms, as they do not correspond with the true interaction effects in nonlinear models (Ai and Norton, 2003).
} 


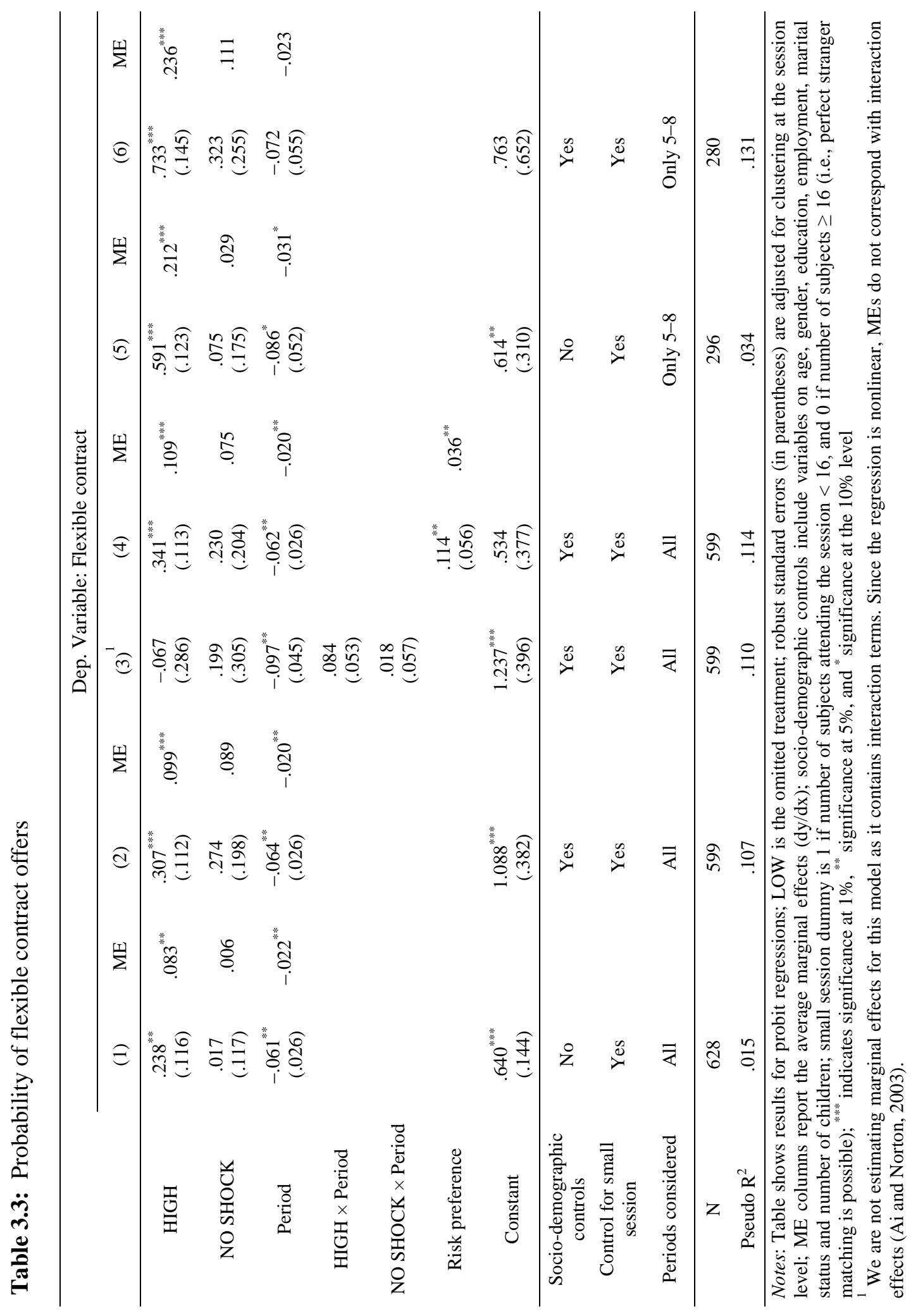


Moreover, model (4) contains an explanatory variable on stated risk preference. The variable takes a value between 1 and 5, depending on how much the subject agreed with the statement "I would invest part of my income if there is a chance that this amount doubles, but also that I lose everything" on a 5-point Likert scale. The coefficient is significant at the 5-percent level, suggesting that the likelihood of an offered contract being flexible increases with decreasing risk aversion. We also find that, controlling for risk preference, the coefficients and marginal effects of $H I G H, N O$ SHOCK and Period do not change considerably compared to model (2).

Result 1: The majority of offered agreements are flexible. Principals are significantly more likely to offer flexible contracts in the high-risk environment compared to the condition with low probability of a shock. The effect becomes particularly strong in the second half of a session when principals have formed expectations about the agents' behavior. This confirms part of hypothesis 1 . However, there is no difference between the LOW and NO SHOCK condition.

\subsubsection{Preferences for contract flexibility II: contract acceptance}

We now turn to the agent's behavior and, to begin with, her decision about signing or rejecting a contract offer. Our descriptive results in Table 3.2 indicate that $82-86$ percent of all offers are being accepted, without significant differences between conditions. This is somewhat below the theoretical agent's best response of signing every contract irrespective of the condition. Figure 3.1 suggests that agents have a higher propensity to sign flexible compared to rigid agreements in the conditions with a potential bad state (HIGH and LOW). There is no such discrimination between contract types in the NO SHOCK condition. 


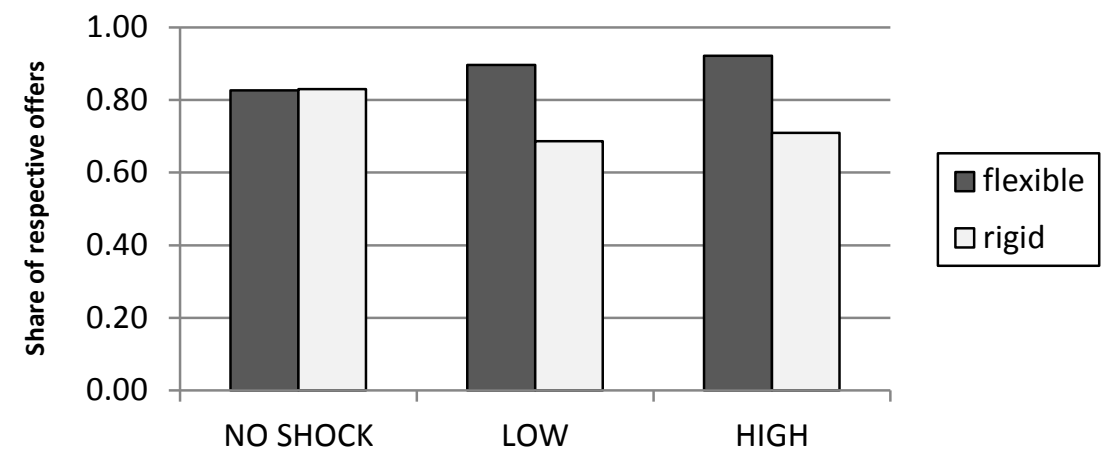

Figure 3.1: Signed flexible and rigid agreements by agents (as share of respective offers of this contract type in a condition)

The regression results in Table 3.4 confirm the descriptive findings. Estimated models are probit regressions with contract acceptance as dependent variable, taking a value of 1 if an agreement is signed by an agent and 0 otherwise. We do not find a difference in contract acceptance between the conditions. Acceptance in general (independent of contract type) increases over time at a very marginal rate and flexible agreements are more likely to be signed by an agent relative to rigid ones. The latter finding is significantly smaller and even seems to vanish for the NO SHOCK treatment (model (2)), as also apparent in Figure 3.1. The preference for flexible contracts in the LOW and HIGH conditions is plausible, if agents fear rigid terms of repayment and harsh sanctioning in the event of a shock (even though based on the expected payoff they should accept rigid contracts as well). When no shock can occur by design, there is also no risk for the agent to lose anything, which is reflected in the lack of discrimination between contract types in the NO SHOCK condition.

In addition, hypothesis 2 predicts an agent's particular reluctance to sign a rigid agreement when the probability of a bad state is high. Based on our data, we cannot confirm this part of hypothesis 2 . The coefficient of the interaction term HIGH $\times$ Flexible contract is not 
statistically significant, suggesting that preferences for flexible agreements of agent players in the high-risk environment are not different from those in the low-risk condition.

Table 3.4: Probability of contract acceptance by agents

\begin{tabular}{|c|c|c|c|c|c|}
\hline & \multicolumn{5}{|c|}{ Dep. Variable: Contract acceptance } \\
\hline & (1) & $\mathrm{ME}$ & $(2)^{1}$ & (3) & $\mathrm{ME}$ \\
\hline HIGH & $\begin{array}{l}.119 \\
(.197)\end{array}$ & .027 & $\begin{array}{l}.081 \\
(.253)\end{array}$ & $\begin{array}{l}.101 \\
(.229)\end{array}$ & .022 \\
\hline NO SHOCK & $\begin{array}{l}-.016 \\
(.384)\end{array}$ & -.004 & $\begin{array}{l}.464 \\
(.299)\end{array}$ & $\begin{array}{l}-.036 \\
(.368)\end{array}$ & -.008 \\
\hline Period & $\begin{array}{l}.044^{* *} \\
(.017)\end{array}$ & $.010^{* *}$ & $\begin{array}{l}.044^{* *} \\
(.019)\end{array}$ & $\begin{array}{l}.048^{* *} \\
(.019)\end{array}$ & $.011^{* *}$ \\
\hline Flexible contract & $\begin{array}{l}.676^{* * * *} \\
(.181)\end{array}$ & $.176^{\text {**** }}$ & $\begin{array}{l}.815^{* * *} \\
(.180)\end{array}$ & $\begin{array}{l}.691^{* * * *} \\
(.184)\end{array}$ & $.168^{* * *}$ \\
\hline $\begin{array}{c}\text { HIGH } \times \\
\text { Flexible contract }\end{array}$ & & & $\begin{array}{l}.056 \\
(.470)\end{array}$ & & \\
\hline $\begin{array}{l}\text { NO SHOCK } \times \\
\text { Flexible contract }\end{array}$ & & & $\begin{array}{c}-.799^{* * *} \\
(.235)\end{array}$ & & \\
\hline Constant & $\begin{array}{l}.357^{* *} \\
(.165)\end{array}$ & & $\begin{array}{l}.276^{* *} \\
(.135)\end{array}$ & $\begin{array}{l}1.544^{* *} \\
(.746)\end{array}$ & \\
\hline $\begin{array}{l}\text { Socio-demographic } \\
\text { controls }\end{array}$ & No & & No & Yes & \\
\hline $\begin{array}{l}\text { Control for small } \\
\text { session }\end{array}$ & Yes & & Yes & Yes & \\
\hline $\mathrm{N}$ & 628 & & 628 & 628 & \\
\hline Pseudo $\mathrm{R}^{2}$ & .057 & & .069 & .110 & \\
\hline $\begin{array}{l}\text { Notes: Table shows } \mathrm{r} \\
\text { bust standard errors } \\
\text { ME columns report th } \\
\text { include variables on a } \\
\text { children; small sessio } \\
\text { and } 0 \text { if number of su } \\
\text { cates significance at } 1 \\
{ }^{1} \text { We are not estimatin } \\
\text { Since the regression i } \\
\text { and Norton, 2003). }\end{array}$ & $\begin{array}{l}\text { s for pro } \\
\text { arenthese } \\
\text { erage } \mathrm{m} \\
\text { gender, e } \\
\text { Immy is } \\
\text { ts } \geq 16 \text { ( } \\
\text { ind }{ }^{* *} \text { sig } \\
\text { arginal e } \\
\text { nlinear, }\end{array}$ & $\begin{array}{l}\text { egressio } \\
\text { re adjus } \\
\text { lal effec } \\
\text { tion, em } \\
\text { number } \\
\text { perfect } \\
\text { ance at } t \\
\text { for this } \\
\text { do not }\end{array}$ & $\begin{array}{l}\text { LOW is t } \\
\text { for cluste } \\
\text { ly/dx); so } \\
\text { iment, ma } \\
\text { ubjects at } \\
\text { ger matcl } \\
\% \text { level } \\
\text { del as it c } \\
\text { espond w }\end{array}$ & $\begin{array}{l}\text { mitted tr } \\
\text { at the se } \\
\text { lemograp } \\
\text { status an } \\
\text { ing the } \mathrm{s} \\
\text { is possib } \\
\text { ins intera } \\
\text { iteraction }\end{array}$ & $\begin{array}{l}\text { ient; ro- } \\
\text { n level; } \\
\text { controls } \\
\text { mber of } \\
\text { n }<16 \text {, } \\
\text { indi- } \\
\text { in terms. } \\
\text { ects (Ai }\end{array}$ \\
\hline
\end{tabular}

Result 2: Agents are more likely to sign a flexible contract relative to a rigid one in environments that exhibit a general risk of shock. They fear principals' retaliation if a bad state prevents them from complying with the contract terms, given that knowledge of the shock is hidden. This confirms part of hypothesis 2. However, we cannot find evidence for the conjecture that agents are particularly reluctant to sign rigid agreements when risk is high. 


\subsubsection{Contractual flexibility, opportunistic behavior, and benefits from interaction}

In this section we analyze the agents' post-contractual behavior as well as the contractual outcome for both players. Since repayment options for the agent differ between the contract designs (that is, they are very restricted with a rigid and very numerous with a flexible agreement) a direct comparison of repayment averages is, strictly speaking, not possible.

Therefore, Figure 3.2 depicts agents' repayment of more than zero (panel (a)) and of 20 points or more (panel (b)) for the various states and contract types. For the rigid contract, of course, both panels are congruent. It confirms our intuition that agents more often return "at least something" with flexible agreements (panel (a)). This holds true for both states, even though the difference between contract designs is larger when the state is bad. At the same time, however, full compliance with the contract terms is much more frequent with rigid agreements (panel (b)). Interestingly, in the case of flexible contracts the difference in full compliance between the states is not large at all.

(a)

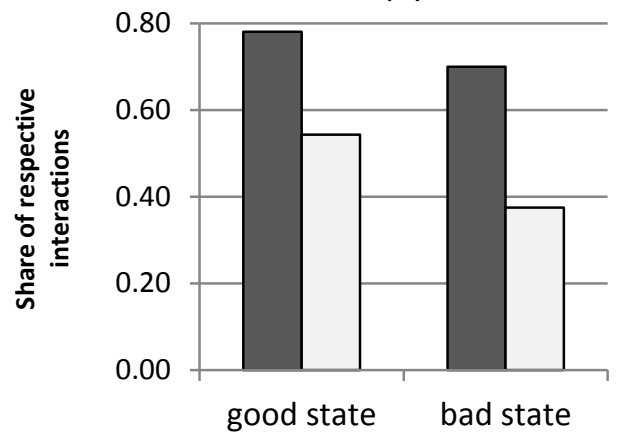

(b)

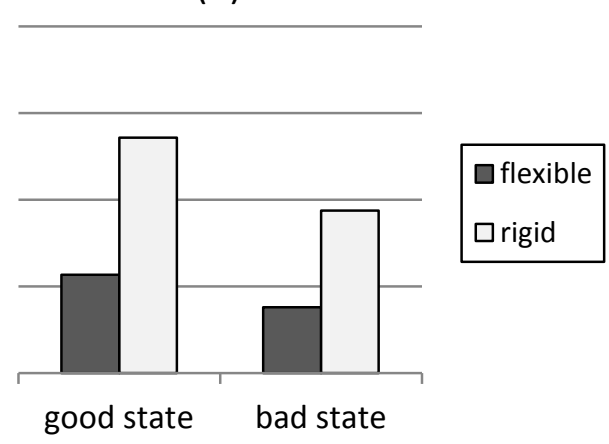

Figure 3.2: Agents' return of (a) more than zero and (b) 20 points or more (as share of respective interactions with this contract type in a certain state)

The first part of Table 3.5 shows results of a linear regression with the amount of points sent back by the agent as dependent variable. As we are now in the ex post "contract performance stage" and the state-of-nature outcome is known to the agent, we omit variables 
for the different conditions in the regressions. We find a slight decrease in repayment over time as well as a significantly higher return rate in a good state. Points sent back by the agent do not differ significantly between flexible and rigid contracts. When interpreting this result, however, it should be kept in mind that repayment amounts are hardly comparable between the contract types, as pointed out above.

The finding that agents return more in a good state may be due to various factors. In the traditional investment game, the second mover's choice has typically been interpreted as reciprocity. However, given that the state in our game is a result of chance, pure reciprocity can only partly explain why agents return more when the state is good; even though one could argue that the principal's decision to offer a contract was a necessary precondition for the agent to gain this surplus. In addition, inequity aversion (as according to the famous model by Fehr and Schmidt, 1999) as well as a positive income effect on giving, confirmed by several studies (e.g., Yen, 2002; Chowdhury and Jeon, 2014), can serve as explanations for the positive effect of a good state on repayment (see, e.g., discussion in Johnson and Mislin, 2011). We believe that a combination of agents' other-regarding preferences and the high "income" when observing a good state leads to the higher repayment rate-which, in fact, is only higher in absolute terms but not relative to productivity.

The probit models in the second part of Table 3.5 treat negative deviations from a repayment of 20 points (as agreed in the rigid and benchmark in the flexible contract) as a binary dependent variable, taking a value of 1 if an agent returned less than 20 , and 0 otherwise. We find that a return of less than 20 is, on the average, about 30 percentage points more likely with a flexible contract. The State of nature coefficient is also significant and negative, indicating that a good state decreases the likelihood of less-than-20 returns. 


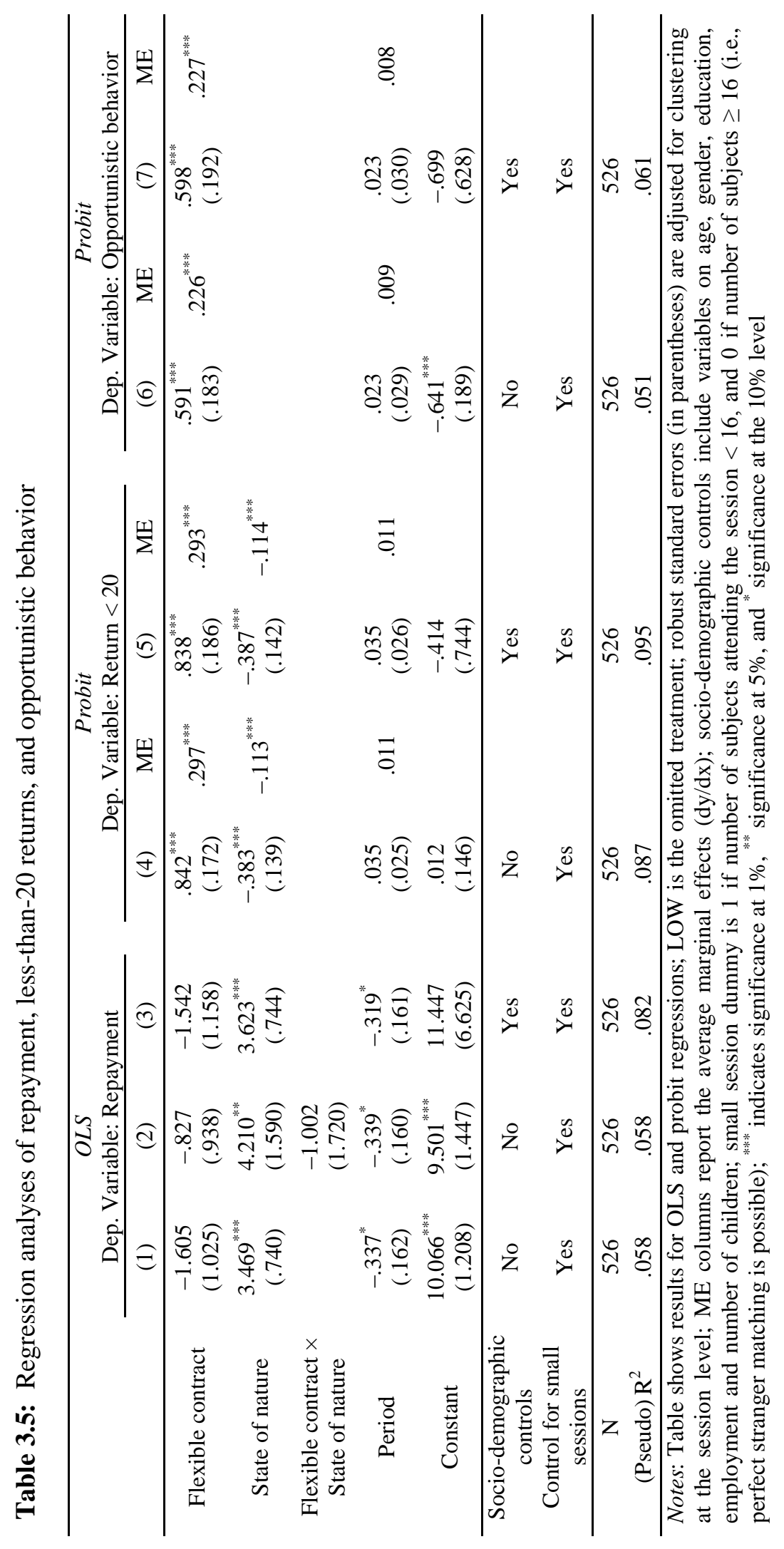


Yet, these regression models do not provide definite information about the occurrence and severity of opportunistic behavior, as they do not allow for differentiating between risk sharing and opportunism. We define opportunistic behavior by the agent as a repayment of less than 20 points in case of a good state. ${ }^{37}$ This way, we clearly distinguish between use and abuse of contract flexibility.

Consequently, the regressions in the third part of Table 3.5 use the dummy Opportunistic behavior as dependent variable, taking a value of 1 if an agent acted opportunistically according to the aforementioned definition and 0 if repayment was at least 20 or less than 20 in a bad state. We find that an agent is about 23 percentage points more likely to act opportunistically if a flexible agreement is being used. ${ }^{38}$

Result 3: We confirm hypothesis 3 that agents fail significantly more often to return 20 points with flexible agreements. Similarly, opportunistic behavior (defined as a return of less than 20 in a good state) is more likely if interaction is facilitated by flexible contracts-although agents more often return at least some positive amount irrespective of the state. Evidently, the repayment amount is positively associated with a good state of nature and agents, to some extent, share a surplus.

Before we turn to the contractual outcomes and payoffs, we should stress that this study is not about optimal contracts. In Section 3.2.2 we argue that we deliberately choose an extreme form of flexibility and an easy setting of sequential exchange. Evidently, both contract designs are rather unfavorable for the principal and therefore not very likely to be

\footnotetext{
${ }^{37}$ We could extend this definition by including returns of less than 10 points in a bad state. This would only marginally change our regression results in Table 3.5 (models (6) and (7)).

${ }^{38}$ All estimated models in Table 3.5 remain robust if we include dummies for the six main ethnic groupsLuo, Luhya, Nubian, Kisii, Kikuyu and Kamba-represented in our experiment. In total, 230 of our 240 participants (96 percent) belong to one of these six ethnicities. We do not find any significant differences between subjects from different ethnicities regarding repayment amounts, return of less than 20 , or opportunistic behavior.
} 
selected for real-world exchange. ${ }^{39}$ The absolute performance of the two agreements is thus not of primary interest to us. Instead, we pay more attention to the comparison of the two contract types in the given situation.

Figure 3.3 plots the players' average payoffs in case a contract was concluded. While panel (a) reveals that sending points barely pays for the principal-a fact often observed in investment games (see, e.g., Camerer, 2003; Cardenas and Carpenter, 2008)—panel (b) suggests that agents derive substantial benefits from interaction. Moreover, we find that agents' mean payoff from exchange decreases with increasing risk level and that across all conditions they are better off with flexible agreements. This latter observation is partly due to the fact that principals retaliate in $83-97$ percent of the cases when agents breach a rigid contract (cf. Table 3.2).

(a)

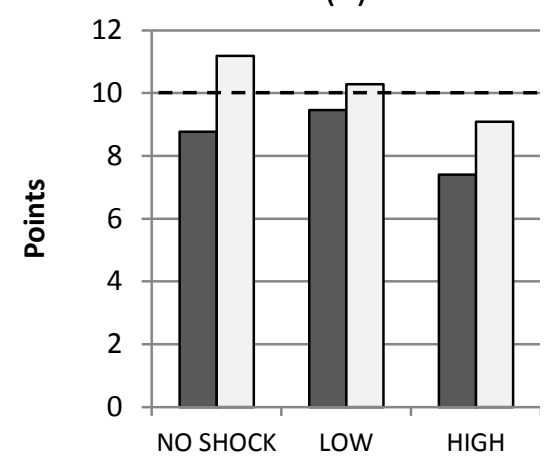

(b)

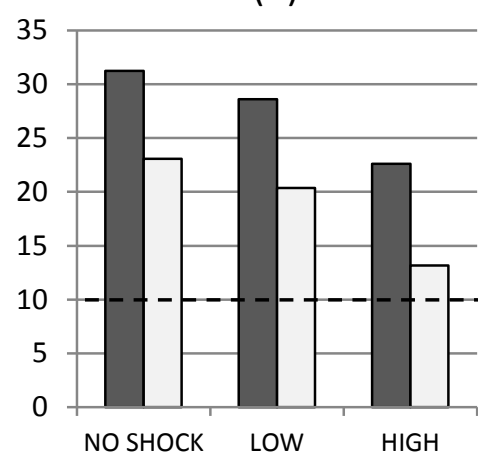

(c)

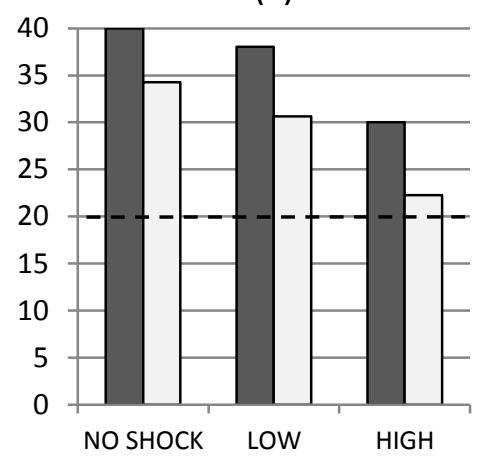

- - - Reservation payoff (w/o interaction)

Figure 3.3: Mean payoffs of (a) principal, (b) agent and (c) mean total payoffs of both players (in case of interaction)

Panel (c) illustrates the total surplus both players could realize through interaction in the various conditions. Besides the negative welfare effect of production shocks, indicated by the changes in total payoff between conditions, an efficiency loss with contractual rigidity

\footnotetext{
${ }^{39}$ See the introduction in Hart (1995) for a nice illustration of why it is important that contracts allow for a reasonable sharing of ex post control.
} 
becomes evident. This loss originates from the frequent retaliation and is also very likely in real-world exchange if an ex post adjustment of contract terms is completely ruled out. More often than not, subjects retaliate at the expense of total welfare-and other studies on cooperation show that this result holds even if retaliation is costly to the punisher (Fehr and Gächter, 2002).

Result 4: We have to reject hypothesis 4 that both players benefit from contract flexibility in the high-risk environment. The agent indeed does, but so she does in the other conditions. For the principal, if sending points at all, rigid agreements are always superior. At the same time, rigid agreements lead to substantial welfare losses as principals extensively retaliate against reneging agents.

\subsection{Conclusion}

Contract flexibility can support exchange in risky environments, but also encourage postcontractual opportunism. In an artefactual field experiment with slum dwellers in Nairobi, Kenya, we investigate preferences for contract flexibility, when subjects face different levels of risk and the common problem of hidden knowledge. Moreover, we examine the occurrence of opportunistic behavior and the contractual outcomes for both parties.

Our main contribution is to show that strong preferences for flexibility exist among slum dwellers and they become even stronger in a high-risk environment (compared to a lowrisk). This is no surprise in the agent's case. Yet, considering that the principal is doing worse with a flexible agreement in all conditions and opportunistic behavior by the agent is encouraged, the question remains why offering flexibility is this prevalent after all.

One explanation could be the existence of corresponding social norms. Offering rigid exchange without flexibility but with the threat of punishment may be considered rude. This 
argument becomes flimsy against the backdrop of the heavy actual retaliation we observe. A second potential explanation is that principals, analogously to the wage premium in a gift-exchange game, hope to trigger positive reciprocity by offering a flexible contract. Similarly, anticipated "hidden costs of control", as reported by Falk and Kosfeld (2006), could have restrained subjects from using rigid contracts. Yet, the high amount of points being controlled in our study and the possible retaliation imply that these control costs are small if not negligible. Note, though, that none of these arguments can explain the differences between conditions.

Our findings do not only shed light on real behavior and actual preferences in developing countries' informal markets, but also suggest some implications for the design of contracts (or implicit agreements) in environments where hazards and information problems are ubiquitous. Accordingly, contracts should take account of the strong preferences and need for flexibility we observe in our controlled experiment. Without flexibility economic exchange is less likely to occur, which, in turn, can result in welfare losses. Nonetheless, to mitigate post-contractual opportunism and make contract flexibility beneficial for both parties, these agreements must allow for a more elaborated sharing of ex post control.

Also from a policy perspective it is a noteworthy fact that flexibility may be desirable to facilitate exchange, but is easily exploited. Solutions thus need to target a stronger symmetry of information in markets (e.g., through monitoring or networks). When shocks are likely, flexibility is preferable to institutions that rigidly enforce all contracts and, that way, ignore the risk-sharing capability and welfare potential of contract flexibility. ${ }^{40}$ In environments where third-party enforcement is ruled out, private institutions-designed or spontaneously arising - may take over the task of information provision. We found that

\footnotetext{
${ }^{40}$ In fact, this positive effect on efficiency is twofold: First, we find that flexible contracts encourage interaction and thus the possible creation of gains. Second, no resources are being wasted by means of retaliation.
} 
hidden knowledge does not prevent exchange and interaction altogether, but mere flexibility seems not sufficient to achieve a fair division of a surplus.

There are at least three aspects of contract flexibility that we ignore in our study but ought to briefly mention at this point. First, the literature often associates flexibility with longterm relationships. Indeed, relational contracts, in the sense of a repeated game, would be likely to discourage opportunism to a certain degree (see, e.g., Kunte, Wollni and Keser, 2014 or Chapter 2 in this dissertation) and thus highlight the risk-sharing function of flexible agreements. As we intended to examine the pure link between risk and contract flexibility, we tried to avoid reputational effects. Second, the opportunity for communication may alter the efficiency of flexible agreements. Brandts, Charness and Ellman (2012) show that contract flexibility coincides with less grievance and better outcomes if unrestricted communication between contracting parties is possible. Third, and related, a proper renegotiation that is ad hoc and different from our unconditional flexibility is indeed more promising for solving hidden knowledge problems of the kind introduced in this study. We must leave it to future research to take these aspects into account. 


\section{Appendix 3A: Experimental instructions, handout, and comprehension survey ${ }^{*}$}

Thank you very much for joining this study!

You will participate in an economic experiment that studies behavior for scientific purposes. Please carefully follow the instructions below.

We play a game in which you will earn money. How much you earn depends on your own decisions and on the decisions by other players. Henceforth, please do not talk to other participants, keep your phone switched off and do not read any magazines or books you might have brought.

In this game, two players have the opportunity to interact, called Player 1 (P1) and Player 2 (P2). Both players will receive 10 points at the beginning of each round. Points are worth real money and both players may increase their points when they interact. P1 can send his points to P2. The points sent will triple (in a good state) or remain unchanged (in a bad state). Only P2 can observe this state. Then, P2 can return points to P1. For a transaction, both players will conclude a blue or yellow agreement (described below).

\section{The decisions:}

The two players can face the following (5) decisions in each round of the game $[\rightarrow$ handout $]$.

(1) P1 decides if he wants to interact with P2 in this round and send him all 10 points. If not, both players keep their 10 points and this round is finished. If so, P1 chooses a blue agreement or a yellow agreement for this transaction (described in the boxes below).

(2) If an agreement is offered, P2 decides if he accepts it. If not, both players keep their 10 points and this round is finished. If so, the transaction takes place.

(3) If an agreement was offered and accepted, P2 observes if the state is good or bad. If he observes a good state, the points sent by $\mathrm{P} 1$ are tripled and $\mathrm{P} 2$ now owns 40 points (his own 10 points + the tripled points sent by $\mathrm{P} 1$ ). If he observes a bad state, the points sent by $\mathrm{P} 1$ remain unchanged and $\mathrm{P} 2$ now owns 20 points (his own 10 points + the 10 points sent by P1). P1 cannot observe how many points P2 now owns.

(4) P2 decides how many points he sends back to P1. In case a yellow agreement was concluded, he can only choose between sending back a fixed amount of 20 points or nothing ( 0 points). In case a blue agreement was concluded, he can send back also any different amount (more or less than 20 points).

\footnotetext{
* This material refers to the HIGH condition. For the other conditions only relevant elements changed (e.g., shock probability), everything else remained the same. Translated to Swahili, the instructions were read aloud to the participants while they received an English handout (see below) with important elements of the game. Comprehension questions had to be answered using the computer, giving participants an immediate feedback; as the screen was locked following a wrong answer, pure guesswork was impossible. The Swahili instructions and the material of the other conditions will be provided upon request.
} 
(5) P1 observes how many points P2 returned to him. If a yellow agreement was chosen and the repayment is zero, $\mathrm{P} 1$ can now delete 15 of P2's points. However, this does not alter $\mathrm{P} 1$ 's points. If a blue agreement was chosen, $\mathrm{P} 1$ accepts the points sent by $\mathrm{P} 2$.

\section{The agreements:}

The interaction and transfer of points is realized through a blue or a yellow agreement. P1 decides which type of agreement he offers P2. Both agreements include different terms of repayment $[\rightarrow$ handoutl. Before we start with the study, please make sure that you have understood the differences between the two agreements.

With a blue agreement, repayment is considered a flexible amount and P2 is allowed to send back also more or less than 20 points depending on the state (Remember: P1 cannot observe this state).

With a yellow agreement, repayment is considered a fixed amount and P2 can only send back 20 points or nothing. If he does not send points, P1 can decide to delete 15 of P2's points (Remember: if a bad state occurs, $\mathrm{P} 2$ only owns 20 points in total and must send everything he owns to comply with the agreement).

\section{Good or bad state:}

If $\mathrm{P} 2$ observes a good state, the 10 points sent by $\mathrm{P} 1$ are tripled. If $\mathrm{P} 2$ observes a bad state, the points remain unchanged. Only P2 can observe this state, P1 is not informed about it. That means, after P1 sent his points, $\mathrm{P} 2$ owns either 20 points or 40 points, but P1 does not know this amount.

The computer determines if the state is good or bad.

- There is a chance of $\mathbf{5 0} \%$ that the state is good.

- There is a chance of $\mathbf{5 0} \%$ that the state is bad.

To get a better idea of the chances, consider the following picture of a bag containing 10 balls $[\rightarrow$ handoutl. 5 of these balls are green and 5 are red. Imagine now, you draw one ball without looking into the bag. The chances of getting a green or red ball are the same as for a good or bad state (50 $\%$ and $\mathbf{5 0} \%$ ).

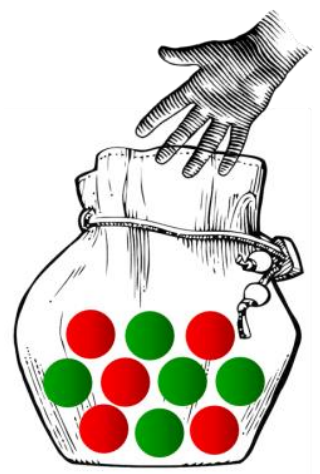




\section{Your profit:}

In each round, you will keep the points you earned. That means

- if no interaction took place, both players keep their 10 points.

- if an interaction took place, P1 earns the points sent back to him; P2 earns the points not sent back.

- in case a yellow agreement was concluded and P2 does not return points, P1 can delete 15 of $\mathrm{P} 2$ 's points.

In the end of the study, the points from all rounds (excluding the two practice rounds) are summed up and exchanged to Kenyan Shilling according to the following rate:

$$
1 \text { point }=2 \mathrm{KSh}
$$

This amount will be added to the payment of $\mathbf{2 0 0} \mathbf{~ K S h}$ for participation and transferred to your cellphone via mPESA after this session.

You will first play the game for two practice rounds. These rounds are only meant to support your understanding of the different decisions, the outcome will not affect your payment. After the two practice rounds, the game is played for eight "real" rounds in which you can earn money. You will keep your role (P1 or P2) throughout the whole game.

In the eight "real" rounds, you will interact with different players. No one will learn the identity of the other players during or after the study. Thus, decisions and earnings cannot be attributed to a specific participant.

All interactions are facilitated by computers. In the course of the game, you will face different screens that either ask you to take a decision yourself or inform you about other decisions. For taking own decisions, you need to push labeled buttons on the touch screen in front of you. For numerical entries a number pad will appear. If information is provided, you may push the "OK" button to proceed.

Before we start with the actual study, you are now asked to answer a few questions to prove full comprehension of the instructions. 


\section{Participants' handout}

Exp1_high_handout

\section{The decisions:}

(1) Player 1 decides if he wants to send his 10 points to Player 2. If not, both keep their 10 points and this round is finished. If so, Player 1 chooses for this transaction a

- blue agreement or

- yellow agreement.

(2) Player 2 decides if he accepts the agreement. If not, both keep their 10 points and this round is finished. If so, the transaction takes place.

(3) Player 2 observes the state. If the state is good, the points sent by Player 1 are tripled and Player 2 now owns 40 points (his 10 points + the tripled points sent by Player 1 ). If the state is bad, the points sent by Player 1 remain unchanged and Player 2 now owns 20 points (his 10 points + the 10 points sent by Player 1 ). Player 1 cannot observe the state.

(4) Player 2 decides how many points he sends back to Player 1 . With a yellow agreement, he can only send back a fixed amount of 20 points or nothing ( 0 points). With a blue agreement, he can send back also any different amount (more or less than 20 points).

(5) Player 1 observes how many points Player 2 returned. If a yellow agreement was chosen and the repayment is zero, Player 1 can now delete 15 of Player 2's points. However, this does not change Player 1's points.

\section{The agreements:}

With a blue agreement, repayment is considered a flexible amount and Player 2 is allowed to send back also more or less than 20 points depending on the state (Remember: Player 1 cannot observe this state).
With a yellow agreement, repayment is considered a fixed amount. Player 2 can only send back 20 points or nothing. If he does not send points, Player 1 can delete 15 of Player 2's points (Remember: in a bad state Player 2 only owns 20 points in total and must send everything he owns to comply with the agreement).

\section{Chances for good and bad state:}

\section{Good}

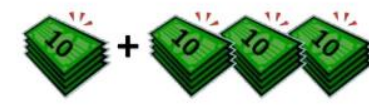

OR

Bad

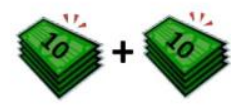

$50 \%$

$50 \%$

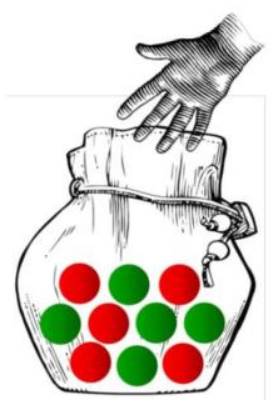




\section{Comprehension questions}

Please answer the following questions. They are only meant to support your understanding of the game and will not directly influence your payment.

\begin{tabular}{|c|c|c|c|c|c|}
\hline $\begin{array}{l}\text { 1. How many points does each player own at the } \\
\text { beginning of a round? }\end{array}$ & 0 & 40 & 20 & 30 & 10 \\
\hline $\begin{array}{l}\text { 2. If Player } 1 \text { sends all points and a GOOD state } \\
\text { occurs, how many points does Player } 2 \text { now own? }\end{array}$ & 20 & 40 & 10 & 0 & 30 \\
\hline $\begin{array}{l}\text { 3. If Player } 1 \text { sends all points and a BAD state oc- } \\
\text { curs, how many points does Player } 2 \text { now own? }\end{array}$ & 20 & 40 & 10 & 0 & 30 \\
\hline
\end{tabular}

4. With a yellow agreement, what can Player 1 do if Player 2 sent back nothing?
Delete points

Tell other players

5. Is it true that Player 1 cannot observe if the state is good or bad?

Yes

No

6. Player 2 can send back also more or less than 20 points with a ...

blue agreement

yellow agreement

7. Player 2 can send back only 20 points or nothing with a ...

blue agreement

yellow agreement

8. What are the chances that a BAD state occurs?

$10 \%$

$50 \%$

9. What are the chances that a GOOD state occurs?

$10 \%$

$50 \%$

10 . Who is setting this state?

Player 2

The computer

11. Do you interact with the same person in each round?

\begin{tabular}{|l|l|} 
Yes & No \\
\hline
\end{tabular}

12. How many KSh will you receive for 1 point?

2

1 


\title{
4. Do inequalities in profit reinforce post-contractual opportunism? Experimental evidence from a slum in Nairobi
}

\begin{abstract}
Even though many informal settlements exhibit vibrant economic activity, behavioral patterns and preferences of slum dwellers are not well understood. We run a lab-in-the-field experiment with subjects from the Kibera slum in Nairobi, Kenya. In a simple principal-agent game with hidden action we study if rejection rates and postcontractual opportunism increase when a contracting party can observe large (disadvantageous) differences in profit from trade. Along the lines of inequity aversion theory, we argue that the feeling of being treated unfairly in an exchange relationship may trigger uncooperative responses. Our results do not confirm this and rather show a very high compliance rate in general. Rejections and opportunistic behavior are not reinforced by profit asymmetries. Yet, we do find significant gender effects. Experimental and survey outcomes jointly suggest a low level of inequity aversion among Nairobi slum dwellers.
\end{abstract}

Keywords: principal-agent theory, hidden action, lab-in-the-field experiment, inequity aversion, post-contractual opportunism, Nairobi slum, Kenya

JEL classification: D82, L14, O12

This chapter is based on a single-authored paper. For their comments, the author thanks Meike Wollni, Martin Schmidt and the participants of the GLOBE Seminar, 18 May 2015 in Göttingen. Moreover, he is grateful to the Busara Center team in Nairobi, in particular Chaning Jang, James Vancel, Lucy Rimmington, Arun Varghese and the research assistants. Financial support by the German Research Foundation (DFG) is gratefully acknowledged. 


\subsection{Introduction}

Informal settlements in developing countries often exhibit vibrant economic activity. An article by The Economist (2012) attests that the Kibera slum in Nairobi, Kenya, "may be the most entrepreneurial place on the planet" and "an African version of a Chinese boomtown, an advertisement for solid human ambition". Given this dynamic economic landscape with its myriad small businesses, adaptive capacity and essential flexibility, remarkably little research has yet been done on patterns of economic behavior and preferences of slum dwellers.

This also and particularly applies to principal-agent arrangements. Many of these relations, which might be embedded in larger value chains or organizations, are characterized by strongly asymmetric gains from trade. Simultaneously, low-income countries often suffer from an inefficient legal system or do not provide access to public enforcement institutions to all citizens (World Bank, 2013a; ibid., 2013b). This makes opportunistic behavior-in one form or another - an impending and often existent problem in bilateral trade.

The main question underlying this lab-in-the-field experiment is whether post-contractual opportunism is reinforced when a producer observes large differences in profits between herself and the buyer. More precisely, in a contractual relation where deviating from certain contract terms is a potentially profitable strategy for the producer and her actions are hidden, how will the knowledge of the buyer's gains from trade affect the producer's behavior within the relationship? The investigation of this question is of particular interest in a developing country context where we assume the necessity to largely rely on private enforcement mechanisms (e.g., McMillan and Woodruff, 2000; Fafchamps, 2004), but can also provide general insights into agents' other-regarding behavior in bilateral contractual relations. 
We run our experiment with individuals from various villages of the Kibera slum, a population that is highly relevant for at least three reasons. First, many slum dwellers are casual workers or produce goods on behalf of others (Government of Kenya and UN-HABITAT, 2005). Hence, the decisions taken in our game are likely to also play a critical role in participants' everyday life. Second, they are constantly confronted with high inequality in wealth and income, which might alter their notion of inequity and their other-regarding preferences. And third, the Kibera population is vastly familiar with institutional failures when it comes to the protection of property rights and contract enforcement (Joireman and Vanderpoel, 2010).

We play a very simplified, one-shot principal-agent game with hidden action, in which the producer can accept a contract and has the choice between two activities: to invest in quality (and comply with the contract terms) or to refrain from investing. The buyer cannot directly observe the investment, only the quality outcome, which is more likely to be high if the producer invested. Both players' payoffs depend on this quality. Our treatment variable is the buyer's profit or, respectively, the producer's knowledge thereof.

Rational and selfish individuals are thought to only care about their own profit and not to alter their behavior when the other party's payoff changes. Yet, a fair-minded producer might be more likely to renege on the contract when knowing that the buyer earns much more from this interaction relative to a setting where profit differences are small or unknown. In the former case, the producer dislikes the existing inequality and feels exploited. In addition, the perceived heterogeneous gains from trade may cause first-party enforcement mechanisms (e.g., guilt feelings) to fail. 
In this vein, other-regarding behavior is central to our experiment. ${ }^{41}$ However, we are not examining the division of a surplus, but decisions taken prior to a chance move. Popular theories of distributional preferences and fairness (Fehr and Schmidt, 1999; Bolton and Ockenfels, 2000; Charness and Rabin, 2002) should thus be applied with caution. Nonetheless, these theories can support the formulation of different hypotheses on producers' behavior and help interpreting the results.

Most experimental examinations of principal-agent relations that are related to our study and exclusively conducted with students in Western countries ${ }^{42}$ (e.g., Keser and Willinger, 2000; ibid., 2007; Anderhub, Gächter and Königstein, 2002; Cochard and Willinger, 2003) emphasize the problem of designing an optimal incentive contract. That is, they primarily focus on the principal's behavior. Perhaps the most remarkable and consistent finding from these controlled experiments is that offered contracts by and large follow norms of fair surplus sharing. Closely related experiments on "gift exchange" stress that higher fixed payments by principals trigger reciprocal responses by agents who, in return, apply higher effort levels (Fehr, Kirchsteiger and Riedl, 1993; Fehr, Gächter and Kirchsteiger, 1997; Fehr, Klein and Schmidt, 2007; Kube, Maréchal and Puppe, 2012). This evidence on reciprocity is robust. Yet, little is known about the pure effect of profit inequalities on the agent's behavior. By only studying the producer's decisions and exogenously determining surplus sharing, our design allows us to exclude the effect of reciprocity. In addition, studies on agents' behavior using non-student and non-Western subjects are sparse. For the aforementioned reasons, we believe that behavior in our study population substantially deviates from that of students.

\footnotetext{
${ }^{41}$ To be precise with theoretical terminology, we address inequality or inequity aversion (both terms are used in the literature) as one form of social preferences, i.e. an individual's utility depends on her material payoff, but also on the payoff of others. "Other-regarding preferences" can be understood as a general category including also interdependent and intention-based preferences (cf. Fehr and Schmidt, 2006 for a classification).

${ }^{42}$ An exception is the study of trust games with hidden action conducted by Binzel and Fehr (2013) in Cairo.
} 
The next section introduces a simple agency problem with hidden action. Section 4.3 explains the experimental design, procedures and different theoretical predictions. Section 4.4 briefly summarizes the study's results. In Section 4.5 we discuss our findings and conclude.

\subsection{A simple agency problem}

In this section we briefly introduce a simple form of an agency problem with hidden action (based on Hart, 1995). Imagine there is one buyer (principal) and one producer (agent) who can conclude a contract for production and purchase of a good with quality $q$, where

$$
q=f(i, \theta)
$$

That is, the good's quality is a function of the producer's activity $i$ (namely, an investment in this quality) and some random factor $\theta$ which is beyond the producer's control. The producer has costs of investment $c(i)$, which are usually assumed to be convex, i.e., $c^{\prime}(i)>0$ and $c^{\prime \prime}(i)>0$. Here we simplify the producer's activity to a binary choice of investing or not investing in quality, $i \in\{0,1\}$. We thus assume $c(i=0)=0$ and $c(i=0)<c(i=1)$.

The buyer's valuation and profit from trade directly depend on the good's quality $q$, thus $\pi(q)$. The producer exhibits a utility function of

$$
u(p, i)=V(p)-c(i)
$$

where $p$ is the payment the producer receives for the good.

The hidden action problem now emerges from the fact that $i$ is unobservable to the buyer or, more specifically, it is impossible to assess whether the producer chose $i=\hat{\imath}$, the buy- 
er's demanded investment level. Instead of offering a fixed-payment contract of $p^{*}$, that would shift all risk to the buyer but eliminate the producer's pecuniary incentives to invest, the buyer can offer an incentive scheme in the form of $p=p(q)$. Note that this is possible since the outcome of $q$ is commonly known. The canonical principal-agent approach is mostly concerned with the principal's (buyer's) design of an optimal contract in the form of

$$
p=\tau+s(q)
$$

where $\tau$ is a fixed payment and $s$ is a share of the produced surplus or, as in our case, a bonus for high quality.

With an incentive scheme of this form, the producer has a general stimulus to invest in quality. Whether or not the incentive is sufficient depends on the particular design of the scheme. ${ }^{43}$ In this study, we ignore the buyer's contractual design choice and exogenously determine a scheme contracting parties will use. Our parameters are introduced in the next section.

\subsection{The experiment}

\subsubsection{Design}

We ran our experiment in the premises of the Busara Center for Behavioral Economics in Nairobi, Kenya, which provides a full laboratory with touchscreen computers (for details see Haushofer et al., 2014). Subjects were randomly recruited from a pool of about 2,500

\footnotetext{
${ }^{43}$ Typically, the buyer maximizes her expected profit $E(\pi)=r(f(i, \theta))-p(f(i, \theta))$, where $r(\cdot)$ is her revenue function and $p(\cdot)$ the payment to the producer, both depend on the quality outcome, subject to the producer's "participation constraint" and "incentive compatibility constraint". The former assures that $E[V(p(\cdot))]-c(i)$ at least equals the producer's reservation utility; the latter states that $E[V(p(\cdot))]-c(i)$ is increasing in $i$.
} 
residents from the Kibera slum, Nairobi's largest informal settlement, and invited via SMS. As an understanding of probabilities is important to our study, participants were required to have a minimum education level of completed primary school.

In a session, all subjects but one assume the role of a producer; one randomly chosen participant is the buyer. The buyer in our study is a dummy player and does not take any active decisions. However, her payoff is affected by the producers' actions.

We play a very simplified and adjusted principal-agent game with hidden action. In a first stage, a producer decides whether to enter into a contract with the buyer (which is automatically offered). By accepting, the producer agrees to deliver her product and promises to invest in high quality. If no contract is concluded, both receive a reservation payoff of $20 .{ }^{44}$ In the second stage, the producer decides on the actual investment $i \in\{0,1\}$. The investment comes at a cost of $c(i=1)=20$, but increases the probability of a high-quality product from $P(q=1 \mid i=0)=0.5$ to $P(q=1 \mid i=1)=0.8$. In the last stage, a computerized random device determines the quality level $q \in\{0,1\}$ (where 0 stands for low and 1 for high quality) contingent on whether or not the producer invested.

Analogously to the agency problem outlined in Section 4.2, the eventual quality outcome can be observed and thus the producer's payment made contingent on this outcome. Yet, the buyer cannot observe the action chosen by the seller, but nonetheless demand a (nonenforceable) activity in the contract. ${ }^{45}$

\footnotetext{
${ }^{44}$ Payoffs and costs are all expressed in monetary units of Kenyan Shillings (KES). At the time of the study USD 1 was worth approximately KES 88. Earnings should be interpreted relative to participants' average daily income, which is KES 160 according to our post-experimental survey for the full sample.

${ }^{45}$ This demanded activity is the equivalent of the desired effort level $\tilde{e}$ in some gift-exchange experiments (e.g., Fehr, Gächter and Kirchsteiger, 1997). While the agent's effort choice of $e<\tilde{e}$ is usually interpreted as "shirking", we understand an investment decision of $i=0$ as "opportunistic behavior".
} 
With a high-quality product a producer receives a payment of $p(q=1)=80$ minus the possible investment $\operatorname{cost} c(i)$; with low quality the producer receives $p(q=0)=40 \mathrm{mi}$ nus the investment. The buyer's profit $\pi$, in turn, does not depend on an investment but solely on the quality of the final product. The buyer earns $\pi(q=1)=\varphi$ with high quality and $\pi(q=0)=\frac{\varphi}{2}$ if a low quality product is delivered. ${ }^{46}$ Table 4.1 summarizes the parameters and payoffs.

Table 4.1: Experimental parameters and payoffs

\begin{tabular}{ccc}
\hline & $\begin{array}{c}\text { high quality } \\
(q=1)\end{array}$ & $\begin{array}{c}\text { low quality } \\
(q=0)\end{array}$ \\
\hline Probability if $i=0$ & 0.5 & 0.5 \\
Probability if $i=1$ & 0.8 & 0.2 \\
Buyer's payoff $(\pi)$ & $\varphi$ & $\varphi / 2$ \\
Producer's payoff $(u)$ & $80-c(i)$ & $40-c(i)$ \\
\hline
\end{tabular}

We use a between-subjects design to compare contract acceptance and compliance in three different conditions. In the first condition, where $\varphi=60$, both producer and buyer earn about the same amount. More precisely, they benefit from trade equally if the producer complies and the quality is high. Expected payoffs are almost the same with investment (52 for the producer vs. 54 for the buyer). This can be labeled the symmetric (SYM) condition. In the second, $\varphi=240$ and the producer knows that the buyer earns up to four times the own amount (ASYM). To analyze whether the actual knowledge of the other's payoff has an effect, we conduct sessions with non-transparency regarding the buyer's earnings. Pro-

\footnotetext{
${ }^{46}$ As we are not interested in buyer behavior and to keep the game as simple as possible, the buyer's profit is only composed of one parameter (instead of a profit function). We can assume that this parameter is already reduced by the payment to the producer. More than a realistic profit function, it is important here to make the height of the payoff very prominent.
} 
ducers are only informed that the buyer's payoff with low quality is merely half the payoff with high quality (UNKNOWN). ${ }^{47}$

\subsubsection{Procedures}

In total, 240 participants attended 15 experimental sessions; no one more than one session. We conducted six sessions of the SYM, six sessions of the ASYM, and three of the UNKNOWN condition. Upon arrival, subjects are identified via fingerprint and receive a first briefing in a waiting room as well as a random place card indicating their respective computer booth. After being seated, every participant was asked to fill a consent form and completed a brief touchscreen test to prove the ability to sufficiently handle the computer. We played two different games in a session of which the first is part of Chapter 3 in this dissertation. ${ }^{48}$ Instructions were read aloud and explained in Swahili, while participants received a handout with graphical illustrations of probabilities, decisions and payoffs in English. After these explanations, participants were asked to complete a number of comprehension questions at the computer. Research assistants were present at all time to support subjects who had trouble continuing. As the game itself, these questions were programmed using the software package z-Tree (Fischbacher, 2007). In case of a wrong answer, subjects had to call a research assistant to "unlock" the screen and explain the question again. This improved understanding and made pure guesswork impossible (see Appendix 4B for instructions and comprehension questions).

\footnotetext{
${ }^{47}$ In the UNKNOWN condition, the buyer de facto had the same payoff structure as in the SYM $(\varphi=60)$. The buyer was informed about this individually at the beginning of the game through a screen message.

${ }^{48}$ To largely avoid influences by the first-game results on behavior in the second game, instructors emphasized in between that the second experiment is completely independent and earnings cannot be lost. Moreover, participants were informed about their total monetary outcome only after the second game. When running regressions, we additionally control for first-experiment earnings and player type. We will further discuss this issue in the results section.
} 
Following this comprehension survey, all subjects in the role of a producer took their decisions and were informed about their results and payment. The buyer received the outcome from interaction with one randomly determined producer; this was explained to everyone beforehand. On the average, a participant earned KES 53 for this short experiment, in addition to a show-up fee of KES 200 and the earnings from the other game (cf. Chapter 3).

\subsubsection{Theoretical predictions}

Game and parameters are chosen such that an incentive contract is offered and both players benefit from high quality. For a risk-neutral producer ${ }^{49}$, however, the incentive compatibility constraint is not satisfied (as shown below). This creates a dilemma between compliance and maximizing the expected profit — and provides monetary incentives to act opportunistically. Different theories of standard and behavioral economics potentially predict different outcomes of the experiment.

Selfishness. If we assume that individuals are entirely self-interested, they exhibit no otherregarding behavior and only care about their own payoff. Consequently, we should not be able to observe differences between conditions. In addition, a rational producer will not invest, even though she and the buyer have the same goal, namely, high quality. The producer's incentive compatibility constraint were satisfied, and investment guaranteed, if

$$
\begin{gathered}
0.2(40-c(i=1))+0.8(80-c(i=1)) \geq \\
0.5(40-c(i=0))+0.5(80-c(i=0)) .
\end{gathered}
$$

As $c(i=1)=20$ and $c(i=0)=0$, however, the producer has an expected profit of 52 with investment and 60 without. As a result, we predict opportunistic behavior and non-

\footnotetext{
${ }^{49}$ To obtain some simple predictions, we assume risk neutrality, even though agency theory is usually assuming the agent to be risk-averse.
} 
investment. Since a contracting producer always earns her reservation payoff of 20 (even in the worst case of investment followed by low quality), her participation constraint is satisfied and she accepts the contract in the first place.

Other-regarding preferences. Many experiments show that individuals value their profit in relation to that of other players. Assuming other-regarding behavior, we predict a potentially different outcome. There are two (somewhat complementary) "fairness arguments" for expecting more opportunism in the ASYM as opposed to the SYM condition. First, if guilt aversion is keeping producers from breaking their promise, these guilt feelings may be weakened by the impression of being treated unfairly in the ASYM condition. In consequence, subjects behave more in favor of their own (expected) payoff and act less cooperatively. ${ }^{50}$ Second, theories of inequity aversion (here we focus on Fehr and Schmidt, 1999) assume that the existence of profit asymmetries - disadvantageous but also advantageous $^{51}$ —negatively affect an agent's utility function. In fact, we can show that individuals who exhibit Fehr-Schmidt utility functions (and consider expected payoffs) never invest in the ASYM, just like selfish individuals do, but possibly switch to investment in the SYM condition if they sufficiently dislike being ahead (see Appendix 4A).

Similarly, even though the producer's participation constraint is satisfied, we would expect more individuals in the ASYM, relative to the SYM or UNKNOWN, to reject the contract offer and to prefer a lower (but equal) payoff over a very unequal payoff distribution. This prediction can be supported by observations of behavior in ultimatum games. Having said that, low-offer rejections in standard ultimatum bargaining games reflect a response to an intended act by the proposing player, and acceptance rates of low ("unfair") offers have

\footnotetext{
${ }^{50}$ Even though also the producer receives a lower payoff in case of low quality, the buyer in the ASYM clearly "loses" much more compared to the high-quality outcome.

${ }^{51}$ Camerer (2003) refers to these two as "envy" and "guilt".
} 
proven to increase if they were determined randomly or by a third party (Blount, 1995). Generally speaking, with our design it is not possible to ascribe the producer's behavior to some kind of reciprocal fairness or use intention-based theories (Rabin, 1993; Dufwenberg and Kirchsteiger, 2004; Falk and Fischbacher, 2006), as payoff distributions and contract offers are exogenously determined and this is commonly known. This ensures that we observe the pure effect of profit allocations or, respectively, the knowledge thereof.

\subsection{Results}

\subsubsection{Descriptive statistics and findings}

Table 4.2 reports summary statistics for selected demographic, economic and preference variables as well as descriptive results of our outcome variables. A comparison of the means suggests that subjects in the different conditions are fairly similar with respect to their demographic and economic characteristics. For number of children and monthly income we find some differences between ASYM and UNKNOWN that are significant at the 10-percent level. Moreover, individuals in the SYM state to use written contracts in everyday life somewhat more often than their counterparts in the UNKNOWN condition. Yet, we also find some differences in inequity aversion and fairness expectations. Risk tolerance seems to be significantly higher in the UNKNOWN relative to the other conditions.

Our descriptive results suggest that the acceptance rate is significantly higher in the ASYM ( 83 of 86 producers accepted the contract) as opposed to the other conditions (SYM: 77 of 92; UNKNOWN: 40 of 47). Contract compliance (investment) is very high in general. Interestingly, it is lowest in the SYM (66 of 77 invested) and rises in the ASYM (77 of 83) and UNKNOWN (38 of 40) condition, though these differences in means are not statistically significant. Consequently, we cannot find differences in producers' payoffs. 
Table 4.2: Summary statistics and descriptive results

\begin{tabular}{|c|c|c|c|c|c|c|}
\hline & \multirow{2}{*}{$\begin{array}{c}(1) \\
\text { SYM } \\
\end{array}$} & \multirow{2}{*}{$\begin{array}{c}(2) \\
\text { ASYM }\end{array}$} & \multirow{2}{*}{$\begin{array}{c}(3) \\
\text { UNKNOWN } \\
\end{array}$} & \multicolumn{3}{|c|}{ Differences } \\
\hline & & & & $(1)-(2)$ & $(1)-(3)$ & $(2)-(3)$ \\
\hline \multicolumn{7}{|l|}{ Demographic variables } \\
\hline Age (years) & $\begin{array}{l}30.78 \\
(9.40)\end{array}$ & $\begin{array}{c}32.81 \\
(10.97)\end{array}$ & $\begin{array}{l}29.90 \\
(9.32)\end{array}$ & -2.03 & .88 & 2.91 \\
\hline Female & $\begin{array}{c}.612 \\
(.490)\end{array}$ & $\begin{array}{l}.500 \\
(.503)\end{array}$ & $\begin{array}{l}.510 \\
(.505)\end{array}$ & .112 & .102 & -.010 \\
\hline Number of children & $\begin{array}{l}1.61 \\
(1.66)\end{array}$ & $\begin{array}{l}1.91 \\
(1.99)\end{array}$ & $\begin{array}{c}1.30 \\
(1.40)\end{array}$ & -.30 & .31 & $.61^{*}$ \\
\hline Education (years) & $\begin{array}{l}11.84 \\
(1.25)\end{array}$ & $\begin{array}{l}11.79 \\
(1.43)\end{array}$ & $\begin{array}{l}11.98 \\
(.979)\end{array}$ & .05 & -.14 & -.19 \\
\hline \multicolumn{7}{|l|}{ Marital status } \\
\hline Single & $\begin{array}{l}.531 \\
(.502)\end{array}$ & $\begin{array}{l}.467 \\
(.502)\end{array}$ & $\begin{array}{l}.480 \\
(.505)\end{array}$ & .064 & .051 & -.013 \\
\hline Married, cohabitating & $\begin{array}{l}.418 \\
(.496)\end{array}$ & $\begin{array}{c}.435 \\
(.498)\end{array}$ & $\begin{array}{l}.440 \\
(.501)\end{array}$ & -.017 & -.022 & -.005 \\
\hline Divorced, separated, widowed & $\begin{array}{l}.051 \\
(.221)\end{array}$ & $\begin{array}{l}.098 \\
(.299)\end{array}$ & $\begin{array}{l}.080 \\
(.274)\end{array}$ & -.047 & -.029 & .018 \\
\hline \multicolumn{7}{|l|}{ Economic variables } \\
\hline Job dummy $(1$ = has a job $)$ & $\begin{array}{l}.265 \\
(.444)\end{array}$ & $\begin{array}{l}.293 \\
(.458)\end{array}$ & $\begin{array}{c}.220 \\
(.418)\end{array}$ & -.028 & .045 & .073 \\
\hline Income (KES per month) & $\begin{array}{l}5160 \\
(7045)\end{array}$ & $\begin{array}{l}5177 \\
(5644)\end{array}$ & $\begin{array}{c}3422 \\
(3935)\end{array}$ & -17 & 1738 & $1755^{*}$ \\
\hline $\begin{array}{l}\text { Contract use in everyday life } \\
(1=\text { never } ; 4=\text { often })\end{array}$ & $\begin{array}{c}2.63 \\
(.897)\end{array}$ & $\begin{array}{l}2.49 \\
(.987)\end{array}$ & $\begin{array}{c}2.30 \\
(.789)\end{array}$ & .14 & $.33^{* *}$ & .19 \\
\hline \multicolumn{7}{|c|}{ Variables on preferences and comprehension } \\
\hline Guilt score $^{\mathrm{a}}$ & $\begin{array}{c}5.21 \\
(1.86)\end{array}$ & $\begin{array}{l}4.93 \\
(1.68)\end{array}$ & $\begin{array}{c}5.29 \\
(1.95)\end{array}$ & .28 & -.08 & -.36 \\
\hline Inequity aversion, disadv. ${ }^{b}$ & $\begin{array}{c}2.09 \\
(1.22)\end{array}$ & $\begin{array}{l}2.08 \\
(1.05)\end{array}$ & $\begin{array}{l}1.76 \\
(.822)\end{array}$ & .01 & $.33^{*}$ & $.32^{*}$ \\
\hline Inequity aversion, $\mathrm{adv}^{\mathrm{c}}$ & $\begin{array}{c}2.40 \\
(1.28)\end{array}$ & $\begin{array}{c}2.33 \\
(1.11)\end{array}$ & $\begin{array}{l}2.68 \\
(1.33)\end{array}$ & .07 & -.28 & $-.35^{*}$ \\
\hline Expect fairness others ${ }^{\mathrm{d}}$ & $\begin{array}{l}.439 \\
(.499)\end{array}$ & $\begin{array}{l}.315 \\
(.467)\end{array}$ & $\begin{array}{l}.420 \\
(.499)\end{array}$ & $.124^{*}$ & .019 & -.105 \\
\hline Risk preference $\mathrm{e}^{\mathrm{e}}$ & $\begin{array}{c}3.09 \\
(1.31)\end{array}$ & $\begin{array}{c}3.35 \\
(1.27)\end{array}$ & $\begin{array}{c}3.72 \\
(1.16)\end{array}$ & -.26 & $-.63^{* * * *}$ & $-.37^{*}$ \\
\hline $\begin{array}{l}\text { Understanding instructions } \\
(1=\text { very poorly } ; 5=\text { very } \text { well })\end{array}$ & $\begin{array}{l}4.16 \\
(.846)\end{array}$ & $\begin{array}{l}4.28 \\
(.803)\end{array}$ & $\begin{array}{l}4.12 \\
(.849)\end{array}$ & -.12 & .04 & .16 \\
\hline \multicolumn{7}{|c|}{ Experimental decisions and outcomes } \\
\hline $\begin{array}{l}\text { Acceptance } \\
(1=\text { accepted })\end{array}$ & $\begin{array}{c}.837 \\
(.371)\end{array}$ & $\begin{array}{l}.965 \\
(.185)\end{array}$ & $\begin{array}{c}.851 \\
(.360)\end{array}$ & $-.128^{* * *}$ & -.014 & $.114^{* *}$ \\
\hline $\begin{array}{l}\text { Investment } \\
(1=\text { invested })\end{array}$ & $\begin{array}{c}.857 \\
(.352)\end{array}$ & $\begin{array}{l}.928 \\
(.261)\end{array}$ & $\begin{array}{l}.950 \\
(.221)\end{array}$ & -.071 & -.093 & -.022 \\
\hline Producer payoff (KES) & $\begin{array}{c}47.61 \\
(19.18)\end{array}$ & $\begin{array}{c}50.70 \\
(17.81)\end{array}$ & $\begin{array}{l}48.09 \\
(18.96)\end{array}$ & -3.09 & -.48 & 2.61 \\
\hline
\end{tabular}

Notes: Data are reported as means with standard deviations in parentheses; significance levels of $1 \%\left({ }^{* * *}\right), 5 \%\left({ }^{* *}\right)$, and $10 \%\left(^{*}\right)$ refer to two-sample $t$ tests; ${ }^{\text {a }}$ measures a subject's average rating of her probability to feel guilty and shameful in four specific situations $(1=$ very unlikely; $7=$ very likely) based on Cohen et al. (2011); ${ }^{\mathrm{b}}$ response to the statement "Other people should not own much more than I do" $(1=$ strongly disagree; $5=$ strongly agree $) ;{ }^{c}$ response to the statement "Other people should not own much less than I do" ( 1 = strongly disagree; 5 = strongly agree $)$; ${ }^{\mathrm{d}}$ response to the question "Do you think most people would try to take advantage of you if they got a chance, or would they try to be fair?" $(1=$ fair $) ;{ }^{\text {e }}$ response to the statement "I would invest part of my income if there is a chance that this amount doubles, but also that I lose everything." $(1=$ strongly disagree $; 5=$ strongly agree $)$ 
Table 4.3: Probability of contract acceptance and investment

\begin{tabular}{|c|c|c|c|c|c|c|c|c|}
\hline & \multicolumn{4}{|c|}{ Dep. Variable: Acceptance } & \multicolumn{4}{|c|}{ Dep. Variable: Investment } \\
\hline & (1) & (2) & (3) & (4) & (5) & (6) & (7) & (8) \\
\hline ASYM & $\begin{array}{l}.831^{* * * *} \\
(.269)\end{array}$ & $\begin{array}{l}.946^{* * * *} \\
(.340)\end{array}$ & $\begin{array}{c}4.581^{* * * *} \\
(.345)\end{array}$ & $\begin{array}{l}1.661^{* *} \\
(.666)\end{array}$ & $\begin{array}{l}.391 \\
(.324)\end{array}$ & $\begin{array}{l}.395 \\
(.353)\end{array}$ & $\begin{array}{l}.663^{* * *} \\
(.303)\end{array}$ & $\begin{array}{l}.774^{*} \\
(.443)\end{array}$ \\
\hline UNKNOWN & $\begin{array}{l}.059 \\
(.207)\end{array}$ & $\begin{array}{l}-.090 \\
(.240)\end{array}$ & $\begin{array}{c}.359 \\
(.317)\end{array}$ & $\begin{array}{c}-.726^{* *} \\
(.343)\end{array}$ & $\begin{array}{l}.577 \\
(.509)\end{array}$ & $\begin{array}{l}.564 \\
(.514)\end{array}$ & $\begin{array}{c}4.562^{* * *} \\
(.191)\end{array}$ & $\begin{array}{l}.764 \\
(.634)\end{array}$ \\
\hline Age (years) & & $\begin{array}{c}-.039^{* * * *} \\
(.008)\end{array}$ & $\begin{array}{c}-.037^{* * *} \\
(.008)\end{array}$ & $\begin{array}{c}-.067^{* * * *} \\
(.019)\end{array}$ & & $\begin{array}{l}.007 \\
(.015)\end{array}$ & $\begin{array}{l}.007 \\
(.016)\end{array}$ & $\begin{array}{c}-.074^{* * *} \\
(.026)\end{array}$ \\
\hline Female & & $\begin{array}{c}-.737^{* * * *} \\
(.217)\end{array}$ & $\begin{array}{l}-.435 \\
(.272)\end{array}$ & $\begin{array}{c}-1.061^{\text {**** }} \\
(.404)\end{array}$ & & $\begin{array}{c}-.369^{* *} \\
(.182)\end{array}$ & $\begin{array}{l}-.031 \\
(.151)\end{array}$ & $\begin{array}{c}-.745^{* *} \\
(.352)\end{array}$ \\
\hline $\begin{array}{l}\text { ASYM × } \\
\text { Female }\end{array}$ & & & $\begin{array}{c}-3.830^{\text {**** }} \\
(.278)\end{array}$ & & & & $\begin{array}{l}-.433 \\
(.356)\end{array}$ & \\
\hline $\begin{array}{l}\text { UNKNOWN } \\
\times \text { Female }\end{array}$ & & & $\begin{array}{l}-.645^{*} \\
(.339)\end{array}$ & & & & $\begin{array}{c}-4.463^{* * *} \\
(.512)\end{array}$ & \\
\hline $\begin{array}{l}\text { Number of } \\
\text { children }\end{array}$ & & & & $\begin{array}{c}.240 \\
(.167)\end{array}$ & & & & $\begin{array}{l}.307^{*} \\
(.186)\end{array}$ \\
\hline $\begin{array}{l}\text { Marital status, } \\
\text { married }\end{array}$ & & & & $\begin{array}{l}-.407 \\
(.558)\end{array}$ & & & & $\begin{array}{l}.890^{*} \\
(.498)\end{array}$ \\
\hline $\begin{array}{l}\text { Marital status, } \\
\text { divorced }\end{array}$ & & & & $\begin{array}{l}-.384 \\
(.941)\end{array}$ & & & & $\begin{array}{l}1.039^{*} \\
(.617)\end{array}$ \\
\hline $\begin{array}{l}\text { Education } \\
\text { (years) }\end{array}$ & & & & $\begin{array}{l}-.172 \\
(.149)\end{array}$ & & & & $\begin{array}{l}-.154 \\
(.158)\end{array}$ \\
\hline $\begin{array}{l}\text { Job dummy } \\
(1=\text { has a job })\end{array}$ & & & & $\begin{array}{l}.304 \\
(.567)\end{array}$ & & & & $\begin{array}{l}.024 \\
(.368)\end{array}$ \\
\hline $\begin{array}{l}\text { Income (KES } \\
\text { per month) }\end{array}$ & & & & $\begin{array}{l}.000^{* * *} \\
(.000)\end{array}$ & & & & $\begin{array}{l}.000^{* * * *} \\
(.000)\end{array}$ \\
\hline Contract use & & & & $\begin{array}{c}-.661^{* *} \\
(.337)\end{array}$ & & & & $\begin{array}{l}-.370^{*} \\
(.196)\end{array}$ \\
\hline Guilt score & & & & $\begin{array}{l}.163^{* *} \\
(.071)\end{array}$ & & & & $\begin{array}{l}.014 \\
(.089)\end{array}$ \\
\hline $\begin{array}{l}\text { Inequity } \\
\text { aversion, } \\
\text { disadv. }\end{array}$ & & & & $\begin{array}{l}-.211 \\
(.172)\end{array}$ & & & & $\begin{array}{l}-.164 \\
(.111)\end{array}$ \\
\hline $\begin{array}{c}\text { Inequity } \\
\text { aversion, adv. }\end{array}$ & & & & $\begin{array}{l}.065 \\
(.137)\end{array}$ & & & & $\begin{array}{c}-.355^{* * * *} \\
(.112)\end{array}$ \\
\hline $\begin{array}{c}\text { Expect } \\
\text { fairness others }\end{array}$ & & & & $\begin{array}{l}-.629 \\
(.487)\end{array}$ & & & & $\begin{array}{l}.484^{* *} \\
(.241)\end{array}$ \\
\hline $\begin{array}{c}\text { Risk } \\
\text { preference }\end{array}$ & & & & $\begin{array}{l}.380^{* * * *} \\
(.127)\end{array}$ & & & & $\begin{array}{l}.010 \\
(.157)\end{array}$ \\
\hline $\begin{array}{l}\text { Understand. } \\
\text { instructions }\end{array}$ & & & & $\begin{array}{l}-.072 \\
(.208)\end{array}$ & & & & $\begin{array}{l}.655^{* * *} \\
(.114)\end{array}$ \\
\hline Constant & $\begin{array}{l}.982^{* * * *} \\
(.193)\end{array}$ & $\begin{array}{l}2.692^{* *} \\
(1.075)\end{array}$ & $\begin{array}{l}2.321^{* *} \\
(1.039)\end{array}$ & $\begin{array}{l}4.370^{*} \\
(2.253)\end{array}$ & $\begin{array}{c}1.068^{* * * *} \\
(.214)\end{array}$ & $\begin{array}{c}1.767^{* *} \\
(.899)\end{array}$ & $\begin{array}{l}1.542 \\
(.982)\end{array}$ & $\begin{array}{c}5.018 \\
(3.359)\end{array}$ \\
\hline $\begin{array}{c}\text { Earnings first } \\
\text { experiment }\end{array}$ & & $\begin{array}{c}.002 \\
(.007)\end{array}$ & $\begin{array}{c}.003 \\
(.007)\end{array}$ & $\begin{array}{l}.020^{* *} \\
(.009)\end{array}$ & & $\begin{array}{l}-.003 \\
(.004)\end{array}$ & $\begin{array}{l}-.002 \\
(.004)\end{array}$ & $\begin{array}{l}-.006 \\
(.005)\end{array}$ \\
\hline $\begin{array}{c}\text { Role first } \\
\text { experiment } \\
(1=\text { principal })\end{array}$ & & $\begin{array}{l}-.193 \\
(.458)\end{array}$ & $\begin{array}{l}-.138 \\
(.449)\end{array}$ & $\begin{array}{c}.009 \\
(.063)\end{array}$ & & $\begin{array}{l}-.725^{* * *} \\
(.311)\end{array}$ & $\begin{array}{c}-.757^{* * *} \\
(.314)\end{array}$ & $\begin{array}{r}-1.355^{* *} \\
(.568)\end{array}$ \\
\hline $\begin{array}{c}\mathrm{N} \\
\text { Pseudo } \mathrm{R}^{2}\end{array}$ & $\begin{array}{l}225 \\
.061\end{array}$ & $\begin{array}{l}222 \\
.185\end{array}$ & $\begin{array}{l}222 \\
.196\end{array}$ & $\begin{array}{l}208 \\
.411\end{array}$ & $\begin{array}{l}200 \\
.028\end{array}$ & $\begin{array}{l}197 \\
.079\end{array}$ & $\begin{array}{l}197 \\
.104\end{array}$ & $\begin{array}{l}187 \\
.304\end{array}$ \\
\hline
\end{tabular}

Notes: Table shows results for probit regressions of producers' decisions; SYM is the omitted category; robust standard errors (in parentheses) are adjusted for clustering at the session level; ${ }^{* * *}$ indicates significance at $1 \%$, ${ }^{* *}$ significance at $5 \%$, and ${ }^{*}$ significance at the $10 \%$ level 


\subsubsection{Regression results}

The results of different probit regression models are reported in Table 4.3. In all specifications SYM is our omitted category and we control for cluster-correlated standard errors at the session level.

Acceptance. In the first part of Table 4.3, contract acceptance is the dependent variable, being 1 if the subject accepted the contract offer and 0 otherwise. Column (1) only includes the condition dummies. We find that acceptance is more likely in the ASYM relative to the SYM condition, while we cannot find a significant effect of $U N K N O W N$. In column (2) we include variables on age and gender, and control for a subject's role and earnings in the first experiment (part of Chapter 3). Our results show that older subjects and women are significantly less likely to accept a contract. The effect of ASYM remains robust. Column (3) integrates interactions of Female and the condition dummies. It turns out that the positive effect of the ASYM condition is significantly larger for males. The gender effect becomes insignificant for the omitted SYM condition, indicated by the coefficient of $\mathrm{Fe}$ male, but considerably grows when subjects observe large differences in profit. In column (4) we include the other demographic and economic variables as well as the variables on preferences and comprehension summarized and explained in Table 4.2. Relative to the SYM, contract acceptance is more (less) likely in the ASYM (UNKNOWN) condition. The coefficients of Age and Female remain negative and significant. The coefficient of Income is significant, but almost zero. Individuals using written contracts more often are less likely to enter into an agreement in the experiment. Being prone to guilt feelings (Guilt score) as 
according to our test ${ }^{52}$ and a rising risk tolerance are associated with a higher probability of acceptance.

In general, a subject's earnings and role in the experiment conducted before seem not to have a decisive effect on her acceptance decision. In one regression (column (4)), firstgame earnings are significant at the 5-percent level, but the coefficient is very small. We are thus optimistic that the first experiment's impact on contract acceptance is negligible.

Investment. The second part of Table 4.3 depicts results of probit regressions with Investment as dependent variable, taking a value of 1 if a subject complied with the agreement and 0 otherwise. In column (5) we again only consider the condition dummies, which are insignificant. Adding subjects' age, gender and first-experiment controls in column (6), we find that women in our experiment are significantly less likely to invest in quality compared to their male counterparts. Column (7) suggests that this gender difference is not significant for all conditions. Yet, for the UNKNOWN condition it is prevalent; here women are particularly less likely than men to invest in quality. In column (8) we include the same demographic, economic and preference variables as for contract acceptance in column (4). In the ASYM condition, individuals are now more likely to invest relative to the SYM. The effect is significant at the 10-percent level (there is no significance for $U N$ KNOWN). Age and Female become/remain both negative and significant. Subjects with more children are more likely to invest. So are individuals who are married/cohabitating or divorced/widowed, relative to singles. Again, the coefficient of income is close to zero, yet significant. The frequent use of written contracts in everyday life and a greater (advantageous) inequity aversion decrease the probability of investing. Individuals who think others

\footnotetext{
${ }^{52}$ This test is based on the Guilt-Negative-Behavior-Evaluation (NBE), which is part of the Guilt and Shame Proneness (GASP) score introduced by Cohen et al. (2011). We just adapted the described situations to the life of slum dwellers.
} 
would try to be fair rather than taking advantage of them (Expect fairness others) and those who rated their comprehension with the experimental instructions higher are more likely to comply and invest.

Also for the investment decision, the control for first-experiment earnings (that are not due to the role) is insignificant and throughout exhibits very small coefficients. This time, however, the role a subject played in the experiment before (principal/agent) becomes significant at the 5-percent level, indicating an influence on the investment decision in this game. Controlling for the role is thus important and makes us more confident that we estimate the real condition effects. Furthermore and importantly, we can expect the first-game roles to influence all conditions the same way as they were assigned randomly to the participants and they are distributed equally between (and even within) the conditions.

\subsection{Discussion}

\subsubsection{Inequity aversion and responses to unfairness}

If subjects were rational and selfish, we should barely observe rejections and investment in our experiment. A robust result of this study is that contract acceptance is more likely if producers know they will get a smaller share of the pie. This finding sounds less counterintuitive if we recognize that the producer's absolute payoff is the same in all conditions, while the "total pie" in the ASYM becomes much greater.

Moreover, the fact that the vast majority of producers does invest in quality is surprising. It is reasonable to say that opportunism does not prove to be a great problem here. Although we control for risk preferences to a certain degree (and the coefficient is insignificant), risk aversion is presumably part of the explanation. In general, when making their investment decision subjects do not seem to bother much about what the other player earns. Perhaps, 
these profit asymmetries are all too common in slum dwellers' daily routine. As an illustration, compare the mean monthly earnings of KES 4,800 in our sample with an average private-sector employee's income in Kenya of around KES 39,000 (KNBS, 2014). This latter figure includes also low-income activities, such as agriculture, mining or waste management. Taking a closer look at the responses in our post-experimental survey, we find support for this hypothesis. In one part subjects were asked to agree/disagree with the statement: "Other people should not own much more than I do." The outcome is depicted in Figure 4.1. Accordingly, 83 percent (strongly) disagree with the statement, while not even 12 percent (strongly) agree. This distribution of responses suggests that Nairobi slum dwellers reveal a very low level of inequity aversion when income or wealth asymmetries are to their disadvantage. ${ }^{53}$ This outcome, however, may be primarily driven by the very low wealth level in our study population.

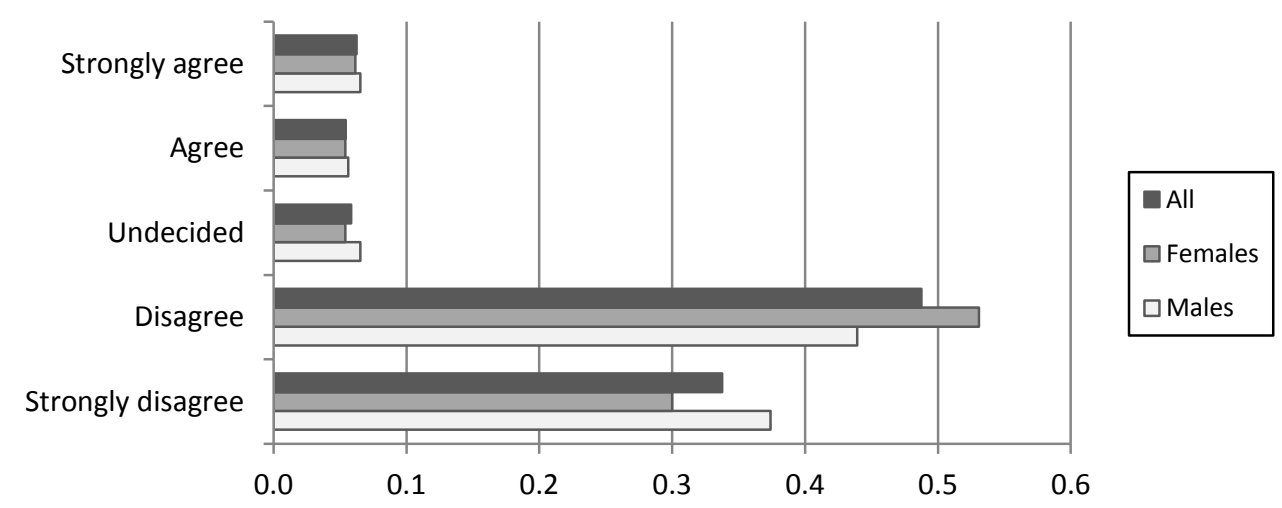

Figure 4.1: Responses to "How much do you agree/disagree with the following statement: Other people should not own much more than I do."

At large, our results strongly contradict standard-theoretic predictions of vast postcontractual opportunism, but also do not confirm our intuition of other-regarding prefer-

\footnotetext{
${ }^{53}$ We also confronted subjects with the opposite statement "Other people should not own much less than I do", with which they agreed more (cf. Table 4.2). The difference in responses between the two statements is highly significant $(p=.0001$, Wilcoxon signed-rank test).
} 
ences or fairness concerns. When controlling for demographic, economic and other variables, we even find a higher probability of investment in the ASYM condition relative to the SYM. Non-transparency with regard to the buyer's profit (UNKNOWN) makes no considerable difference in post-contractual behavior, confirming that this information seems not to be very relevant for the producers. While all this clearly indicates that inequity aversion does not explain behavioral patterns in our game, these results are largely in line with other studies' findings that many individuals reveal preferences for social welfare and efficiency. Charness and Rabin (2002: 819) claim that "the role of inequality reduction in motivating subjects has been exaggerated." They find that for many individuals increasing social welfare seems more of a matter than decreasing pecuniary differences. This would explain the high compliance rates within "unfair" arrangements in our experiment. ${ }^{54}$

Our results also appear contradictory to many outcomes of other experimental examinations, like rejections in ultimatum or altruistic punishment in cooperation games. Yet, again, it is important to bear in mind that we exclude reciprocity as a potential driver of behavior, since contract offers and, most of all, profit shares are not a result of the buyer's intention. In a series of simplified ultimatum games, Falk, Fehr and Fischbacher (2003) show that a responder's reaction to an unequal allocation strongly depends on the alternative allocations available to the proposer. That is, "responders take into account not only the distributive consequences of the proposer's action but also the intention signaled by the action" (ibid.: 25). Seemingly, behavioral responses to inequality in contractual relations are much more a reaction to the intended "unfairness" of the other party than to pure profit allocations. This presumption, though, cannot be tested with our data. On the contrary, Charness (2004) demonstrates in a gift-exchange experiment with U.S. students that even

\footnotetext{
${ }^{54}$ The expected total profit in the SYM is almost equal in case of investment (106) and non-investment (105). Yet, in the ASYM it is higher when the producer invests (268 vs. 240).
} 
though reciprocity plays a crucial role when agents decide about their costly action, there is also a positive wage-effort relationship if an external third party or a random device determines the height of the agent's payment. That is, intentions matter-but so do outcomes.

\subsubsection{Gender differences}

Throughout our analysis we find significant gender effects. We saw that women are less likely than men to accept a contract. Furthermore, we show that the gender effect becomes very salient in the ASYM condition. Again, acceptance is always rational and comes without risk. At first glance, the gender difference in the ASYM looks like evidence for stronger fairness preferences compared to men, but also women have with 93 percent the highest acceptance rate in the ASYM (81 percent in the SYM; 74 percent in the UNKNOWN), while men accept every single contract in this condition (89 percent in the SYM; 96 percent in the UNKNOWN). Also the survey results do not lend support to the presumption that females dislike inequity more than men do (Figure 4.1; responses between women and men not different, $p=0.4724$, Mann-Whitney $\mathrm{U}$ test). Women appear a bit more reluctant to enter a relationship altogether-yet on a very high general level.

Furthermore, women are somewhat less likely to invest. According to our regression analysis, the gender difference this time is pronounced in the UNKNOWN. This seems to be driven by a very high investment rate of male subjects in this condition, however. While women chose to invest in 88 percent of all possible cases in the UNKNOWN (90 percent in the SYM; 85 percent in the ASYM), again, men in this condition always invested (87 percent in the SYM; 95 percent in the ASYM). 


\subsubsection{Concluding remarks}

Following standard theoretic predictions, opportunistic behavior should be a severe problem in our simple principal-agent experiment. This proves wrong, however, as the vast majority of producers honor the agreement and invest in quality. Theories of fairness and inequ(al)ity aversion extend the standard model of behavior and assume that individuals dislike unequal outcomes. Again, we cannot find evidence that producers' behavior is more opportunistic when differences in payoffs between the contracting parties are large. A plausible reason is that Nairobi slum dwellers exhibit a rather low level of inequity aversion (at least when the reference player is a peer slum resident).

Even though newer studies put parsimonious theories of inequity aversion into perspective and stress the role of fairness intentions, negative reciprocity and concerns for social welfare (e.g., Charness and Rabin, 2002; Falk, Fehr and Fischbacher, 2003; ibid., 2008), there is long-standing evidence that individuals do not like earning less than others and respond to disadvantageous inequality — even if this response is costly (see Clark and D'Ambrosio, 2015 for a recent review). Charness (2004) suggests that, albeit reciprocity is indeed essential in contractual relations, agents' decisions are influenced by outcomes that are determined randomly or by a third party. Our results from urban slum dwellers are at odds with this intuition. To this end, more research is required to truly explore other-regarding preferences and consequent economic conduct of the poor. These preferences appear to be different from those revealed by students in industrial countries. 


\section{Appendix 4A: Producers' investment decision and the theory of inequity aversion}

In this appendix, we formally analyze the opportunistic/compliance behavior of inequityaverse producers. The general theory of inequity aversion (or fairness), as developed by Fehr and Schmidt (1999), assumes that an individual's utility function is not merely influenced by her own pecuniary outcome, but also by that of other players and the resulting difference in payoffs. Thereby, a player experiences a utility loss from both, disadvantageous inequality (being behind) and advantageous inequality (being ahead). Due to the design of our experiment we can simplify and only consider the two-player case. Analogously to the Fehr-Schmidt model, we denote the producer's monetary payoff $x_{P}$ and the buyer's monetary payoff $x_{B}$. The producer's utility function is given by

$$
u_{P}\left(x_{P}, x_{B}\right)=x_{P}-\alpha_{P} \max \left\{x_{B}-x_{P}, 0\right\}-\beta_{P} \max \left\{x_{P}-x_{B}, 0\right\}
$$

For the three possible situations that (i) both players' payoffs are equal, (ii) the producer is behind in monetary terms, and (iii) the producer is ahead, this gives us

$$
u_{P}\left(x_{P}, x_{B}\right)= \begin{cases}x_{P} & , x_{P}=x_{B} \\ \left(1+\alpha_{P}\right) x_{P}-\alpha_{P} x_{B} & , x_{P}<x_{B} \\ \left(1-\beta_{P}\right) x_{P}+\beta_{P} x_{B} & , x_{P}>x_{B}\end{cases}
$$

where $\alpha_{P}$ is a measure of the producer's utility loss from disadvantageous inequality and $\beta_{P}$ weights her loss from advantageous inequality with $0 \leq \beta_{P}<1$ and $\beta_{P} \leq \alpha_{P}$. If an individual is entirely selfish, i.e., $\beta_{P}=\alpha_{P}=0$, we obtain the usual $u_{P}\left(x_{P}\right)=x_{P}$.

As our experiment is not about distributional preferences with regard to a known surplus but features a stochastic outcome, we have to make use of expected payoffs. Since we 
know the probabilities of a quality outcome contingent on whether or not the producer invested, we can substitute the expected payoffs in equation (4A.1) above and get

$$
E\left(u_{P}\right)= \begin{cases}60-\alpha_{P} \max \{0.75 \varphi-60,0\}-\beta_{P} \max \{60-0.75 \varphi, 0\} & , i=0 \\ 52-\alpha_{P} \max \{0.9 \varphi-52,0\}-\beta_{P} \max \{52-0.9 \varphi, 0\} & , i=1\end{cases}
$$

Now, we first look at the ASYM condition where we set $\varphi=240$ and get

$$
E\left(u_{P}\right)_{A S Y M}= \begin{cases}60-120 \alpha_{P} & , i=0 \\ 52-164 \alpha_{P} & , i=1\end{cases}
$$

Independently of the (positive) value of $\alpha_{P}$, the producer always has a higher utility when breaching the contract and refraining from investing.

In the SYM condition, the scenario is somewhat different. Here, the producer is again slightly behind the buyer in expected values when investing, but ahead when not investing. For $\varphi=60$ we get

$$
E\left(u_{P}\right)_{S Y M}= \begin{cases}60-15 \beta_{P} & , i=0 \\ 52-2 \alpha_{P} & , i=1\end{cases}
$$

Conditional on the individual's value of $\alpha_{P}$ and $\beta_{P}$, a shift towards contract compliance is now generally possible if

$$
\beta_{P} \geq \frac{4+\alpha_{P}}{7.5}
$$


Therefore, if we exemplarily assume that $\alpha_{P}=1$ and $\beta_{P}=0.7$, then a rational but inequity-averse producer would decide to comply with the contract. If, say, $\alpha_{P}=2$ and $\beta_{P}=$ 0.8 , then a producer were indifferent between investment and non-investment. Recall that the Fehr-Schmidt model assumes that $\beta_{P}$ is positive, strictly smaller than 1, and not larger than $\alpha_{P}$.

Producers who sufficiently dislike being ahead thus potentially shift from non-investment to investment. This formal argument supports the presumption that we observe more opportunism in the ASYM relative to the SYM (and UNKNOWN) condition. However, it should not be confused with our second (non-formal) "fairness argument" that subjects start out with the intention to invest—because, e.g., guilt feelings make them comply—but switch to non-investment in the ASYM condition as they feel treated unfairly.

We should sound a note of caution, however. Even though the formal argument of a potential switch to compliance in the SYM holds true mathematically, the $\beta_{P}$ required for this switch is rather large. That is, a subject must greatly dislike being ahead-even by a bit. The largest $\beta_{i}$ Fehr and Schmidt (1999) but also Fehr, Klein and Schmidt (2007) assume is 0.6. If we maintain the assumption of $\beta_{P} \leq \alpha_{P}$, no switch in our game is predicted with this value of $\beta_{P}$.

The question arising from the outcome of this study and in particular the questionnaire is whether the assumption of $\beta_{i} \leq \alpha_{i}$ is a reasonable one and adequately describes most of our slum population's social preferences. Future research should tackle this question more rigorously as the answer could have substantial theoretical and practical implications. 


\section{Appendix 4B: Experimental instructions, handout, and comprehension survey*}

We will now play a short game in which you can earn real money. How much you earn also depends on your own decisions. Please do not talk to other participants and keep your phone switched off until the end of the session.

In this game, imagine you are the Producer of a product. You can choose to enter an agreement with a Buyer, to produce and later sell your product to him. The Buyer wants a high quality and, thus, that you invest in this quality. The investment is costly for you, but if you invest, the chances for high quality are better than without investment. Both, you and the Buyer earn more with a high than a low quality product.

There is only one Buyer sitting in this room. All other people are Producers. That means, all Producers who accept an agreement sell their product to the same person. This one Buyer will be informed about his role at the beginning of the game.

\section{The decisions}

The game consists of the following decisions:

1. Acceptance: You decide if you accept the Buyer's offer to produce and later sell a product to him. If you do not accept this offer, you and the Buyer earn KSh 20 each, and the game is over. If you accept, you promise the Buyer that you will invest in a high quality of the product.

2. Investment: If you accepted the offer, you now decide if you want to invest in the product's quality. The Buyer cannot observe if you really invested, he only observes the quality of the product. The investment costs you KSh 20 (no investment costs you nothing).

3. Quality: The computer now sets the quality of the product. The chances for high quality are $80 \%$ if you made the investment, and $50 \%$ if you did not make the investment.

\section{High and low quality}

The chances for a high quality product are better if you decided to invest ( $80 \%$ compared to $50 \%$ ). For a better understanding of these chances, consider the following two images of bags, each containing ten balls $[\rightarrow$ handout $]$. Green balls represent high quality and red balls low quality.

\footnotetext{
* This material refers to the ASYM condition. For the other conditions only relevant elements changed (e.g., the buyer's payoff), everything else remained the same. Translated to Swahili, the instructions were read aloud to the participants while they received an English handout (see below) with important elements of the game. Comprehension questions had to be answered using the computer, giving participants an immediate feedback; as the screen was locked following a wrong answer, pure guesswork was impossible. The Swahili instructions and the material of the other conditions will be provided upon request.
} 
Imagine you draw a ball from one bag without looking. If you invested, you are drawing from the left bag. If you did not invest, you draw from the right bag.

with investment

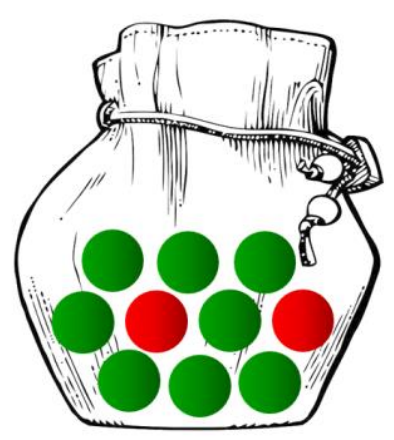

without investment

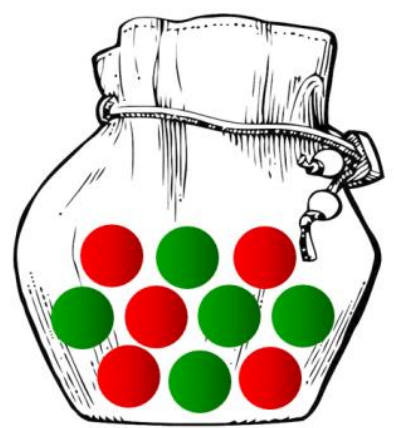

\section{The payment:}

You and the Buyer will earn the following points with an agreement. Please make sure you understand the different profits before taking your decisions.

- High quality: You earn KSh 80 (minus the cost of 20 if you invested), the Buyer earns KSh 240

- Low quality: You earn KSh 40 (minus the cost of 20 if you invested), the Buyer earns KSh 120

This amount will be added to the money you earned so far for your participation and transferred to your cellphone via mPESA after this session.

Let's discuss the Buyer's payment: As he is interacting with different players, he only earns the points from interaction with one of the Producers. By chance, the computer picks the one trade for the Buyer's payment. That means, the Buyer will earn KSh 20, 120 or 240, depending on your decisions and the quality of the product. He will not earn the sum of all trades!

This game will only be played for one single round. Consequently, you make the decisions only once. Please take your time to decide carefully.

The one person in this room who represents the Buyer will be informed by a message on the screen. The Buyer does not take any decisions, but only observes his profit.

No one will get to know your identity or the identity of the Buyer. All your decisions are made completely anonymously.

The illustration $[\rightarrow$ handout $]$ summarizes the different decisions and earnings. 


\section{Participants' handout}

Exp2_asymmetric_handout

High and low quality

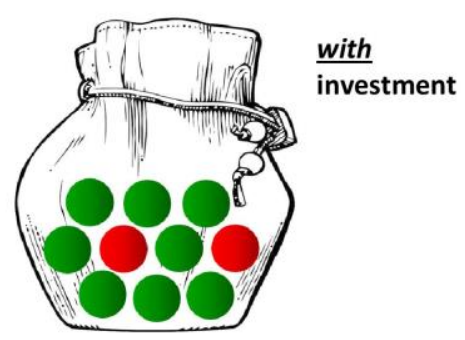

$80 \%$ chance of high quality if invested

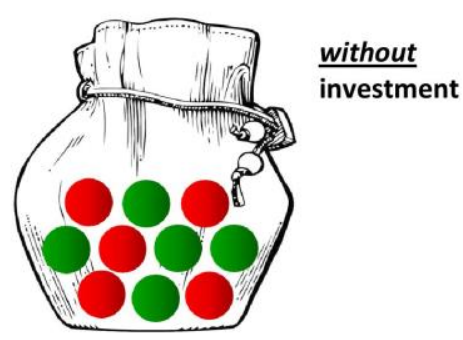

$50 \%$ chance of high quality if not invested

\section{Decisions and profit}

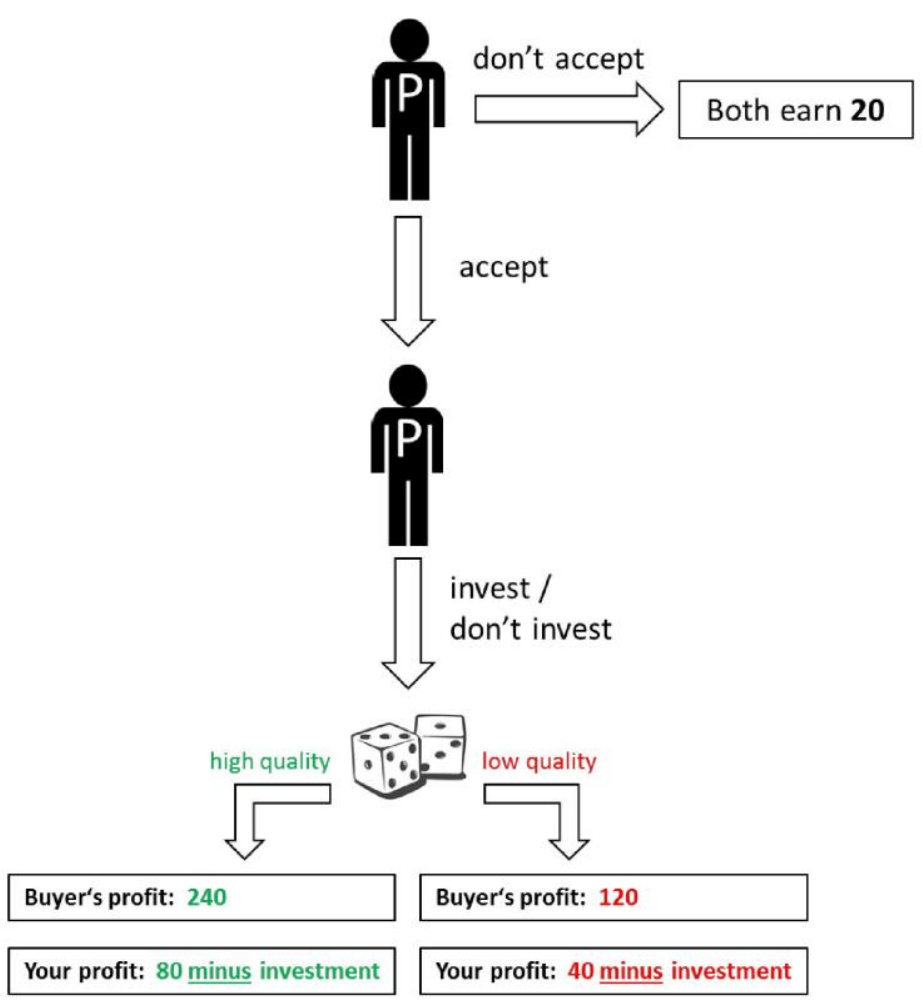




\section{Comprehension questions}

Please answer the following questions. They are only meant to support your understanding of the game and will not directly influence your payment.

\begin{tabular}{|l|l|l|l|l|l|}
\hline 1. How many rounds is the game played for? & 2 & 4 & 3 & 5 & 1 \\
\hline
\end{tabular}

\begin{tabular}{|l|l|l|l|l|l|}
\hline $\begin{array}{l}\text { 2. If you as a Producer invest, how big are the } \\
\text { chances that the product is of high quality? }\end{array}$ & $50 \%$ & $0 \%$ & $30 \%$ & $100 \%$ & $80 \%$ \\
\hline
\end{tabular}

3. If you as a Producer do NOT invest, how big are the chances that the product is of high quality?

\begin{tabular}{|l|l|l|l|l|}
\hline $80 \%$ & $50 \%$ & $0 \%$ & $100 \%$ & $10 \%$ \\
\hline
\end{tabular}

\begin{tabular}{|l|l|l|}
\hline $\begin{array}{l}\text { 4. With accepting an agreement, do you promise } \\
\text { the Buyer to invest? }\end{array}$ & Yes & No \\
\hline
\end{tabular}

5. Can the Buyer observe if you REALLY invested?

Yes

No

6. How much will an investment cost you?

KSh 20

Nothing

7. How much will you earn if you invest and the quality is high?

KSh 60

KSh 80

8. How much will the Buyer earn if the quality is high?

The same (KSh 60)

KSh 240

9. How many Buyers are sitting in this room?

10 1

10. Will the Buyer earn the money from ALL trades or only from ONE of the trades?
Money from
ALL trades

Money from ONE

of the trades 


\section{Conclusion}

In the preceding chapters, we presented three experimental studies of contracting and sequential exchange in situations where neither party can rely on formal external enforcement. In what follows, we will summarize our main findings and provide some cautious implications for real-world relationships and institutions. Moreover, we discuss the studies' limitations and derive suggestions for future research.

\subsection{Summary and implications}

\subsubsection{Chapter 2}

In a laboratory experiment we study behavior in a novel contract farming game. Two players were able to conclude a contract, but both could also breach it ex post by side-selling to an external "spot market" (farmer player) or reducing the price paid for the delivered produce (company player).

We find that long-term relations improve cooperation and compliance, but do not lead to proper self-enforcement and satisfying private ordering in most cases. This holds true, even though we can show that cooperation would pay off in the long run, as demonstrated by the significantly higher profit for individuals in well-functioning dyads. Voluntary free-form communication to bargain terms directly or communicate discontent does not improve relations and was often expected to be mere cheap talk (and therefore not executed). This stands in sharp contrast to the impact of communication found in other bargaining or principal-agent experiments (Charness, 2012). Company players understand that they can extend the contract's self-enforcing range, and thus the probability of delivery, if they offer 
higher contract prices in the condition without private enforcement. Yet, we also show that these price premiums are only "allurements" and actually paid prices are lower compared to the other conditions.

Previous experimental research suggests that markets witness a strong "bilateralization" if third-party enforcement is absent (Brown, Falk and Fehr, 2004; Fehr, Brown and Zehnder, 2009). That is, traders commit themselves to long-term dyads that become dominant relative to anonymous spot market interactions. Our study — featuring a more specific settingreveals that long-term relations per se have a disciplining effect as opposed to one-shot interactions. This holds, even if a party cannot choose among many potential trading partners in a market — as would be ideal, but is often not the case in economies with high transaction costs and poor information (McMillan and Woodruff, 2000). For real-world exchange, the accumulation of (bilateral) reputation capital can thus improve the outcome. While this repeated game effect has also been observed in similar settings, our results are more informative with respect to what happens within these partnerships:

First, the sequence of actions and the power relation between contracting parties play a crucial role. In our experiment, the first- and last-moving company player was able to skim off the surplus from private enforcement. Relatedly, we found that price reductions by the company are more frequent than (predicted) side-selling. Remaining in the realm of contract agriculture, producer organizations could represent an institutional solution to these problems by constituting an intermediary between seller and buyer (Minot, 2007). If opportunistic price reductions arise from the buyer's non-transparent quality control, the possibility for external quality checks to remove information asymmetries can increase farmers' effort and investment (Sänger, Torero and Qaim, 2014) and potentially reduce sideselling that is caused by the fear of betrayal in the final (payment) stage. 
Second, the finding that long-term benefits of well-functioning relations do not make most contracts readily self-enforcing points towards the vulnerability of private enforcement under dysfunctional public order. Here, external private institutions can provide information about the fact that breach, albeit tempting in a specific moment, is likely to cause mutual losses in the long run. Whether this information makes a difference or is, similar to our voluntary communication, only cheap talk must be investigated empirically. In countries with a reasonable judicial system, small-claims courts can support parties to credibly threat with legal consequences. Even so, long-term relations and reputation will remain central means for diminishing transaction costs.

\subsubsection{Chapter 3}

This study originates from the notion that contract flexibility can be advantageous or even necessary for trade in very hazardous environments, where information on the reason of breach is usually asymmetric. Empirical research in sub-Saharan Africa (Bigsten et al., 2000; Fafchamps, 2004) demonstrates that exchange in developing countries exhibits a high degree of flexibility. With observational data, however, it is hardly possible to link this finding directly to the actual existence or extent of risk. To the best of our knowledge, we present the first controlled study with subjects from a low-income country that investigates preferences for contract flexibility. For this purpose, we introduce an adjusted investment game with two different agreements and hidden knowledge. The experiment is conducted with urban slum dwellers in Nairobi.

We confirm the existence of strong preferences for flexibility; two out of three offered contracts are flexible. Principals are more likely to offer flexible agreements in the high-risk relative to the low-risk environment. Agents accept more flexible than rigid contracts when 
facing the risk of a productivity shock, as they fear harsh retaliation when experiencing a bad state and not returning anything. They show, however, no particular reluctance to sign a rigid contract when risk is high.

In addition, our results indicate that flexible contracts more often allow for a return of more than zero, but also encourage opportunistic behavior and returns of less than the agreed amount. A good state is generally associated with a (slightly) higher repayment. When they mean to interact, principals are always better off opting for a rigid agreement. This also holds true in the high-risk environment. At the same time, rigid contracts lead to considerable welfare losses owing to extensive retaliation.

For real-world exchange in environments with high risk and ambiguity, our study suggests that the strong preferences for flexibility should be taken into account. Formal contracts, but also implicit agreements, ought to leave space for ex post adjustments and excusable breach. Nevertheless, flexibility should not be confused with full discretion. We reasoned why we decide for this extreme form in our experiment. Opportunism and the abuse of flexibility must be discouraged either by a lower level of total discretion for the agent or by the formation of long-term relationships. Fafchamps (1996) proposes to limit the number of times the principal is willing to accept a deviation from the original contract terms. ${ }^{55}$

Existing or emerging institutions should rather aim at solving the information problems than to rigidly enforce all contracts. The ignorance of these preferences for flexibility would lead to potential welfare losses. First, resources are wasted by means of retaliation (usually a lose-lose situation) and, second, the reluctance to trade entails unexploited welfare opportunities. We agree with Fafchamps' conclusion that "contractual flexibility is

\footnotetext{
${ }^{55}$ He illustrates this situation with Aesop's tale of the shepherd boy who cried "wolf" too many times to fool his fellow villagers. When a real wolf appears and the boy cries again, nobody believes and comes to support him. This moral may sustain voluntary flexibility when interaction is repeated.
} 
necessary and will continue to be. [...] No new institution can-or should try toeliminate noncompliance altogether" (2004: 460).

\subsubsection{Chapter 4}

In this study we argue that, despite the severe poverty that undeniably exists, slums are not the idle places many people imagine them to be. Instead, they are environments of lively economic interaction. Understanding dwellers' behavior in exchange relationships is thus important to extend our knowledge of markets and value chains in developing countries, but also to shape their framework conditions.

Our study is among the few controlled examinations of slum dweller's other-regarding behavior. With residents from the Kibera slum in Nairobi, we study agents' conduct in a simple principal-agent setting with hidden action. In particular, we are interested in the effect of the principal's profit from the contract (or, more precisely, the agent's information about it). Behavior and other-regarding preferences are likely to differ from what was found in former studies, as (1) we exclude reciprocity as a driving force and look at given distributions, (2) slum dwellers are familiar with missing formal institutions for enforcement and protection, and (3) they witness tremendous inequalities in wealth and income on a daily basis.

We find a very low level of post-contractual opportunism and no pronounced differences between various profit ratios (symmetric, asymmetric or unknown). This neither confirms predictions by the self-interest model nor a determinative role of fairness concerns. Together with our survey results, this suggests a fairly low level of inequity aversion among Nairobi slum dwellers. Even though there is convincing evidence that reactions to unequal payoff distributions are stronger if the distribution signals unfair intentions by the other 
party (Charness, 2004; Falk, Fehr and Fischbacher, 2003; ibid., 2008), the same studies show that individuals dislike to be worse off even if their share is generated randomly or by a third party. We do not find support for this intuition. A cautious implication from our results could hence be that costly monitoring and control may be less necessary than standard theory makes us believe. At least we cannot report an increase in opportunism simply based on envy, even when actions are hidden. Thus, inefficiencies in value chains and moral hazard in working relations in developing countries are not readily becoming more severe because there are perceived differences in profit.

To sound a note of caution, the lack of reaction to inequality in our principal-agent setting is a result that cannot be generalized yet (see also critique by Güth, Kliemt and Levati, 2009). Instead, more research is required to profoundly understand slum dwellers' otherregarding preferences. This is important not only to further test related theories, but also for more practical purposes. First, social preferences have been proven to influence "real" economic outcomes (Carpenter and Seki, 2011; Fehr and Fischbacher, 2002). Second, they are likely to have critical implications for the design of institutions or aid programs in developing countries and slums in particular. Who should benefit first from scarce resources? How is redistribution perceived? Which contracts provide adequate incentives? What kind or extend of inequity in wealth starts to become a threat to social peace? This small experiment cannot answer these larger questions - but it can motivate further research along these lines.

\subsection{Limitations and scope for future research}

The five points of criticism towards economic (lab) experiments that were briefly mentioned in the introductory chapter also hold for this dissertation. First, we confront subjects 
with an artificial setting that ignores important elements of reality. This, however, is inevitable and the cost we pay for solving identification problems and obtaining a high level of control. The remuneration of subjects contingent on their decisions in the experiment and the use of framing (Chapter 2) make us optimistic that we created dilemmas individuals would also face in the real world outside the laboratory. Nonetheless, the extent of external validity in laboratory (or lab-like field) experiments is always a critical issue.

Second, the subject pools we use are not representative. This is particularly obvious for the contribution in Chapter 2. There are two main intuitions why students might behave differently compared to a random sample drawn from the whole population: They are more educated and younger. While using student subjects is common practice in experimental economics and psychology, there is evidence that their level of cooperative behavior and trust is lower (Gächter, Herrmann and Thöni, 2004). Additionally, strong behavioral differences between cultures exist (Henrich et al., 2001).

Third, as in most experiments stakes are rather small. We endeavored, however, to cover most participants' opportunity cost of time. Several studies cannot confirm significant behavioral changes in games were more money was at stake (Camerer and Hogarth, 1999).

Fourth, while we ensured that there are sufficient numbers of subjects and observations in each experiment, there are only few truly independent observations. When analyzing our data, we follow seminal experimental papers in their application of statistical and econometric methods and use non-parametric tests or regression analysis with controlling for time trends and cluster-correlated standard errors.

And finally, we cannot entirely rule out self-selection into the experiments and subject pools. This, however, is likely to be a minor problem, since both pools we used are ade- 
quately large and access is easy. For the study in Chapter 2, we randomly recruited participants from a university subject pool where everyone is free to register online. The Kibera pool contains about 2,500 registered individuals - not counting those from other slums or the Nairobi University. The Busara Center frequently extends the pool; requirements for slum dwellers are low (e.g., they do not have to possess an ID card or be able to read) and registration is done in the slum by field officers (see Haushofer et al., 2014 for details). Only invited participants were allowed to attend our experiments.

Where to go from here?

Several potential paths of future research were addressed in the preceding chapters. As experimental research comes with the great advantage of replicability, we encourage scholars to carry out extensions and robustness checks of the experiments presented in this dissertation. Regarding the study in Chapter 2, it would be interesting to see whether the results are sensitive to a change in the framing or whether "tying the hands" of the company player and policing the payment process leads to a great rise in the number of wellfunctioning relations. But also a first lab-test of other potential private-order mechanisms can generate interesting findings. For real-world contract farming these investigations eventually need to be conducted in the field.

Our examination of contract flexibility (Chapter 3) can be enhanced running sessions with different degrees of flexibility or a different study population in which flexible agreements play a crucial role (business owners, smallholder farmers). Limiting the agent's discretion or number of times she is allowed to defect would be an interesting variation. Three aspects mentioned in the conclusion of Chapter 3 should be investigated, namely, long-term relationships, communication and a proper (ad hoc) renegotiation. 
In addition, slum dwellers' other-regarding behavior and social preferences in exchange relationships must be further explored to properly understand markets and sequential exchange in developing countries. As we are only looking at inequalities in profits that are exogenously determined and not a result of the buyer's intention (Chapter 4), this should be included in future experiments to allow for reciprocal responses.

In general, behavior in contractual relations is likely to remain a fruitful research topic. The psychological foundations of contracts and how they influence (or are influenced by) preferences must be identified and investigated more profoundly (Kőszegi, 2014); but also how institutions and informal mechanisms for contract enforcement should be designed in order to provide the right incentives. At this, considering the context of a specific country, cultural peculiarities and societal norms that interact with individuals' behavior, preferences and expectations will be indispensable. 


\section{References}

Aboal, D., Noya, N. and Rius, A. (2014). Contract Enforcement and Investment: A Systematic Review of the Evidence. World Development 64: 322-38.

Acemoglu, D. and Robinson, J. A. (2012). Why Nations Fail: The Origins of Power, Prosperity, and Poverty. New York: Crown Publishers.

Aghion, P. and Holden, R. (2011). Incomplete Contracts and the Theory of the Firm: What Have We Learned over the Past 25 Years? Journal of Economic Perspectives 25(2): 181-97.

Ai, C. and Norton, E. C. (2003). Interaction Terms in Logit and Probit Models. Economics Letters 80(1): 123-29.

Amis, P. (1984). Squatters or Tenants: The Commercialization of Unauthorized Housing in Nairobi. World Development 12(1): 87-96.

Anderhub, V., Gächter, S. and Königstein, M. (2002). Efficient Contracting and Fair Play in a Simple Principal-Agent Experiment. Experimental Economics 5: 5-27.

Arrow, K. J. (1985). The Economics of Agency. In J.W. Pratt and R.J. Zeckhauser (eds.) Principals and Agents. The Structure of Business. Boston, MA: Harvard Business School Press.

Banerjee, A. V. and Duflo, E. (2009). The Experimental Approach to Development Economics. Annual Review of Economics 1(1): 151-78.

Barrett, C. B., Bachke, M. E., Bellemare, M. F., Michelson, H. C., Narayanan, S. and Walker, T. F. (2012). Smallholder Participation in Contract Farming: Comparative Evidence from Five Countries. World Development 40(4): 715-30.

Bartling, B. and Schmidt, K. M. (2015). Reference Points, Social Norms, and Fairness in Contract Renegotiations. Journal of the European Economic Association 13(1): 98-129.

Becchetti, L., Conzo, P. and Romeo, A. (2014). Violence, Trust, and Trustworthiness: Evidence from a Nairobi Slum. Oxford Economic Papers 66(1): 283-305.

Beckmann, V. and Boger, S. (2004). Courts and Contract Enforcement in Transition Agriculture: Theory and Evidence from Poland. Agricultural Economics 31: 251-63.

Bellemare, M. F. (2012). As You Sow, So Shall You Reap: The Welfare Impacts of Contract Farming. World Development 40(7): 1418-34.

Ben-Ner, A. and Putterman, L. (2001). Trusting and Trustworthiness. Boston University Law Review 81(3): 523-51.

Ben-Ner, A. and Putterman, L. (2009). Trust, Communication and Contracts: An Experiment. Journal of Economic Behavior \& Organization 70(1-2): 106-21.

Berg, J., Dickhaut, J. and McCabe, K. (1995). Trust, Reciprocity, and Social History. Games and Economic Behavior 10: 122-42.

Bigsten, A., Collier, P., Dercon, S., Fafchamps, M., Gauthier, B., Gunning, J. W., Oduro, A., Oostendorp, R., Patillo, C., Soderbom, M., Teal, F. and Zeufack, A. (2000). Contract Flexibility and Dispute Resolution in African Manufacturing. Journal of Development Studies 36(4): 1-37. 
Binzel, C. and Fehr, D. (2013). Social Distance and Trust: Experimental Evidence from a Slum in Cairo. Journal of Development Economics 103: 99-106.

Blount, S. (1995). When Social Outcomes Aren't Fair: The Effect of Causal Attributions on Preferences. Organizational Behavior and Human Decision Processes 63(2): 131-44.

Bohnet, I., Frey, B. S. and Huck, S. (2001). More Order with Less Law: On Contract Enforcement, Trust, and Crowding. American Political Science Review 95(1): 131-44.

Bolton, G. E. and Ockenfels, A. (2000). ERC: A Theory of Equity, Reciprocity, and Competition. American Economic Review 90(1): 166-93.

Bolton, P. and Dewatripont, M. (2005). Contract Theory. Cambridge, MA/London: MIT Press.

Bolwig, S., Gibbon, P. and Jones, S. (2009). The Economics of Smallholder Organic Contract Farming in Tropical Africa. World Development 37(6): 1094-104.

Brandts, J., Charness, G. and Ellman, M. (2012). Let's Talk: How Communication Affects Contract Design. CESifo Working Paper Series No. 3883.

Brousseau, E. and Glachant, J.-M. (2002). The Economics of Contracts and the Renewal of Economics. In E. Brousseau and J.-M. Glachant (eds.) The Economics of Contracts: Theory and Applications (pp. 3-30). Cambridge, UK: Cambridge University Press.

Brown, M., Falk, A. and Fehr, E. (2004). Relational Contracts and the Nature of Market Interactions. Econometrica 72(3): 747-80.

Camerer, C. (2003). Behavioral Game Theory: Experiments in Strategic Interaction. New York, NY/Princeton, NJ: Russell Sage Foundation/Princeton University Press.

Camerer, C. and Hogarth, R. M. (1999). The Effects of Financial Incentives in Experiments: A Review and Capital-Labor-Production Framework. Journal of Risk and Uncertainty 19(1-3): 742.

Cardenas, J. C. and Carpenter, J. (2008). Behavioural Development Economics: Lessons from Field Labs in the Developing World. Journal of Development Studies 44(3): 311-38.

Carpenter, J. and Seki, E. (2011). Do Social Preferences Increase Productivity? Field Experimental Evidence from Fishermen in Toyama Bay. Economic Inquiry 49(2): 612-30.

Castillo, M. and Leo, G. (2010). Moral Hazard and Reciprocity. Southern Economic Journal 77(2): 271-81.

Charness, G. (2004). Attribution and Reciprocity in an Experimental Labor Market. Journal of Labor Economics 22(3): 665-88.

Charness, G. (2012). Communication in Bargaining Experiments. In G.E. Bolton and R.T.A. Croson (eds.) The Oxford Handbook of Economic Conflict Resolution (pp. 7-18). Oxford, UK et al.: Oxford University Press.

Charness, G. and Dufwenberg, M. (2006). Promises and Partnership. Econometrica 74(6): 1579601.

Charness, G. and Rabin, M. (2002). Understanding Social Preferences with Simple Tests. Quarterly Journal of Economics 117(3): 817-69. 
Chowdhury, S. M. and Jeon, J. Y. (2014). Impure Altruism or Inequality Aversion?: An Experimental Investigation Based on Income Effects. Journal of Public Economics 118: 143-50.

Clark, A. E. and D'Ambrosio, C. (2015). Attitudes to Income Inequality: Experimental and Survey Evidence. In A.B. Atkinson and F. Bourguignon (eds.) Handbook of Income Distribution, Vol. 2 (pp. 1147-208). Amsterdam: Elsevier.

Clots-Figueras, I., Hernán González, R. and Kujal, P. (2012). Information Asymmetry and Deception in the Investment Game. Economics Working Papers 12-27, Universidad Carlos III, Departamento de Economía.

Coase, R. (1937). The Nature of the Firm. Economica 4(16): 386-405.

Cochard, F. and Willinger, M. (2005). Fair Offers in a Repeated Principal-Agent Relationship with Hidden Actions. Economica 72(286): 225-40.

Cohen, T. R., Wolf, S. T., Panter, A. T. and Insko, C. A. (2011). Introducing the GASP Scale: A New Measure of Guilt and Shame Proneness. Journal of Personality and Social Psychology 100(5): 947-66.

Coricelli, G., Morales, L. G. and Mahlstedt, A. (2006). The Investment Game with Asymmetric Information. Metroeconomica 57(1): 13-30.

Croson, R. T. (2002). Why and How to Experiment: Methodologies from Experimental Economics. University of Illinois Law Review 2002(4): 921-45.

Croson, R. and Gächter, S. (2010). The Science of Experimental Economics. Journal of Economic Behavior \& Organization 73(1): 122-31.

Cungu, A., Gow, H., Swinnen, J. F. M. and Vranken, L. (2008). Investment with Weak Contract Enforcement: Evidence from Hungary During Transition. European Review of Agricultural Economics 35(1): 75-91.

Davis, D. D. and Holt, C. A. (1993). Experimental Economics. Princeton, NJ et al.: Princeton University Press.

Dufwenberg, M. and Kirchsteiger, G. (2004). A Theory of Sequential Reciprocity. Games and Economic Behavior 47(2): 268-98.

Eaton, C. and Shepherd, A. W. (2001). Contract Farming: Partnerships for Growth. FAO Agricultural Services Bulletin 145.

Ellingsen, T. and Johannesson, M. (2004). Promises, Threats and Fairness. The Economic Journal 114: $397-420$.

Erlei, M. and Reinhold, C. (2010). To Choose or Not to Choose: Contracts, Reference Points, Reciprocity, and Signaling. Beiträge zur Jahrestagung des Vereins für Socialpolitik 2010: Ökonomie der Familie - Session: Incentives and Contracts, No. G10-V1.

Fafchamps, M. (1996). The Enforcement of Commercial Contracts in Ghana. World Development 24(3): 427-48.

Fafchamps, M. (1997). Trade Credit in Zimbabwean Manufacturing. World Development 25(5): 795-815.

Fafchamps, M. (2004). Market Institutions in Sub-Saharan Africa: Theory and Evidence. Cambridge, MA: MIT Press. 
Fafchamps, M., Biggs, T., Conning, J. and Srivastava, P. (1994). Enterprise Finance in Kenya. Regional Program on Enterprise Development. Africa Region. Washington, DC: The World Bank.

Fafchamps, M. and Minten, B. (2001). Property Rights in a Flea Market Economy. Economic Development and Cultural Change 49(2): 229-67.

Falk, A., Fehr, E. and Fischbacher, U. (2003). On the Nature of Fair Behavior. Economic Inquiry 41(1): 20-26.

Falk, A., Fehr, E. and Fischbacher, U. (2008). Testing Theories of Fairness-Intentions Matter. Games and Economic Behavior 62(1): 287-303.

Falk, A. and Fischbacher, U. (2006). A Theory of Reciprocity. Games and Economic Behavior 54(2): 293-315.

Falk, A. and Heckman, J. J. (2009). Lab Experiments Are a Major Source of Knowledge in the Social Sciences. Science 326(5952): 535-38.

Falk, A. and Kosfeld, M. (2006). The Hidden Costs of Control. American Economic Review 96(5): $1611-30$.

FAO (n.d.). Legal Fundamentals for the Design of Contract Farming Agreements. FAO Policy Brief.

Fehr, E., Brown, M. and Zehnder, C. (2009). On Reputation: A Microfoundation of Contract Enforcement and Price Rigidity. The Economic Journal 119: 333-53.

Fehr, E. and Fischbacher, U. (2002). Why Social Preferences Matter - The Impact of Non-Selfish Motives on Competition, Cooperation and Incentives. The Economic Journal 112: C1-C33.

Fehr, E. and Gächter, S. (2002). Altruistic Punishment in Humans. Nature 415: 137-40.

Fehr, E., Gächter, S. and Kirchsteiger, G. (1997). Reciprocity as a Contract Enforcement Device: Experimental Evidence. Econometrica 65(4): 833-60.

Fehr, E., Hart, O. and Zehnder, C. (2011a). Contracts as Reference Points-Experimental Evidence. American Economic Review 101(2): 493-525.

Fehr, E., Hart, O. and Zehnder, C. (2011b). How Do Informal Agreements and Renegotiation Shape Contractual Reference Points? NBER Working Paper No. 17545.

Fehr, E., Kirchsteiger, G. and Riedl, A. (1993). Does Fairness Prevent Market Clearing? An Experimental Investigation. Quarterly Journal of Economics 108(2): 437-59.

Fehr, E., Klein, A. and Schmidt, K. M. (2007). Fairness and Contract Design. Econometrica 75(1): 121-54.

Fehr, E. and Schmidt, K. M. (1999). A Theory of Fairness, Competition, and Cooperation. Quarterly Journal of Economics 114(3): 817-68.

Fehr, E. and Schmidt, K. M. (2006). The Economics of Fairness, Reciprocity and Altruism - Experimental Evidence and New Theories. In S.-C. Kolm and J.M. Ythier (eds.) Handbook of the Economics of Giving, Altruism and Reciprocity, Vol. 1 (pp. 615-91). Amsterdam et al.: Elsevier. 
Fehr, E. and Zehnder, C. (2009). Reputation and Credit Market Formation: How Relational Incentives and Legal Contract Enforcement Interact. IZA Discussion Papers No. 4351.

Fehr, E., Zehnder, C. and Hart, O. (2009). Contracts, Reference Points, and Competition - Behavioral Effects of the Fundamental Transformation. Journal of the European Economic Association 7(2-3): 561-72.

Fischbacher, U. (2007). Z-Tree: Zurich Toolbox for Ready-Made Economic Experiments. Experimental Economics 10: 171-78.

Friedman, D. and Sunder, S. (1994). Experimental Methods: A Primer for Economists. Cambridge, UK: Cambridge University Press.

Gächter, S. and Falk, A. (2002). Reputation and Reciprocity: Consequences for the Labour Relation. Scandinavian Journal of Economics 104(1): 1-26.

Gächter, S., Herrmann, B. and Thöni, C. (2004). Trust, Voluntary Cooperation, and SocioEconomic Background: Survey and Experimental Evidence. Journal of Economic Behavior \& Organization 55(4): 505-31.

Gambetta, D. (1993). The Sicilian Mafia: The Business of Private Protection. Cambridge, MA: Harvard University Press.

Glover, D. J. (1984). Contract Farming and Smallholder Outgrower Schemes in Less-Developed Countries. World Development 12(11/12): 1143-57.

Government of Kenya and UN-HABITAT (2005). Kibera Social and Economic Mapping: Household Survey Report. Research International RI/4733.

Gow, H. R., Streeter, D. H. and Swinnen, J. F. M. (2000). How Private Contract Enforcement Mechanisms Can Succeed Where Public Institutions Fail: the Case of Juhocukor a.s. Agricultural Economics 23: 253-65.

Gow, H. R. and Swinnen, J. F. M. (2001). Private Enforcement Capital and Contract Enforcement in Transition Economies. American Journal of Agricultural Economics 83(3): 686-90.

Greif, A. (1992). Institutions and International Trade: Lessons from the Commercial Revolution. American Economic Review: Papers and Proceedings 82(2): 128-33.

Greif, A. (1993). Contract Enforceability and Economic Institutions in Early Trade: The Maghribi Traders' Coalition. American Economic Review 83(3): 525-48.

Greif, A., Milgrom, P. and Weingast, B. R. (1994). Coordination, Commitment, and Enforcement: The Case of the Merchant Guild. Journal of Political Economy 102(4): 745-76.

Greig, F. and Bohnet, I. (2008). Is There Reciprocity in a Reciprocal-Exchange Economy? Evidence of Gendered Norms from a Slum in Nairobi, Kenya. Economic Inquiry 46(1): 77-83.

Greiner, B. (2004). An Online Recruitment System for Economic Experiments. In K. Kremer and V. Macho (eds.) Forschung und wissenschaftliches Rechnen 2003. GWDG Bericht 63 (pp. 79 93). Göttingen: Ges. für Wiss. Datenverarbeitung.

Guo, H. and Jolly, R. W. (2008). Contractual Arrangements and Enforcement in Transition Agriculture: Theory and Evidence from China. Food Policy 33(6): 570-75.

Guo, H., Jolly, R. W. and Fischer, S. (2007). Contract Farming in China: Perspectives of Farm Households and Agribusiness Firms. Comparative Economic Studies 49(2): 285-312. 
Güth, W., Kliemt, H. and Levati, M. V. (2009). (Over-)Stylizing Experimental Findings and Theorizing with Sweeping Generality. Perspectives in Moral Science RMM 0: 239-49.

Harrison, G. W. and List, J. A. (2004). Field Experiments. Journal of Economic Literature 42(4): 1009-55.

Hart, O. (1995). Firms, Contracts, and Financial Structure. Claredon Lectures in Economics. Oxford, UK et al.: Oxford University Press.

Hart, O. and Holmström, B. (1987). The Theory of Contracts. In T.F. Bewley (ed.) Advances in Economics Theory, Fifth World Congress (pp. 71-155). Cambridge, UK: Cambridge University Press.

Hart, O. and Moore, J. (1988). Incomplete Contracts and Renegotiation. Econometrica 56(4): 75585.

Hart, O. and Moore, J. (2008). Contracts as Reference Points. Quarterly Journal of Economics 123(1): $1-48$.

Haushofer, J., Collins, M., Giusti, G. de, Njoroge, J. M., Odero, A., Onyango, C., Vancel, J., Jang, C., Kuruvilla, M. V. and Hughes, C. (2014). A Methodology for Laboratory Experiments in Developing Countries: Examples from the Busara Center. Mimeo.

Hay, J. R. and Shleifer, A. (1998). Private Enforcement of Public Laws: A Theory of Legal Reform. American Economic Review: Papers and Proceedings 88(2): 398-403.

Henrich, J., Boyd, R., Bowles, S., Camerer, C., Fehr, E., Gintis, H. and McElreath, R. (2001). In Search of Homo Economicus: Behavioral Experiments in 15 Small-Scale Societies. American Economic Review 91(2): 73-78.

Holmström, B. and Milgrom, P. (1987). Aggregation and Linearity in the Provision of Intertemporal Incentives. Econometrica 55(2): 303-28.

Hoppe, E. I. and Schmitz, P. W. (2011). Can Contracts Solve the Hold-Up Problem? Experimental Evidence. Games and Economic Behavior 73(1): 186-99.

Johnson, N. D. and Mislin, A. A. (2011). Trust Games: A Meta-Analysis. Journal of Economic Psychology 32(5): 865-89.

Joireman, S. and Vanderpoel, R. S. (2010). In Search of Order: Property Rights Enforcement in Kibera Settlement, Kenya. Prepared for the World Bank Conference on Land Policy and Administration, April 26-27, 2010, Washington, DC.

Just, D. R. and Wu, S. Y. (2009). Experimental Economics and the Economics of Contracts. American Journal of Agricultural Economics 91(5): 1382-88.

Karanja, M. (2010). Myth Shattered: Kibera Numbers Fail to Add Up. Accessed (September 3, 2014) at http://www.nation.co.ke/News/Kibera\%20numbers\%20fail\%20to\%20add\%20up//1056/1003404/-/13ga38xz/-/index.html.

Kenya National Bureau of Statistics (KNBS) (2014). Economic Survey 2014. Nairobi: KNBS.

Keser, C. and Willinger, M. (2000). Principals' Principles When Agents' Actions are Hidden. International Journal of Industrial Organization 18: 163-85.

Keser, C. and Willinger, M. (2007). Theories of Behavior in Principal-Agent Relationships with Hidden Action. European Economic Review 51(6): 1514-33. 
Key, N. and Runsten, D. (1999). Contract Farming, Smallholders, and Rural Development in Latin America: The Organization of Agroprocessing Firms and the Scale of Outgrower Production. World Development 27(2): 381-401.

Klein, B. (1996). Why Hold-Ups Occur: The Self-Enforcing Range of Contractual Relationships. Economic Inquiry 34(3): 444-63.

Klein, B., Crawford, R. G. and Alchian, A. A. (1978). Vertical Integration, Appropriable Rents, and the Competitive Contracting Process. Journal of Law and Economics 21(2): 297-326.

Klein, P. G. (2000). New Institutional Economics. In G. de Geest and B. Bouckaert (eds.) Encyclopedia of Law and Economics (pp. 456-89). Cheltenham: Edward Elgar.

Köszegi, B. (2014). Behavioral Contract Theory. Journal of Economic Literature 52(4): 1075-118.

Kube, S., Maréchal, M. A. and Puppe, C. (2012). The Currency of Reciprocity: Gift Exchange in the Workplace. American Economic Review 102(4): 1644-62.

Kunte, S. and Wollni, M. (2015). Risky Environments, Hidden Knowledge, and Preferences for Contract Flexibility: An Artefactual Field Experiment. GlobalFood Discussion Papers No. 69.

Kunte, S., Wollni, M. and Keser, C. (2014). Making It Personal: Breach and Private Ordering in a Contract Farming Experiment. GlobalFood Discussion Papers No. 47.

Loewenstein, G. (1999). Experimental Economics from the Vantage-Point of Behavioural Economics. The Economic Journal 109: F25-F34.

MacDonald, J., Perry, J., Ahearn, M., Banker, D., Chambers, W., Dimitri, C., Key, N., Nelson, K. and Southard, L. (2004). Contracts, Markets, and Prices: Organizing the Production and Use of Agricultural Commodities. Washington, DC: USDA.

MacLeod, W. B. (2007). Reputations, Relationships, and Contract Enforcement. Journal of Economic Literature 45(3): 595-628.

Masakure, O. and Henson, S. (2005). Why Do Small-Scale Producers Choose to Produce Under Contract? Lessons from Nontraditional Vegetable Exports from Zimbabwe. World Development 33(10): 1721-33.

McMillan, J. and Woodruff, C. (1999a). Interfirm Relationships and Informal Credit in Vietnam. The Quarterly Journal of Economics 114(4): 1285-320.

McMillan, J. and Woodruff, C. (1999b). Dispute Prevention Without Courts in Vietnam. Journal of Law, Economics, \& Organization 15(3): 637-58.

McMillan, J. and Woodruff, C. (2000). Private Order under Dysfunctional Public Order. Michigan Law Review 98(8): 2421-58.

Milgrom, P. R. and Roberts, J. (1992). Economics, Organization, and Management. Englewood Cliffs, NJ: Prentice-Hall.

Minot, N. (2007). Contract Farming in Developing Countries: Patterns, Impact, and Policy Implications. Case Study 6-3 of the Program Food Policy for Developing Countries: The Role of Government in the Global Food System.

Minten, B., Randrianarison, L. and Swinnen, J. F. (2009). Global Retail Chains and Poor Farmers: Evidence from Madagascar. World Development 37(11): 1728-41. 
Normann, H.-T. and Wallace, B. (2012). The Impact of the Termination Rule on Cooperation in a Prisoner's Dilemma Experiment. International Journal of Game Theory 41(3): 707-18.

North, D. C. (1990). Institutions, Institutional Change, and Economic Performance. Cambridge, UK: Cambridge University Press.

Paarsch, H. J. and Shearer, B. S. (2009). The Response to Incentives and Contractual Efficiency: Evidence from a Field Experiment. European Economic Review 53(5): 481-94.

Platteau, J.-P. (1994). Behind the Market Stage Where Real Societies Exist - Part II: The Role of Moral Norms. Journal of Development Studies 30(3): 753-817.

Posner, R. A. (1997). Social Norms and the Law: An Economic Approach. American Economic Review: Papers and Proceedings 87(2): 365-69.

Posner, R. A. (1998). Creating a Legal Framework for Economic Development. The World Bank Research Observer 13(1): 1-11.

Prowse, M. (2012). Contract Farming in Developing Countries - A Review. A Savoir No. 12. Paris: AFD Research Department.

Quervain, D. J.-F. de, Fischbacher, U., Treyer, V., Schellhammer, M., Schnyder, U., Buck, A. and Fehr, E. (2004). The Neural Basis of Altruistic Punishment. Science 305: 1254-58.

Rabin, M. (1993). Incorporating Fairness into Game Theory and Economics. American Economic Review 83(5): 1281-302.

Rasmusen, E. (2007). Games and Information: An Introduction to Game Theory. $4^{\text {th }}$ ed. Malden, MA: Blackwell.

Reardon, T. and Barrett, C. B. (2000). Agroindustrialization, Globalization, and International Development: An Overview of Issues, Patterns, and Determinants. Agricultural Economics 23: 195-205.

Reardon, T., Barrett, C. B., Berdegué, J. A. and Swinnen, J. F. (2009). Agrifood Industry Transformation and Small Farmers in Developing Countries. World Development 37(11): 1717-27.

Rehber, E. (2007). Contract Farming: Theory and Practice. Hyderabad, India: ICFAI University Press.

Rodrik, D., Subramanian, A. and Trebbi, F. (2004). Institutions Rule: The Primacy of Institutions Over Geography and Integration in Economic Development. Journal of Economic Growth 9(2): $131-65$.

Roth, A. E. (1995). Introduction to Experimental Economics. In J.H. Kagel and A.E. Roth (eds.) The Handbook of Experimental Economics (pp. 3-109). Princeton, NJ: Princeton University Press.

Salanié, B. (2005). The Economics of Contracts: A Primer. Cambridge, MA: MIT Press.

Sänger, C., Qaim, M., Torero, M. and Viceisza, A. (2013). Contract Farming and Smallholder Incentives to Produce High Quality: Experimental Evidence from the Vietnamese Dairy Sector. Agricultural Economics 44(3): 297-308.

Sänger, C., Torero, M. and Qaim, M. (2014). Impact of Third-party Contract Enforcement in Agricultural Markets-A Field Experiment in Vietnam. American Journal of Agricultural Economics 96(4): 1220-38. 
Sappington, D. E. M. (1991). Incentives in Principal-Agent Relationships. Journal of Economic Perspectives 5(2): 45-66.

Schipmann, C. and Qaim, M. (2011). Supply Chain Differentiation, Contract Agriculture, and Farmers' Marketing Preferences: The Case of Sweet Pepper in Thailand. Food Policy 36(5): $667-77$.

Selten, R. and Stoecker, R. (1986). End Behavior in Sequences of Finite Prisoner's Dilemma Supergames: A Learning Theory Approach. Journal of Economic Behavior \& Organization 7(1): $47-70$.

Shearer, B. S. (2004). Piece Rates, Fixed Wages and Incentives: Evidence from a Field Experiment. Review of Economic Studies 71(2): 513-34.

Swinnen, J. F. M. and Vandeplas, A. (2010). Market Power and Rents in Global Supply Chains. Agricultural Economics 41(S1): 109-20.

Swinnen, J. and Vandeplas, A. (2011). Rich Consumers and Poor Producers: Quality and Rent Distribution in Global Value Chains. Journal of Globalization and Development 2(2): Art. 2.

The Economist (2012). Boomtown Slum - A Day in the Economic Life of Africa's Biggest ShantyTown. Accessed (October 16, 2014) at http://www.economist.com/news/christmas/21568592day-economic-life-africas-biggest-shanty-town-boomtown-slum.

Tirole, J. (1999). Incomplete Contracts: Where Do We Stand? Econometrica 67(4): 741-81.

Torero, M. and Viceisza, A. C. G. (2011). Potential Collusion and Trust: Evidence from a Field Experiment in Vietnam. IFPRI Discussion Papers 01100.

Williamson, O. E. (1979). Transaction-Cost Economics: The Governance of Contractual Relations. Journal of Law and Economics 22(2): 233-61.

Williamson, O. E. (1985). The Economic Institutions of Capitalism: Firms, Markets, Relational Contracting. New York, NY: The Free Press.

Williamson, O. E. (2002). The Lens of Contract: Private Ordering. American Economic Review: Papers and Proceedings 92(2): 438-43.

World Bank (2013a). Doing Business 2013: Smarter Regulations for Small and Medium-Size Enterprises. Washington, DC: The World Bank.

World Bank (2013b). Doing Business 2014: Understanding Regulations for Small and MediumSize Enterprises. Washington, DC: The World Bank.

Wu, S. Y. (2014). Adapting Contract Theory to Fit Contract Farming. American Journal of Agricultural Economics 96(5): 1241-56.

Wu, S. Y. and Roe, B. (2007). Contract Enforcement, Social Efficiency, and Distribution: Some Experimental Evidence. American Journal of Agricultural Economics 89(2): 243-58.

Yen, S. T. (2002). An Econometric Analysis of Household Donations in the USA. Applied Economics Letters 9(13): 837-41. 
